\title{
Estimating the effects of ionospheric plasma on solar wind/ magnetosphere coupling via mass loading of dayside reconnection: Ion-plasma-sheet oxygen, plasmaspheric drainage plumes, and the plasma cloak
}

\author{
Joseph E. Borovsky, ${ }^{1,2,3}$ Michael H. Denton, ${ }^{1,3}$ Richard E. Denton, ${ }^{4}$ \\ Vania K. Jordanova, ${ }^{5}$ and Jonathan Krall ${ }^{6}$ \\ Received 15 March 2013; revised 12 August 2013; accepted 22 August 2013; published 19 September 2013.
}

[1] Estimates are calculated for the storm time reduction of solar wind/magnetosphere coupling by the mass density $\rho_{\mathrm{m}}$ of the magnetospheric plasma. Based on the application of the Cassak-Shay reconnection-rate formula at the dayside magnetopause, a numerical factor $M$ is developed to quantify the effect of $\rho_{m}$ on the dayside reconnection rate. It is argued that the mass loading of dayside reconnection by $\rho_{\mathrm{m}}$ also makes reconnection more susceptible to shutoff by magnetosheath velocity shear: a formula is developed to estimate the shortening of the dayside reconnection X-line by $\rho_{\mathrm{m}}$. Surveys of plasmaspheric drainage plumes at geosynchronous orbit during high-speed-stream-driven storms and coronal mass ejection (CME)-driven storms are presented: in the surveys the CME-driven storms are separated into sheath-driven portions and magnetic-cloud-driven portions. The storm time mass density of the warm plasma cloak (ionospheric outflows into the electron plasma sheet) is obtained from Alfven-wave analysis at geosynchronous orbit. A methodology is developed to extrapolate geosynchronous-orbit plasma measurements to the dayside magnetopause. For each of the three plasmas, estimates of the fractional reduction of the total dayside reconnection rate vary, with typical values of tens of percent; i.e., solar wind/ magnetosphere coupling is reduced by tens of percent during storms by oxygen in the ion plasma sheet, by the plasmaspheric drainage plume, and by the plasma cloak. Dependence of the reduction on the $F_{10.7}$ solar radio flux is anticipated. Via these ionospheric-origin plasmas, the magnetosphere can exert some control over solar wind/magnetosphere coupling. Pathways to gain a fuller understanding of the physics of the solar wind-driven magnetosphere-ionosphere system are discussed.

Citation: Borovsky, J. E., M. H. Denton, R. E. Denton, V. K. Jordanova, and J. Krall (2013), Estimating the effects of ionospheric plasma on solar wind/magnetosphere coupling via mass loading of dayside reconnection: Ion-plasma-sheet oxygen, plasmaspheric drainage plumes, and the plasma cloak, J. Geophys. Res. Space Physics, 118, 5695-5719, doi:10.1002/jgra.50527.

\section{Introduction}

[2] The amount of coupling of the solar wind to the Earth's magnetosphere-ionosphere system is controlled by the amount of magnetic field-line reconnection between the solar wind and the magnetosphere. That rate of magnetic field-line reconnection is controlled by local plasma parameters at the site of the reconnection [Borovsky et al., 2008].

\footnotetext{
${ }^{1}$ Space Science Institute, Boulder, Colorado, USA.

${ }^{2}$ AOSS, University of Michigan, Ann Arbor, Michigan, USA.

${ }^{3}$ Department of Physics, Lancaster University, Lancaster, UK.

${ }^{4}$ Department of Physics and Astronomy, Dartmouth College, Hanover, New Hampshire, USA.

${ }^{5}$ Los Alamos National Laboratory, Los Alamos, New Mexico, USA.

${ }^{6}$ Naval Research Laboratory, Washington, District of Columbia, USA.

Corresponding author: J. E. Borovsky, Space Science Institute, Boulder, CO 80301, USA. (jborovsky@spacescience.org)

(C2013. American Geophysical Union. All Rights Reserved. 2169-9380/13/10.1002/jgra.50527
}

[3] For antiparallel reconnection between symmetric (same magnetic field strength and same mass density) collisionless plasmas, the reconnection rate $\mathrm{R}$ is given by $\mathrm{R} \approx 0.1 \mathrm{v}_{\mathrm{A}} \mathrm{B}$ [Parker, 1973; Shay et al., 1999; Birn et al., 2001] where $\mathrm{v}_{\mathrm{A}}=\mathrm{B} /(4 \pi \rho)^{1 / 2}$ is the Alfven speed in the plasmas near the reconnection site and $\mathrm{B}$ is the magnetic field strength in the plasmas near the reconnection site. The quantity $0.1 \mathrm{v}_{\mathrm{A}} \mathrm{B}$ represents a magnetic flux of strength $B$ flowing into the reconnection X-line at the plasma inflow speed $0.1 \mathrm{v}_{\mathrm{A}}$. When the two reconnecting collisionless plasmas are asymmetric (differing magnetic field strengths and differing mass densities), the antiparallel reconnection rate is given by the Cassak-Shay equation

$$
\mathrm{R}=\left(0.1 / \pi^{1 / 2}\right) \mathrm{B}_{\mathrm{m}}{ }^{3 / 2} \mathrm{~B}_{\mathrm{s}}{ }^{3 / 2} /\left\{\left(\mathrm{B}_{\mathrm{m}} \rho_{\mathrm{s}}+\mathrm{B}_{\mathrm{s}} \rho_{\mathrm{m}}\right)^{1 / 2}\left(\mathrm{~B}_{\mathrm{m}}+\mathrm{B}_{\mathrm{s}}\right)^{1 / 2}\right\}
$$

[Cassak and Shay, 2007; Birn et al., 2008, 2010, 2012], where $B$ and $\rho$ are the magnetic field strength and mass density of the two plasmas and where here the subscript 


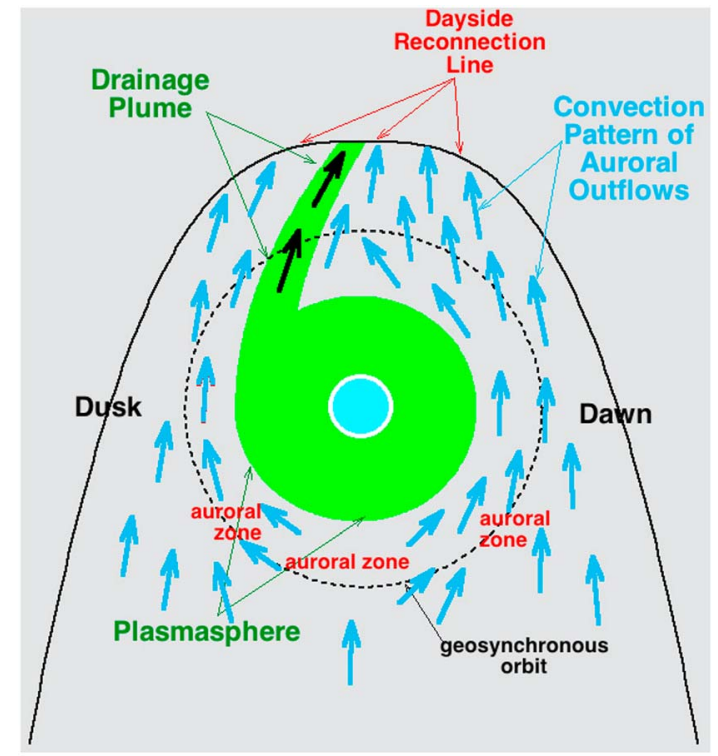

Figure 1. A sketch of the low-energy plasmas in the equatorial plane of the magnetosphere during a geomagnetic storm. Indicated in green is the plasmaspheric drainage plume flowing into the dayside reconnection line, and indicated in blue is the warm plasma cloak flowing into the dayside reconnection line. Geosynchronous orbit is indicated as the dashed black circle.

" $\mathrm{m}$ " denotes the magnetospheric plasma and the subscript "s" denotes the magnetosheath plasma. According to expression (1), four fundamental plasma parameters determine the dayside reconnection rate: $B_{m}, B_{s}, \rho_{m}$, and $\rho_{s}$. Whatever controls those four plasma parameters at the magnetopause controls the reconnection rate between the solar wind and the magnetosphere. Ionospheric outflows, which can control the magnetospheric mass density $\rho_{\mathrm{m}}$, can have a role in controlling the dayside reconnection rate; hence, ionospheric outflows can play a role in controlling solar wind/magnetosphere coupling. One can see from expression (1) that large values of $\rho_{\mathrm{m}}$ lead to reductions in the dayside reconnection rate. This effect is a mass loading of the reconnection site: lowering Alfven speeds, lowering reconnection-outflow velocities, and lowering reconnection inflow rates.

[4] Another manner by which large values of $\rho_{\mathrm{m}}$ reduce the amount of dayside reconnection is by lowering the threshold for velocity shears to suppress reconnection. When shear velocities between two plasmas exceed the outflow velocities of reconnection jets, reconnection becomes difficult. A highmass-density magnetospheric plasma will mass load the reconnection outflow, reducing the jetting velocity and making it easier for the flow shear of the magnetosheath plasma along the magnetopause to cut off reconnection. Hence, the length of the dayside reconnection X-line will be shorter if $\rho_{\mathrm{m}}$ becomes large.

[5] In this report we will survey the mass density $\rho_{\mathrm{m}}$ of the dayside magnetosphere and assess the impact that the density $\rho_{\mathrm{m}}$ has on the dayside reconnection rate and hence on solar wind/magnetosphere coupling. Three specific sources for large mass density will be examined (cf. Figure 1): (1) the oxygen content of the dayside ion plasma sheet, (2) the plasmaspheric drainage plume, and
(3) low-energy ionospheric outflows that are seen across the dayside magnetosphere. For the latter two sources the mass densities are carried by cool ions: cool ions E-cross-B drift, and hence they follow the convection of the magnetic field lines. The magnetospheric magnetic field lines flow into the dayside reconnection X-line; hence, so do the cool ions. The ion plasma sheet also flows into the dayside magnetopause and hence will interfere with the reconnection process.

[6] This paper is organized as follows. In section 2 a numerical factor $\mathrm{M}$ is derived that quantifies the effect of magnetospheric mass density on the rate of reconnection at the dayside magnetopause. In section 3 a parameterization is given for the length of the dayside reconnection $\mathrm{X}$-line $\mathrm{L}_{\mathrm{X} \text {-line }}$ that depends on the mass density of the dayside magnetosphere and the Alfven Mach number of the upstream solar wind. In section 4 a formula is derived to extrapolate plasma densities measured at geosynchronous orbit to the magnetopause where they can be inserted into the CassakShay equation. In section 5 the effect that the mass density of the ion plasma sheet in the dayside magnetosphere has on dayside reconnection is estimated (Table 1). In section 6 the effect of plasmaspheric drainage plumes on dayside reconnection is studied: the properties of plumes measured at geosynchronous orbit are examined for high-speedstream-driven storms and coronal mass ejection (CME)driven storms, estimates for the reduction of the local reconnection rate accounting for plume density are given (Table 2), and estimates for the reduction of the total dayside reconnection rate accounting for plume width are given (Table 3). In section 7 the effect that ionospheric outflows into the electron plasma sheet (the warm plasma cloak) has on dayside reconnection is studied: mass densities measured at geosynchronous orbit during geomagnetic storms are used to estimate the reduction of the local reconnection rate, the reduction of the length of the dayside $\mathrm{X}$-line, and the reduction of the total reconnection rate. To summarize, the estimates (Table 4) for the reconnection reduction by the ion plasma sheet, by plumes, and by ionospheric outflows are assessed in section 8 . Section 9 discusses work needed to improve the estimates and to gain a fuller understanding of how ionospheric plasma alters solar wind/magnetosphere coupling.

\section{The Reconnection-Rate Reduction Factor for Magnetospheric Density}

[7] The Cassak-Shay equation (expression (1)) applied to reconnection between magnetosheath plasma and magnetospheric plasma at the dayside magnetopause has a term $\left(\rho_{m} B_{s}+\rho_{s} B_{m}\right)^{1 / 2}$ in the denominator. Since we do not have a parameterization for the mass density $\rho_{\mathrm{m}}$ of the magnetospheric plasma, in driver functions based on the CassakShay equation we have been taking $\rho_{\mathrm{m}}=0$ [Borovsky, 2008, 2013a, 2013b]. For the $\rho_{\mathrm{m}}=0$ Cassak-Shay equation, the term used in the denominator is $\left(\rho_{\mathrm{s}} \mathrm{B}_{\mathrm{m}}\right)^{1 / 2}$. The correction to the $\rho_{\mathrm{m}}=0$ Cassak-Shay equation to account for nonzero magnetospheric mass density can be expressed as

$$
M=\left(\rho_{s} B_{m}\right)^{1 / 2} /\left(\rho_{m} B_{s}+\rho_{s} B_{m}\right)^{1 / 2} .
$$

This parameter $\mathrm{M}$ is the fractional reduction of the dayside local reconnection rate owed to the mass density of the magnetospheric plasma. $\mathrm{M}$ is conveniently written as 
Table 1. The Effect of the Mass Density of the Ion Plasma Sheet in the Dayside Magnetosphere on the Dayside Reconnection Rate Is Estimated for Three Times ${ }^{\mathrm{a}}$

\begin{tabular}{|c|c|c|c|c|}
\hline & $\begin{array}{l}\text { Superdense-Plasma-Sheet } \\
\text { Phase of High-Speed- } \\
\text { Stream-Driven Storm }\end{array}$ & $\begin{array}{l}\text { Later-Time } \\
\text { Phase of High-Speed- } \\
\text { Stream-Driven Storm }\end{array}$ & $\begin{array}{c}\text { Superdense-Plasma-Sheet } \\
\text { Phase of Magnetic-Cloud- } \\
\text { Driven Storm }\end{array}$ & Quantity \\
\hline $\mathrm{n}_{\text {geo }}$ & $0.8 \mathrm{~cm}^{-3}$ & $0.6 \mathrm{~cm}^{-3}$ & $1.2 \mathrm{~cm}^{-3}$ & $\begin{array}{l}\text { Measured plume number density at } \\
\text { geosynchronous orbit }\end{array}$ \\
\hline$f_{O}$ & 0.34 & 0.34 & 0.5 & $\begin{array}{c}\text { The oxygen mass fraction } \\
\text { of the ion plasma sheet }\end{array}$ \\
\hline$\rho_{\text {geo }}$ & $6.6 \mathrm{amu} / \mathrm{cm}^{3}$ & $4.9 \mathrm{amu} / \mathrm{cm}^{3}$ & $16.3 \mathrm{amu} / \mathrm{cm}^{3}$ & $\begin{array}{l}\text { Upper limit of the mass density } \\
\text { at geosynchronous orbit }(26)\end{array}$ \\
\hline $\mathrm{n}_{\mathrm{sw}}$ & $8.2 \mathrm{~cm}^{-3}$ & $3 \mathrm{~cm}^{-3}$ & $5.5 \mathrm{~cm}^{-3}$ & Number density of solar wind \\
\hline$P_{\text {ram }}$ & $3.6 \mathrm{nPa}$ & $1.9 \mathrm{nPa}$ & $2.2 \mathrm{nPa}$ & Ram pressure of solar wind \\
\hline $\mathrm{M}_{\mathrm{A}}$ & 7.2 & 10.4 & 3.6 & Alfven Mach number of solar wind \\
\hline $\mathrm{B}_{\text {geo }}$ & $127 \mathrm{nT}$ & $115 \mathrm{nT}$ & $110 \mathrm{nT}$ & $\begin{array}{l}\text { Estimated field strength } \\
\text { at geosynchronous orbit (23a) }\end{array}$ \\
\hline $\mathrm{R}_{\mathrm{n}}$ & 0.49 & 0.36 & 0.41 & $\begin{array}{l}\text { Density ratio magnetopause to } \\
\text { geosynchronous orbit (24) }\end{array}$ \\
\hline$\rho_{\mathrm{m}}$ & $3.2 \mathrm{amu} / \mathrm{cm}^{3}$ & $1.7 \mathrm{amu} / \mathrm{cm}^{3}$ & $6.7 \mathrm{amu} / \mathrm{cm}^{3}$ & $\begin{array}{l}\text { Mass density of plume plasma } \\
\text { at magnetopause } \rho_{\text {geo }} R_{n}\end{array}$ \\
\hline $\mathrm{C}$ & 3.4 & 3.6 & 2.7 & Compression ratio of the bow shock (8b) \\
\hline$\rho_{\mathrm{m}} \rho_{\mathrm{o}}$ & 0.39 & 0.58 & 1.2 & $\begin{array}{l}\text { Upper limit of the density } \\
\text { ratio magnetosphere to solar wind }\end{array}$ \\
\hline $\mathrm{p}$ & 0.074 & 0.081 & 0.39 & Mass-correction factor (9) \\
\hline $\mathrm{M}$ & 0.96 & 0.96 & 0.85 & $\begin{array}{l}\text { Multiplicative factor for } \\
\text { local reduction of reconnection } \\
\text { rate and for the reduction of the } \\
\text { X-line length (3) }\end{array}$ \\
\hline $1-\mathrm{M}$ & $3.5 \%$ & $3.8 \%$ & $15 \%$ & $\begin{array}{l}\text { Fractional reduction of local } \\
\text { reconnection rate and of the } \\
\text { reduction of the X-line length }\end{array}$ \\
\hline $\mathrm{M}^{2}$ & 0.93 & 0.93 & 0.72 & $\begin{array}{l}\text { Multiplicative factor for } \\
\text { the reduction of total reconnection rate }\end{array}$ \\
\hline $1-\mathrm{M}^{2}$ & $6.9 \%$ & $7.5 \%$ & $28 \%$ & $\begin{array}{l}\text { Fractional reduction of } \\
\text { the total reconnection rate }\end{array}$ \\
\hline
\end{tabular}

${ }^{a}$ Estimated during the superdense-plasma-sheet phase of a high-speed-stream-driven storm (when the CIR is driving the magnetosphere), during the later stage of a high-speed-stream-driven storm (when uncompressed fast wind of coronal-hole origin is driving the magnetosphere), and during the superdense phase of magnetic-cloud-driven storms. The relevant expression numbers for certain quantities are given in the last column.

Table 2. For Drainage Plumes Collected During High-Speed-Stream-Driven Storms and CME-Driven Storms, the Observed Properties of the Plumes Are Combined With Observed Properties of the Solar Wind to Calculate the Effect of Drainage Plumes on the Dayside Local Reconnection Rate

\begin{tabular}{|c|c|c|c|c|c|}
\hline & $\begin{array}{l}\text { Early Time High-Speed- } \\
\text { Stream-Driven Storm }\end{array}$ & $\begin{array}{l}\text { Later-Time High-Speed- } \\
\text { Stream-Driven Storm }\end{array}$ & $\begin{array}{l}\text { Sheath Portion of } \\
\text { CME Storm }\end{array}$ & $\begin{array}{l}\text { Magnetic-Cloud Portion } \\
\text { of CME Storm }\end{array}$ & Quantity \\
\hline $\mathrm{n}_{\text {geo }}$ & $5-145 \mathrm{~cm}^{-3}$ & $3-115 \mathrm{~cm}^{-3}$ & $5-55 \mathrm{~cm}^{-3}$ & $5-75 \mathrm{~cm}^{-3}$ & $\begin{array}{l}\text { Measured plume number density } \\
\text { at geosynchronous orbit }\end{array}$ \\
\hline $\mathrm{n}_{\mathrm{sw}}$ & $9.5 \mathrm{~cm}^{-3}$ & $4.1 \mathrm{~cm}^{-3}$ & $8.3 \mathrm{~cm}^{-3}$ & $5.6 \mathrm{~cm}^{-3}$ & Number density of solar wind \\
\hline$P_{\text {ram }}$ & $4.0 \mathrm{nPa}$ & $2.5 \mathrm{nPa}$ & $3.7 \mathrm{nPa}$ & $1.9 \mathrm{nPa}$ & Ram pressure of solar wind \\
\hline $\mathrm{M}_{\mathrm{A}}$ & 6.4 & 8.3 & 4.7 & 3.4 & Alfven Mach number of solar wind \\
\hline PCI & 1.9 & 1.9 & 3.4 & 3.0 & Polar Cap Index \\
\hline Dst & $-25 \mathrm{nT}$ & $-37 \mathrm{nT}$ & $-43 \mathrm{nT}$ & $-87 \mathrm{nT}$ & Dst Index \\
\hline $\mathrm{B}_{\text {geo }}$ & $133 \mathrm{nT}$ & $121 \mathrm{nT}$ & $124 \mathrm{nT}$ & $108 \mathrm{nT}$ & $\begin{array}{l}\text { Estimated field strength } \\
\text { at geosynchronous orbit }(23 a)\end{array}$ \\
\hline $\mathrm{R}_{\mathrm{n}}$ & 0.51 & 0.41 & 0.52 & 0.39 & $\begin{array}{l}\text { Density ratio magnetopause to } \\
\text { geosynchronous orbit (24) }\end{array}$ \\
\hline $\mathrm{n}_{\mathrm{m}}$ & $2.5-74 \mathrm{~cm}^{-3}$ & $1.2-47 \mathrm{~cm}^{-3}$ & $2.6-29 \mathrm{~cm}^{-3}$ & $1.9-29 \mathrm{~cm}^{-3}$ & Number density at magnetopause (24) \\
\hline$\rho_{\mathrm{m}}$ & $5.0-147 \mathrm{amu} / \mathrm{cm}^{3}$ & $2.4-93 \mathrm{amu} / \mathrm{cm}^{3}$ & $5.2-57 \mathrm{amu} / \mathrm{cm}^{3}$ & $3.9-58 \mathrm{amu} / \mathrm{cm}^{3}$ & $\begin{array}{l}\text { Mass density of plume plasma } \\
\text { at magnetopause (26) }\end{array}$ \\
\hline$\rho_{\mathrm{m}} \rho_{\mathrm{o}}$ & $0.53-15$ & $0.6-23$ & $0.6-6.9$ & $0.7-10.3$ & Density ratio magnetosphere to solar wind \\
\hline $\mathrm{p}$ & $0.11-3.1$ & $0.10-3.9$ & $0.16-1.8$ & $0.23-3.4$ & Mass-correction factor (9) \\
\hline $\mathrm{M}$ & $0.95-0.49$ & $0.95-0.45$ & $0.93-0.60$ & $0.90-0.48$ & $\begin{array}{l}\text { Multiplicative factor for local reduction } \\
\text { of reconnection rate }(3)\end{array}$ \\
\hline $1-\mathrm{M}$ & $5 \%-51 \%$ & $5 \%-55 \%$ & $7 \%-40 \%$ & $10 \%-52 \%$ & $\begin{array}{l}\text { Fractional reduction of reconnection } \\
\text { rate within plume }\end{array}$ \\
\hline
\end{tabular}


Table 3. For Drainage Plumes Collected During High-Speed-Stream-Driven Storms and CME-Driven Storms, the Observed Properties of the Plumes Are Combined With Observed Properties of the Solar Wind to Calculate the Effect of Drainage Plumes on the Dayside Total Reconnection Rate

\begin{tabular}{|c|c|c|c|c|c|}
\hline & $\begin{array}{l}\text { Early Time High-Speed- } \\
\text { Stream-Driven Storm }\end{array}$ & $\begin{array}{l}\text { Later-Time High-Speed- } \\
\text { Stream-Driven Storm }\end{array}$ & $\begin{array}{l}\text { Sheath Portion } \\
\text { of CME Storm }\end{array}$ & $\begin{array}{l}\text { Magnetic-Cloud } \\
\text { Portion of CME Storm }\end{array}$ & Quantity \\
\hline M & $0.95-0.49$ & $0.95-0.45$ & $0.93-0.60$ & $0.90-0.48$ & $\begin{array}{l}\text { Multiplicative factor for local } \\
\text { reduction of reconnection rate }\end{array}$ \\
\hline $1-\mathrm{M}$ & $5 \%-51 \%$ & $5 \%-55 \%$ & $7 \%-40 \%$ & $10 \%-52 \%$ & $\begin{array}{l}\text { Fractional reduction of reconnection } \\
\text { rate within plume }\end{array}$ \\
\hline $\mathrm{W}_{\text {geo }}$ & $7.1 R_{E}$ & $4.5 R_{E}$ & $5.9 R_{E}$ & $3.8 R_{E}$ & $\begin{array}{l}\text { Width of the plume at } \\
\text { geosynchronous orbit }\end{array}$ \\
\hline$P_{\text {ram }}$ & $4.0 \mathrm{nPa}$ & $2.5 \mathrm{nPa}$ & $3.7 \mathrm{nPa}$ & $1.9 \mathrm{nPa}$ & Ram pressure of solar wind \\
\hline $\mathrm{M}_{\mathrm{A}}$ & 6.4 & 8.3 & 4.7 & 3.4 & Alfven Mach number of solar wind \\
\hline$r_{\mu \pi}$ & $9.3 R_{E}$ & $10.0 R_{E}$ & $9.4 R_{E}$ & $10.4 R_{E}$ & Radius of the magnetopause at nose (21) \\
\hline $\mathrm{L}_{\mathrm{X} \text {-line }}(\mathrm{M}=1)$ & $20.1 R_{E}$ & $23.3 R_{E}$ & $23.7 R_{E}$ & $31.3 R_{E}$ & Length of dayside $X$-line (17a) \\
\hline $\mathrm{W}_{\mu \pi} 1$ & $7.1 R_{E}$ & $4.5 R_{E}$ & $5.9 R_{E}$ & $3.8 R_{E}$ & $\begin{array}{l}\text { Width of plume at magnetopause } \\
\text { (constant width) }\end{array}$ \\
\hline $\mathrm{W}_{\mu \pi} 2$ & $10.0 R_{E}$ & $6.8 R_{E}$ & $8.4 R_{E}$ & $6.0 R_{E}$ & $\begin{array}{l}\text { Width of plume at magnetopause } \\
\text { (constant local-time width) }\end{array}$ \\
\hline $\mathrm{W}_{\mu \pi} / \mathrm{L}_{\mathrm{X} \text {-line }} 1$ & 0.35 & 0.19 & 0.25 & 0.12 & $\begin{array}{l}\text { Fraction of X-line that has plume } \\
\text { plasma (constant width) }\end{array}$ \\
\hline $\mathrm{W}_{\mu \pi} / \mathrm{L}_{\mathrm{X} \text {-line }} 2$ & 0.50 & 0.29 & 0.35 & 0.19 & $\begin{array}{l}\text { Fraction of X-line that has plume } \\
\text { plasma (constant local-time width) }\end{array}$ \\
\hline$\Delta \mathrm{R} / \mathrm{R} 1$ & $1.8 \%-18 \%$ & $1.0 \%-10 \%$ & $1.8 \%-13 \%$ & $1.2 \%-6.2 \%$ & $\begin{array}{l}\text { Fractional reduction of total } \\
\text { reconnection rate (constant width) }\end{array}$ \\
\hline$\Delta \mathrm{R} / \mathrm{R} 2$ & $2.5 \%-25 \%$ & $1.5 \%-16 \%$ & $2.5 \%-14 \%$ & $1.9 \%-9.9 \%$ & $\begin{array}{l}\text { Fractional reduction of total reconnection } \\
\text { rate (constant local-time width) }\end{array}$ \\
\hline
\end{tabular}

$$
\mathrm{M}=(1+\mathrm{p})^{-1 / 2}
$$

where the ratio

$$
\mathrm{p} \equiv \rho_{\mathrm{m}} \mathrm{B}_{\mathrm{s}} / \rho_{\mathrm{s}} \mathrm{B}_{\mathrm{m}}
$$

is a mass-correction factor. The expressions for $\mathrm{p}$ and $\mathrm{M}$ can be written in terms of upstream-solar wind parameters as follows. Pressure balance between the magnetospheric plasma (with $\beta \approx 0$ ) and the magnetosheath plasma (with $\beta=\beta_{\mathrm{s}}$ ) gives [cf. Borovsky, 2008, equations (4) and (5)]

$$
\mathrm{B}_{\mathrm{s}} / \mathrm{B}_{\mathrm{m}}=\left(1+\beta_{\mathrm{s}}\right)^{-1 / 2} \text {. }
$$

The plasma beta of the magnetosheath near the nose of the magnetosphere can be parameterized as a function of the Alfven Mach number $\mathrm{M}_{\mathrm{A}}$ of the solar wind as [cf. Borovsky, 2008, equation (7); cf. Borovsky, 2013b, equation (5)]

$$
\beta_{\mathrm{s}}=\left(\mathrm{M}_{\mathrm{A}} / 6\right)^{1.92} \text {. }
$$

Finally, the mass density $\rho_{\mathrm{s}}$ of the magnetosheath plasma near the nose of the magnetosphere can be written as [cf. Borovsky, 2008, equation (9)]

$$
\rho_{\mathrm{s}}=\mathrm{C} \rho_{\mathrm{o}}
$$

where $\rho_{\mathrm{o}}$ is the mass density of the solar wind and $\mathrm{C}$ is the compression ratio of the bow shock, which can be written as [cf. Borovsky, 2013a, equation (32)]

$$
\begin{gathered}
\mathrm{C}=\mathrm{C}_{\perp} \sin ^{2} \theta_{\mathrm{Bn}}+\mathrm{C}_{\|}\left(1-\sin ^{2} \theta_{\mathrm{Bn}}\right) \\
\mathrm{C}_{\perp}=\left\{2.44 \times 10^{-4}+\left[1+1.38 \log _{\mathrm{e}}\left(\mathrm{M}_{\mathrm{A}}\right)\right]^{-6}\right\}^{-1 / 6} \\
\mathrm{C}_{\|}=4 /\left(1+3 \mathrm{M}_{\mathrm{s}}^{-2}\right),
\end{gathered}
$$

where $\theta_{\mathrm{Bn}}$ is the angle of the interplanetary magnetic field (IMF) relative to the Sun-Earth line, $\mathrm{C}_{\perp}$ is the density compression ratio of the quasi-perpendicular (to the IMF $\underline{B}$ vector) bow shock, and $\mathrm{C}_{\|}$is the density compression ratio of the quasiparallel bow shock. Using expressions (5), (6), and (7), expression (4) for the mass-correction factor becomes

\begin{tabular}{|c|c|c|c|}
\hline & $\begin{array}{l}\text { Fractional Reduction of } \\
\text { Local Reconnection Rate }\end{array}$ & $\begin{array}{l}\text { Fractional Reduction of } \\
\text { Length of X-Line }\end{array}$ & $\begin{array}{l}\text { Fractional Reduction of the Total } \\
\text { Dayside Reconnection Rate }\end{array}$ \\
\hline Dayside ion plasma sheet & $3.5 \%-15 \%$ & $3.5 \%-15 \%$ & $6.9 \%-28 \%$ \\
\hline Plasmaspheric drainage plumes & $3 \%-45 \%$ & $\mathrm{~N} / \mathrm{A}$ & $1 \%-22 \%$ \\
\hline Ionospheric outflows into electron plasma sheet: low $F_{10.7}$ & $2 \%-10 \%$ & $2 \%-10 \%$ & $5 \%-20 \%$ \\
\hline Ionospheric outflows into electron plasma sheet: high $F_{10.7}$ & $10 \%-40 \%$ & $10 \%-40 \%$ & $20 \%-60 \%$ \\
\hline
\end{tabular}

$$
\mathrm{p}=\left(\rho_{\mathrm{m}} / \rho_{\mathrm{o}}\right) \mathrm{C}^{-1}\left[1+\left(\mathrm{M}_{\mathrm{A}} / 6\right)^{1.92}\right]^{-1 / 2} .
$$

[8] Taking $\theta_{\mathrm{Bn}} \sim 90^{\circ}$, expression (3) for the reconnectionrate reduction $\mathrm{M}$ by magnetospheric mass density (with

Table 4. For the Dayside Ion Plasma Sheet, for Drainage Plumes, and for the Ionospheric Outflows (Plasma Cloak), the Estimates Obtained in This Report for the Fractional Reduction in the Local Reconnection Rate, Length of the X-Line, and Total Reconnection Rate Are Summarized 


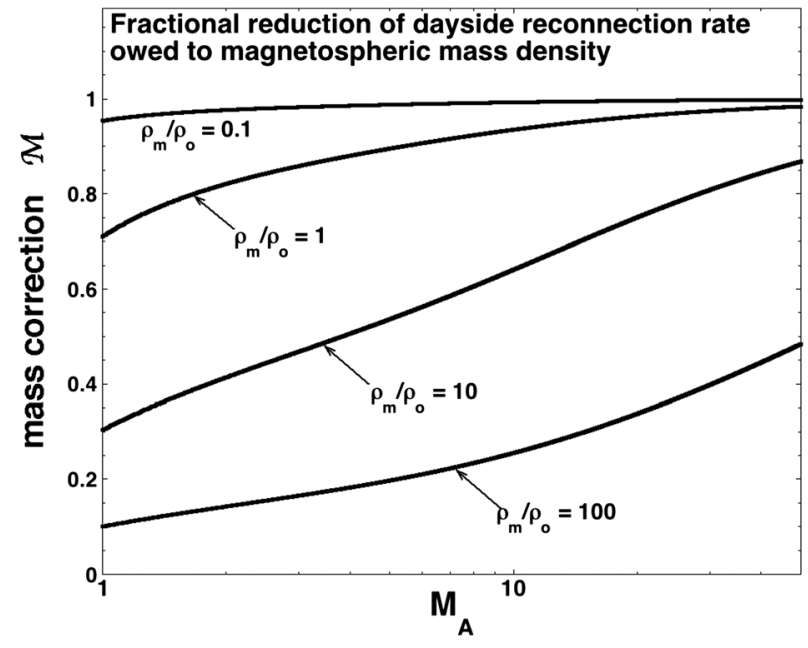

Figure 2. The reconnection-rate multiplicative reduction factor M (expressions (3) and (9)) is plotted as a function of the solar wind Alfven Mach number $\mathrm{M}_{\mathrm{A}}$ for various values of the mass ratio $\rho_{\mathrm{m}} / \rho_{\mathrm{o}}$.

expression (9) for $\mathrm{p}$ ) is plotted as a function of the solar wind Alfven Mach number $\mathrm{M}_{\mathrm{A}}$ in Figure 2 for four different values of $\rho_{m} / \rho_{o}: \rho_{m} / \rho_{o}=0.1, \rho_{m} / \rho_{o}=1, \rho_{m} / \rho_{o}=10$, and $\rho_{m} / \rho$ $\mathrm{o}=100$. As can be seen in Figure 2, the local reconnection rate is reduced further for lower Mach numbers. This is because the magnetosheath magnetic field strength $B_{s}$ is reduced by the higher plasma $\beta$ of the magnetosheath at high Mach numbers (cf. expressions (5) and (6)), reducing the term $p=\rho_{m} B_{s} /$ $\rho_{\mathrm{s}} B_{\mathrm{m}}=\left(\rho_{\mathrm{m}} / \rho_{\mathrm{s}}\right)\left(1+\beta_{\mathrm{s}}\right)^{-1 / 2}$ given by expression (4).

\section{The Length of the Dayside Reconnection X-Line}

[9] Borovsky [2013b] derived an estimate of the effective length $\mathrm{L}_{\mathrm{X} \text {-line }}$ of the dayside $\mathrm{X}$-line based on the property that velocity shear can reduce reconnection rates and strong velocity shear can prevent reconnection. That derivation, for simplicity, assumed $\rho_{\mathrm{m}}=0$. Here, the length $\mathrm{L}_{\mathrm{X} \text {-line }}$ will be rederived including $\rho_{\mathrm{m}} \neq 0$.

[10] The magnetosheath plasma and the magnetospheric plasma undergo reconnection with each other across the dayside magnetopause. There is also a flow shear between the magnetosheath plasma and the magnetospheric plasma across the magnetopause. Reconnection rates are significantly reduced when the velocity of the flow shear $v_{\text {shear }}$ exceeds the outflow velocity of the reconnection $\mathrm{v}_{\text {out }}$ [Mitchell and Kan, 1978; Chen et al., 1997; La Belle-Hamer et al., 1994; Cassak and Otto, 2011]. For symmetric antiparallel reconnection the reconnection-outflow speed $\mathrm{v}_{\text {out }}$ is approximately $\mathrm{v}_{\mathrm{A}}$ of the plasma outside the reconnection site [Borovsky and Hesse, 2007]. For asymmetric antiparallel reconnection between the magnetosphere and the magnetosheath, the reconnection-outflow speed $\mathrm{v}_{\text {out }}$ is given by [cf. Cassak and Shay, 2007, equation (13)]

$$
\mathrm{v}_{\text {out }}^{2}=\left(B_{m} B_{s} / 4 \pi\right)\left(\left(B_{m}+B_{s}\right) /\left(\rho_{m} B_{s}+\rho_{s} B_{m}\right)\right) .
$$

Writing the mass-density factor in the denominator of expression (10) as
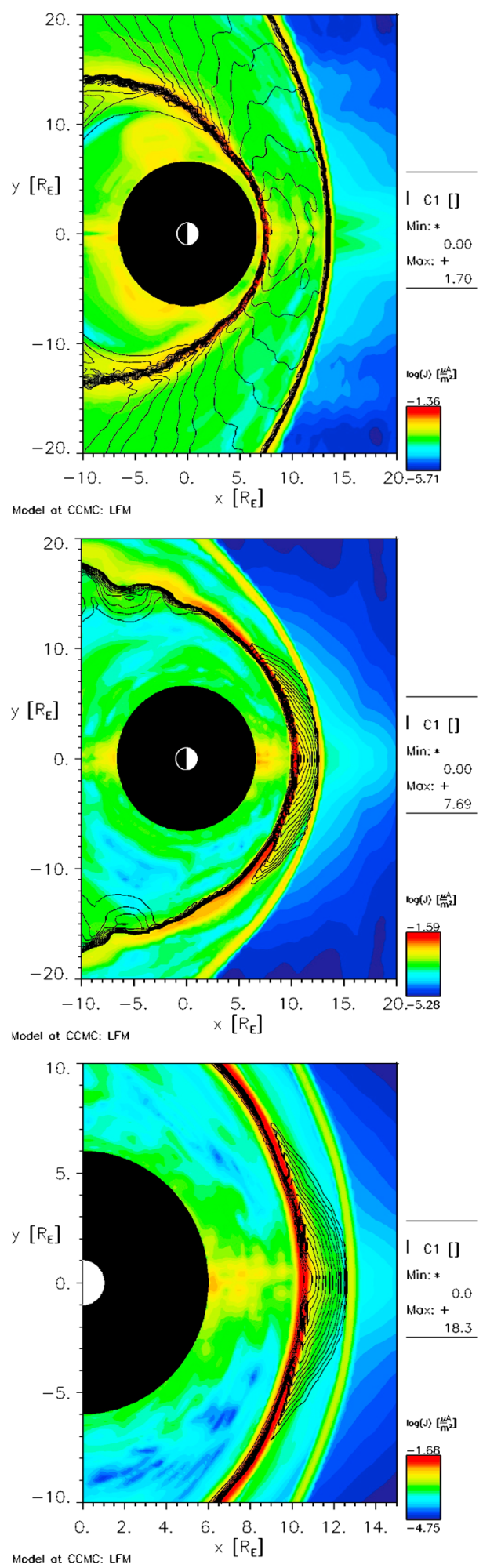

Figure 3. Three snapshots from an LFM MHD simulation at the Community Coordinated Modeling Center (CCMC) with solar wind Alfven Mach numbers (top) $\mathrm{M}_{\mathrm{A}}=2.03$, (middle) $\mathrm{M}_{\mathrm{A}}=10.2$, and (bottom) $\mathrm{M}_{\mathrm{A}}=27.9$; contours of the quantity $\mathrm{M}_{\mathrm{As}}\left[\left(1+\beta_{\mathrm{s}}\right)^{1 / 2}+1\right]^{-1 / 2}$ are plotted in black. In color the logarithm of the total current density $\mathrm{J}$ is plotted in the equatorial plane. The CCMC simulation is entitled Joe_Borovsky_111412_2. 


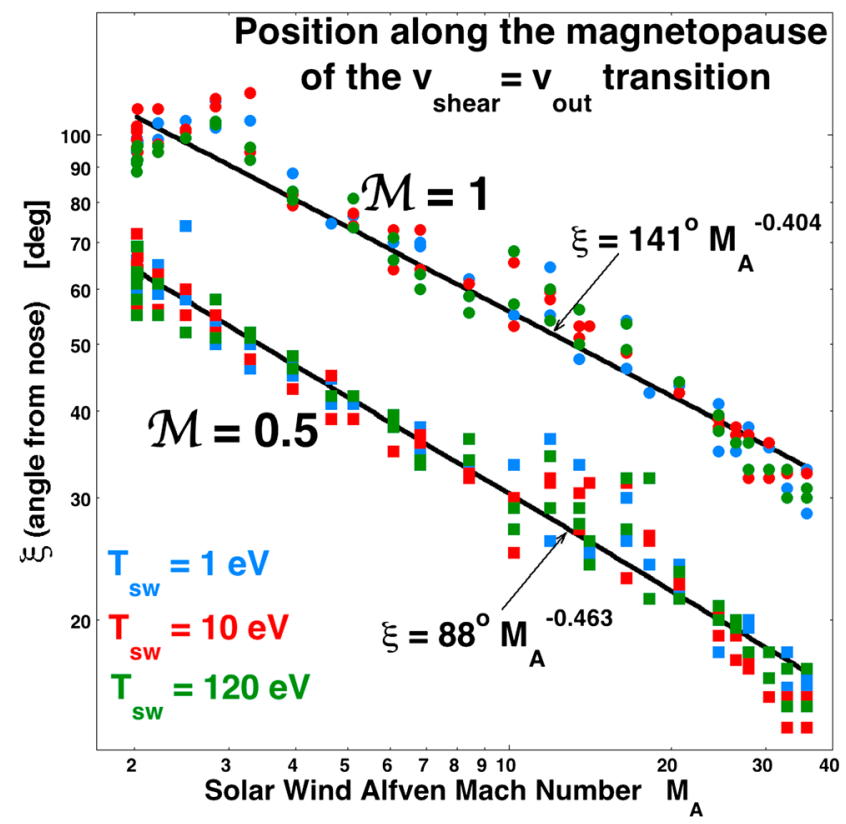

Figure 4. From three LFM computer simulations with a time varying solar wind magnetic field strength, the position angle $\xi$ where the magnetosheath flow along the magnetopause goes through the critical value $\mathrm{M}_{\mathrm{A}}\left[\left(1+\beta_{\mathrm{s}}\right)^{1 / 2}+1\right]^{-1 / 2}=1$ (upper points) and through $\mathrm{M}_{\mathrm{A}}\left[\left(1+\beta_{\mathrm{s}}\right)^{1 / 2}+1\right]^{-1 / 2}=0.5$ (lower points) is plotted as a function of the Alfven Mach number $\mathrm{M}_{\mathrm{A}}$ of the solar wind. The three simulations have three different temperatures of the solar wind plasma upstream of the bow shock: $\mathrm{T}=1 \mathrm{eV}$ (blue), $\mathrm{T}=10 \mathrm{eV}$ (red), and $\mathrm{T}=120 \mathrm{eV}$ (green).

$$
\left(\rho_{\mathrm{m}} \mathrm{B}_{\mathrm{s}}+\rho_{\mathrm{s}} \mathrm{B}_{\mathrm{m}}\right)=\rho_{\mathrm{s}} \mathrm{B}_{\mathrm{m}}(1+\mathrm{p})
$$

where $p \equiv \rho_{m} B_{s} / \rho_{s} B_{m}$ (cf. expression (4)), expression (10) can be written as

$$
\mathrm{v}_{\text {out }}=\mathrm{v}_{\text {As }}\left(\left(B_{\mathrm{m}} / \mathrm{B}_{\mathrm{s}}\right)+1\right)^{1 / 2}(1+\mathrm{p})^{-1 / 2} .
$$

Using expression (5) to replace $\mathrm{B}_{\mathrm{m}} / \mathrm{B}_{\mathrm{s}}$ and expression (3) to replace $(1+p)^{-1 / 2}$, expression $(12)$ becomes

$$
\mathrm{v}_{\mathrm{out}}=\mathrm{v}_{\mathrm{As}}\left[\left(1+\beta_{\mathrm{s}}\right)^{1 / 2}+1\right]^{1 / 2} \mathrm{M}
$$

In the Borovsky [2013b] derivation for the estimate of the length of the reconnection $\mathrm{X}$-line, the condition $\mathrm{p}=0$, which is $\mathrm{M}=1$, was taken. For $\mathrm{p} \neq 0$, which gives $\mathrm{M}<1$, the reconnection-outflow speed $\mathrm{v}_{\text {out }}$ is slower than assumed by Borovsky [2013b]; hence, when $\rho_{\mathrm{m}} \neq 0$, the shutdown of reconnection by shear associated with the magnetosheath flow is more severe and the reconnection X-line will be shorter than that derived by Borovsky [2013b]. For the magnetosheath plasma flowing around the magnetosphere, flow shear increases in intensity with increasing distance from the nose of the magnetosphere. When the flow speed $\mathrm{v}$ of the magnetosheath along the magnetopause exceeds the local value of $\mathrm{v}_{\text {out }}$, the reconnection will be strongly reduced. Here we will take the position in the magnetosheath flow along the magnetopause where $\mathrm{v}=\mathrm{v}_{\text {out }}$ to give the effective length of the $\mathrm{X}$-line. Writing $\mathrm{v}=\mathrm{v}_{\text {out }}$, using expression (13) for $\mathrm{v}_{\text {out }}$, and dividing both sides by $\mathrm{v}_{\mathrm{As}}\left[\left(1+\beta_{\mathrm{s}}\right)^{1 / 2}+1\right]^{1 / 2}$ yields the condition

$$
\mathrm{M}_{\mathrm{As}}\left[\left(1+\beta_{\mathrm{s}}\right)^{1 / 2}+1\right]^{-1 / 2}=\mathrm{M}
$$

in the magnetosheath flow along the magnetopause for the effective length of the X-line. Note in expression (14) that $\mathrm{M}_{\mathrm{As}}$ is the local Alfven Mach number of the magnetosheath flow, not the Alfven Mach number of the upstream solar wind.

[11] The reconnection reduction parameter $M$ can vary from 0 (for $\rho_{m} B_{s}>>\rho_{s} B_{m}$ ) to 1 (for $\left.\rho_{m} B_{s}<<\rho_{s} B_{m}\right)$. In Figure 3 contours of the quantity $\mathrm{M}_{\mathrm{As}}\left[\left(1+\beta_{\mathrm{s}}\right)^{1 / 2}+1\right]^{-1 / 2}$ from $\mathrm{M}_{\mathrm{As}}$ $\left[\left(1+\beta_{\mathrm{s}}\right)^{1 / 2}+1\right]^{-1 / 2}=0$ to $\mathrm{M}_{\mathrm{As}}\left[\left(1+\beta_{\mathrm{s}}\right)^{1 / 2}+1\right]^{-1 / 2}=1$ are plotted from an Lyon-Fedder-Mobarry (LFM) [Lyon et al., 2004; Wiltberger et al., 2005] global-MHD simulation at three different solar wind Alfven Mach numbers: $\mathrm{M}_{\mathrm{A}}=2.03$ (top), $\mathrm{M}_{\mathrm{A}}=10.2$ (middle), and $\mathrm{M}_{\mathrm{A}}=27.9$ (bottom). Note in the three panels of Figure 3 the uniform spacing of the $\mathrm{M}_{\mathrm{As}}\left[\left(1+\beta_{\mathrm{s}}\right)^{1 / 2}+1\right]^{-1 / 2}$ contours where they intersect the dayside magnetopause. If we take the length of the dayside reconnection $\mathrm{X}$-line $\mathrm{L}_{\mathrm{X} \text {-line }}$ to be gauged by the location along the magnetopause where $\mathrm{M}_{\mathrm{As}}\left[\left(1+\beta_{\mathrm{s}}\right)^{1 / 2}+1\right]^{-1 / 2}=\mathrm{M}$ (expression (14)) in the magnetosheath, then the uniform spacing of the $\mathrm{M}_{\mathrm{As}}\left[\left(1+\beta_{\mathrm{s}}\right)^{1 / 2}+1\right]^{-1 / 2}$ contours means that the length of the $\mathrm{X}$-line will be roughly linearly proportional to $\mathrm{M}$. Thus, $L_{X-l i n e} \propto M$. Hence, with one factor of $M$ for the reduction of the reconnection rate and a second factor of $\mathrm{M}$ for the reduction of the length of the X-line, magnetospheric mass density can at times reduce the total reconnection rate between the solar wind and the magnetosphere by the combined factor $\mathrm{M}^{2}$.

[12] To obtain a parametric formula for the length of the reconnection $\mathrm{X}$-line, the position at which the magnetosheath flow along the magnetopause goes through $\mathrm{M}_{\mathrm{As}}\left[\left(1+\beta_{\mathrm{s}}\right)^{1 / 2}+1\right]^{-1 / 2}=\mathrm{M}$ with $\mathrm{M}=1$ and $\mathrm{M}=0.5$ will be examined. For a series of computer simulations using the LFM MHD code at the Community Coordinated Modeling Center [Bellaire, 2006; Rastatter et al., 2012], contour plots of the quantity $\mathrm{M}_{\mathrm{As}}\left[\left(1+\beta_{\mathrm{s}}\right)^{1 / 2}+1\right]^{-1 / 2}$ were examined and the location where $\mathrm{M}_{\mathrm{As}}\left[\left(1+\beta_{\mathrm{s}}\right)^{1 / 2}+1\right]^{-1 / 2}=\mathrm{M}$ in the magnetosheath flow along the magnetopause was measured as a function of the Alfven Mach number $\mathrm{M}_{\mathrm{A}}$ of the upstream solar wind. For three computer simulations in which the solar wind magnetic field strength is varied gradually with time to vary the solar wind Alfven Mach number, the position angle $\xi$ (in degrees) of the location along the magnetopause where the magnetosheath flow goes through the critical conditions $\mathrm{M}_{\mathrm{As}}\left[\left(1+\beta_{\mathrm{s}}\right)^{1 / 2}+1\right]^{-1 / 2}=1$ and $\mathrm{M}_{\mathrm{As}}$ $\left[\left(1+\beta_{\mathrm{s}}\right)^{1 / 2}+1\right]^{-1 / 2}=0.5$ are plotted as functions of the Alfven Mach number $\mathrm{M}_{\mathrm{A}}$ of the solar wind in Figure 4. The three simulations have three different temperatures of the solar wind plasma upstream of the bow shock: $\mathrm{T}=1 \mathrm{eV}$ (blue), $\mathrm{T}=10 \mathrm{eV}$ (red), and $\mathrm{T}=120 \mathrm{eV}$ (green). This variation in solar wind temperature varies the relationship between the Alfven Mach number $\mathrm{M}_{\mathrm{A}}$ and 


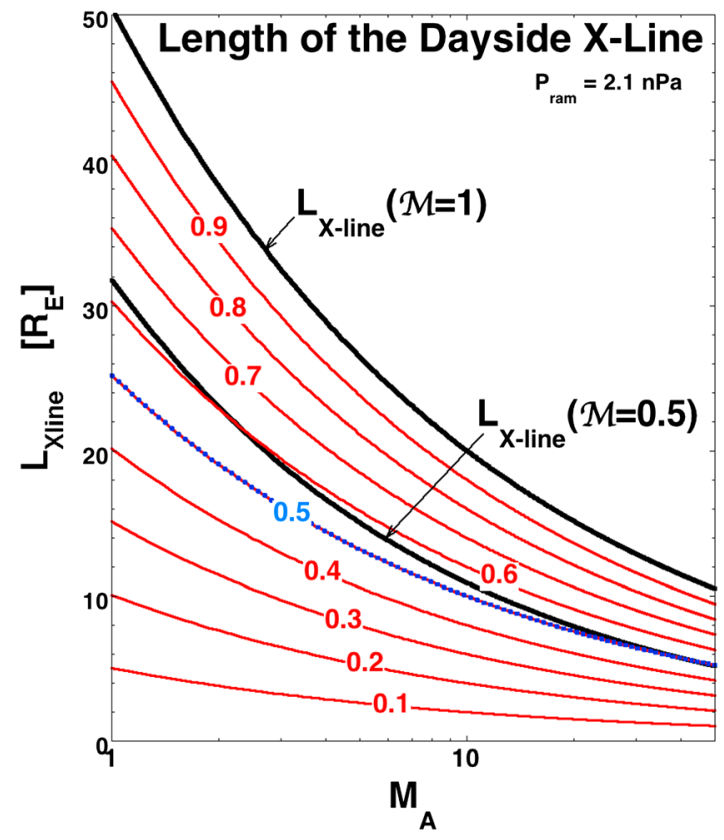

Figure 5. The two fits from Figure 4 for the length of the Xline as a function of the solar wind Alfven Mach number are plotted in black, and multiplicative factors (labeled) times the $\mathrm{M}=1$ fit are plotted in red.

magnetosonic Mach number $\mathrm{M}_{\mathrm{ms}}$ of the solar wind. As can be seen in Figure 4, the temperature of the solar wind plasma does not affect the position of the $\mathrm{M}_{\mathrm{As}}\left[\left(1+\beta_{\mathrm{s}}\right)^{1 /}\right.$ $2+1]^{-1 / 2}$ contours in the magnetosheath along the magnetopause. Power law fits to the $\mathrm{M}_{\mathrm{As}}\left[\left(1+\beta_{\mathrm{s}}\right)^{1 / 2}+1\right]^{-1 / 2}=\mathrm{M}$ data points in Figure 4 yield

$$
\begin{array}{ll}
\xi=141^{\circ} \mathrm{M}_{\mathrm{A}}^{-0.404} & (\text { for } \mathrm{M}=1) \\
\xi=88^{\circ} \mathrm{M}_{\mathrm{A}}^{-0.463} & (\text { for } \mathrm{M}=0.5),
\end{array}
$$

where $\xi$ is in degrees. As an effective length of the dayside X-

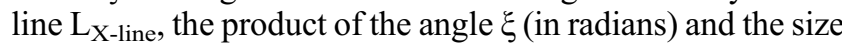
$\mathrm{d}$ of the magnetosphere will be taken: $\mathrm{L}_{\mathrm{X}-\mathrm{line}}=2 \xi \mathrm{d}$, with a factor of 2 for the two sides away from the nose. For the size of the magnetosphere, the standoff distance d along the SunEarth line will be taken; ignoring a correction for very lowMach-number solar wind (cf. section 4), this standoff distance can be written

$$
\mathrm{d}=11.7 \mathrm{P}_{\mathrm{ram}}{ }^{-1 / 6}
$$

[cf. Walker and Russell, 1995, equation (6.21)], where $\mathrm{d}$ is in units of $R_{E}$ and $\mathrm{P}_{\text {ram }}$ is in units of $\mathrm{nPa}$. The ram pressure of the solar wind $\mathrm{P}_{\text {ram }}$ in units of $\mathrm{nPa}$ can be obtained from $\mathrm{P}_{\mathrm{ram}}=1.67 \times 10^{-6}(1+4 \alpha / \mathrm{p}) \mathrm{n}_{\mathrm{sw}} \mathrm{V}_{\mathrm{sw}}{ }^{2}$, where $\mathrm{n}_{\mathrm{sw}}$ is the solar wind number density in units of $\mathrm{cm}^{-3}, \mathrm{v}_{\mathrm{sw}}$ is the solar wind velocity in units of $\mathrm{km} / \mathrm{s}$, and $\alpha / \mathrm{p}$ is the alpha-to-proton density ratio in the solar wind. Taking $\xi$ from expressions (15a) and (15b) and using expression (16), the effective length $\mathrm{L}_{\mathrm{X} \text {-line }}=2 \xi \mathrm{d}$ of the dayside $\mathrm{X}$-line is

$$
\begin{gathered}
\mathrm{L}_{\mathrm{X} \text {-line }}=57.6 \mathrm{P}_{\mathrm{ram}}{ }^{-1 / 6} \mathrm{M}_{\mathrm{A}}^{-0.404}(\text { for } \mathrm{M}=1) \\
\mathrm{L}_{\mathrm{X} \text {-line }}=35.9 \mathrm{P}_{\mathrm{ram}}{ }^{-1 / 6} \mathrm{M}_{\mathrm{A}}{ }^{-0.463}(\text { for } \mathrm{M}=0.5),
\end{gathered}
$$

where $\mathrm{L}_{\mathrm{X} \text {-line }}$ is in units of $R_{E}$ and $\mathrm{P}_{\text {ram }}$ is in units of $\mathrm{nPa}$. These two $\mathrm{L}_{\mathrm{X} \text {-line }}$ curves given by expressions (17a) and (17b) are plotted in black as functions of the solar wind Alfven Mach number $\mathrm{M}_{\mathrm{A}}$ in Figure 5.

[13] The nearly uniform spacing of the $\mathrm{M}_{\mathrm{As}}\left[\left(1+\beta_{\mathrm{s}}\right)^{1 / 2}+1\right]^{-1 / 2}$ contours in Figure 3 led to the inference that $\mathrm{L}_{\mathrm{X} \text {-line }} \propto \mathrm{M}$. To test this assumption, expression (17a) is multiplied by factors of $0.1,0.2,0.3, \ldots .0 .9$, and those nine expressions are plotted in red in Figure 5. The 0.5 expression is over-plotted a second time with a blue dashed curve. If $\mathrm{L}_{\mathrm{X} \text {-line }}$ were exactly proportional to $\mathrm{M}^{1}$, the blue-highlighted 0.5 curve would lie close to the black curve of expression (17b) for $M=0.5$. At higher Mach numbers they are quite close, but at lower Mach numbers expression (17b) is greater than 0.5 times expression (17a) by $20 \%$ or so. Nevertheless, for simplicity the magnetospheric-mass-density-corrected length of the dayside reconnection $\mathrm{X}$-line will be taken to be

$$
\mathrm{L}_{\mathrm{X}-\text { line }} \approx 58 \mathrm{M \textrm {P } _ { \mathrm { ram } }}{ }^{-1 / 6} \mathrm{M}_{\mathrm{A}}^{-0.404}
$$

where $\mathrm{L}_{\mathrm{X} \text {-line }}$ is in units of $R_{E}$ and where $\mathrm{P}_{\text {ram }}$ is in units of $\mathrm{nPa}$. The red curves of Figure 5 are expression (18) with various values of $M$. As the Alfven Mach number $\mathrm{M}_{\mathrm{A}}$ of the solar wind increases, the length of the X-line decreases, and as the reconnection reduction factor $M$ decreases (as the magnetospheric mass density increases), the length of the $\mathrm{X}$-line decreases.

[14] An indication of the Alfven-Mach-number dependence of the length of the dayside neutral line can be seen in the six panels of Figure 6 where flow streamlines inside the dayside magnetosphere are traced in LFM global-MHD simulations of the solar wind-driven magnetosphere. In those simulations the Earth is not rotating. The three panels on the left are from a simulation with a purely southward IMF with $\left(B_{x}, B_{y}\right.$, $\left.\mathrm{B}_{\mathrm{z}}\right)=\left(0,0,-\mathrm{B}_{\mathrm{o}}\right)$, with $\mathrm{B}_{\mathrm{o}}$ varied to vary the Alfven Mach number of the solar wind. The three panels on the right are from a simulation with a purely dawnward IMF with $\left(B_{x}, B_{y}, B_{z}\right)=\left(0,-B_{o}, 0\right)$, with $B_{o}$ varied to vary the Alfven Mach number of the solar wind. The top two panels have $\mathrm{M}_{\mathrm{A}}=2.03$ for the solar wind, the middle two panels have $\mathrm{M}_{\mathrm{A}}=10.2$, and the bottom two panels have $\mathrm{M}_{\mathrm{A}}=27.9$. In the higher-Mach-number cases (middle and bottom panels) the flow streamlines inside the magnetosphere focus toward the nose of the magnetosphere, as if the reconnection intensity is strong at the nose and weak away from the nose. In the lowMach-number cases in the top two panels the streamlines aim sunward, without a focus on the nose, as if the reconnection $\mathrm{X}$-line were strong all across the magnetosphere. The flow-vector directions shown by the field of black arrowheads within the dayside magnetosphere in the six panels show the same behavior: a dayside-magnetospheric flow pattern focused toward the nose when the solar wind Alfven Mach number is high and a dayside-magnetosphere flow that does not focus to the nose when the Alfven Mach number of the solar wind is low. One must use caution in the MHD 

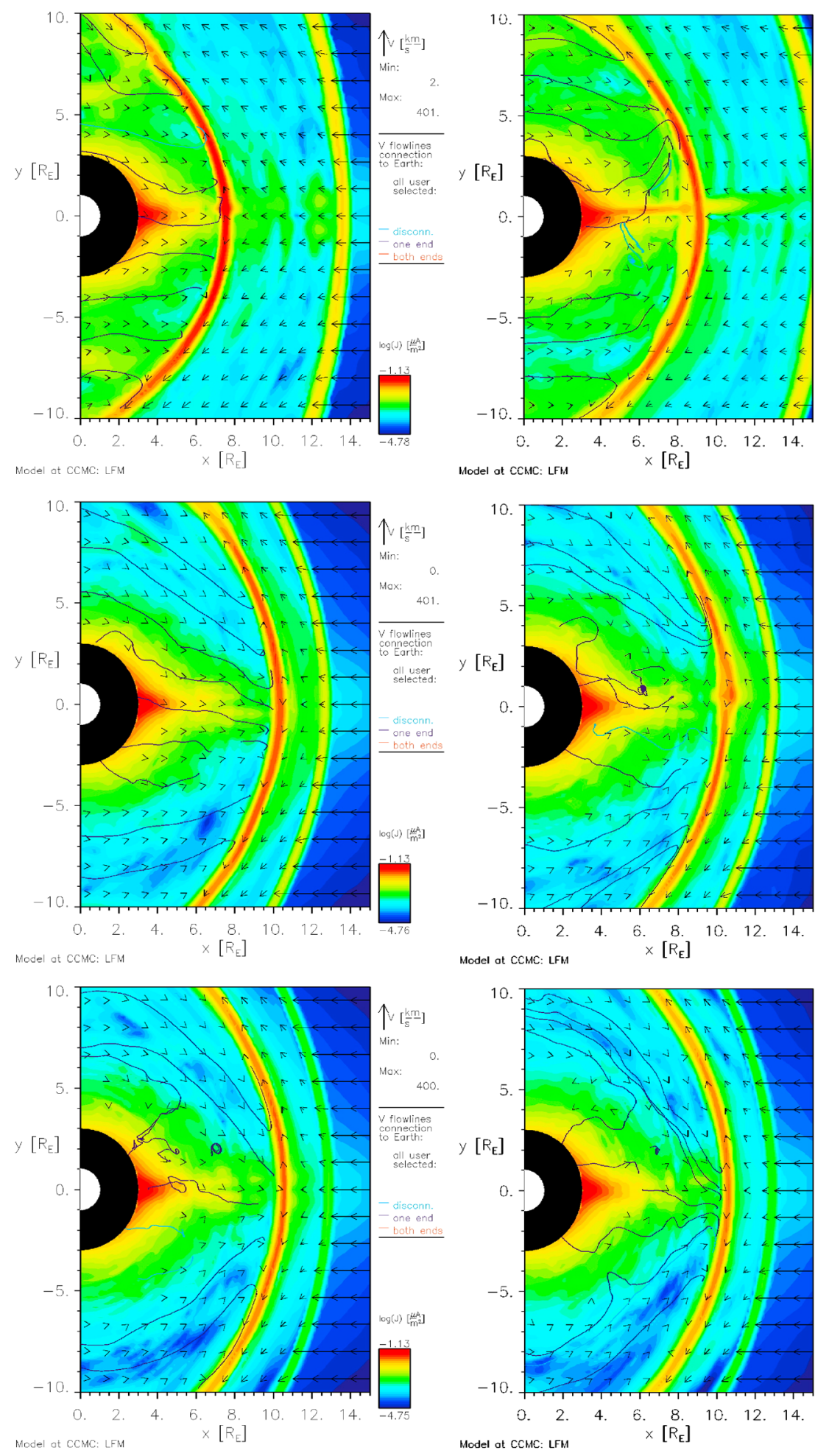

Figure 6. For three different solar wind Alfven Mach numbers $\mathrm{M}_{\mathrm{A}}$, flow vectors and streamlines of flow in the dayside magnetosphere are plotted in the equatorial plane. The Mach numbers are (top) $\mathrm{M}_{\mathrm{A}}=2.03$, (middle) $\mathrm{M}_{\mathrm{A}}=10.2$, and (bottom) $\mathrm{M}_{\mathrm{A}}=27.9$. The color contours are the logarithm of the total current density in the plasma, highlighting the dayside magnetopause in red and the bow shock in yellow. All three panels on the left are from the run Joe_Borovsky_111712_2 at the CCMC. All three panels on the right are from the run Joe_Borovsky_120812_1 at the CCMC. 


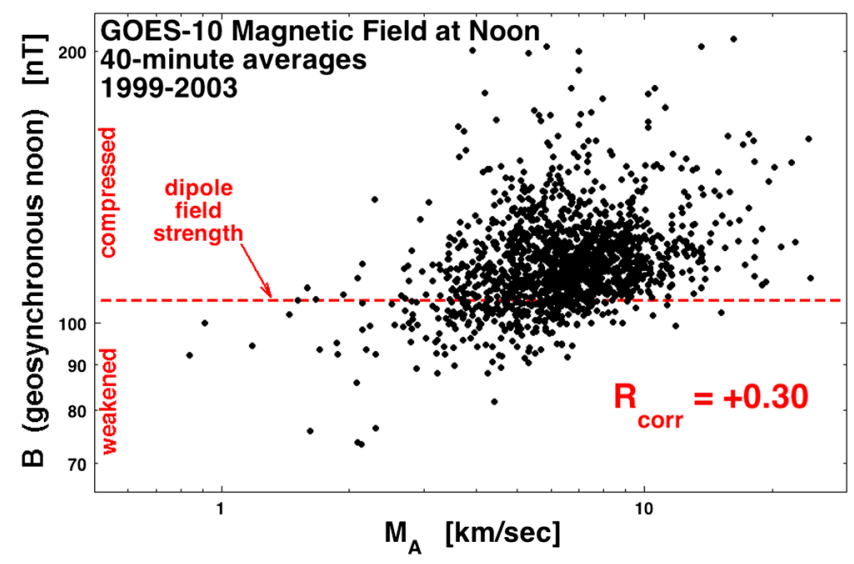

Figure 7. The measured magnetic field strength at geosynchronous-orbit local noon is plotted as a function of the Alfven Mach number of the solar wind. The magnetic field strength of the Earth's dipole at geosynchronous orbit is indicated as the horizontal dashed line. The Pearson correlation coefficient $\mathrm{R}_{\text {corr }}$ between the field strength and the Mach number is indicated in red. For 1521 point pairs, correlation at the $95 \%$ confidence level has a coefficient with a magnitude of 0.051 .

simulations when gauging the strength of reconnection since (1) reconnection is enabled by numerical errors (high-order numerical diffusivity) acting on the magnetic field at current sheets with thicknesses approaching gridspacing [Kuznetsova et al., 2007; John Lyon, private communication, 2013] and (2) numerical errors in the momentum equation at narrow flow gradients prevent the magnetic field from being convected with the flow. However, this pattern at high Mach number is also borne out by the measured plasmaspheric-drainage-plume flow vectors displayed in Borovsky and Denton [2008, Figure 12].

\section{Extrapolating Geosynchronous-Orbit Plasma Measurements to the Dayside Magnetopause}

[15] From plasma-conservation arguments in expanding flux tubes, the cool-plasma density should vary with distance from the Earth inversely as the volume of a magnetic-flux tube varies. For dipolar flux tubes the volume varies as $\mathrm{B}_{\mathrm{eq}}{ }^{-1} \mathrm{~L}_{\text {tube }}$, where $\mathrm{B}_{\mathrm{eq}}$ is the equatorial magnetic field strength and $\mathrm{L}_{\text {tube }}$ is the length of the flux tube. The length $\mathrm{L}_{\text {tube }}$ should vary approximately linearly with the radial distance in the equator of the flux tube. Hence, the cool-plasma number density at the magnetopause $\mathrm{n}_{\mathrm{mp}}$ should be related to the number density at geosynchronous orbit $\mathrm{n}_{\text {geo }}$ according to

$$
\mathrm{R}_{\mathrm{n}}=\mathrm{n}_{\mathrm{mp}} / \mathrm{n}_{\text {geo }}=\left(\mathrm{B}_{\mathrm{mp}} / \mathrm{B}_{\mathrm{geo}}\right)\left(\mathrm{r}_{\mathrm{geo}} / \mathrm{r}_{\mathrm{mp}}\right),
$$

where $R_{n}$ is the density ratio between the plasma at the magnetopause and the plasma at geosynchronous orbit.

[16] In expression (19) the distance to geosynchronous orbit is $r_{\text {geo }}=6.6 R_{E}$. For high-Mach-number solar wind (where the magnetic and thermal pressures of the solar wind plasma can be ignored compared with the ram pressure) the distance to the magnetopause $r_{m p}$ can be estimated as $\mathrm{r}_{\mathrm{mp}}=11.7 \mathrm{P}_{\mathrm{ram}}{ }^{-1 / 6}$ [cf. Walker and Russell, 1995], where $\mathrm{r}_{\mathrm{mp}}$ is in units of $R_{E}$ and $\mathrm{P}_{\text {ram }}$ is the ram pressure of the solar wind in units of $\mathrm{nPa}$. At low Mach numbers the thermal pressure $n k_{B} T$ and the magnetic field pressure $B^{2} / 8 \pi$ of the solar wind plasma become comparable in magnitude to the ram pressure $P_{r a m}=\rho v^{2}$ of the wind. For interaction
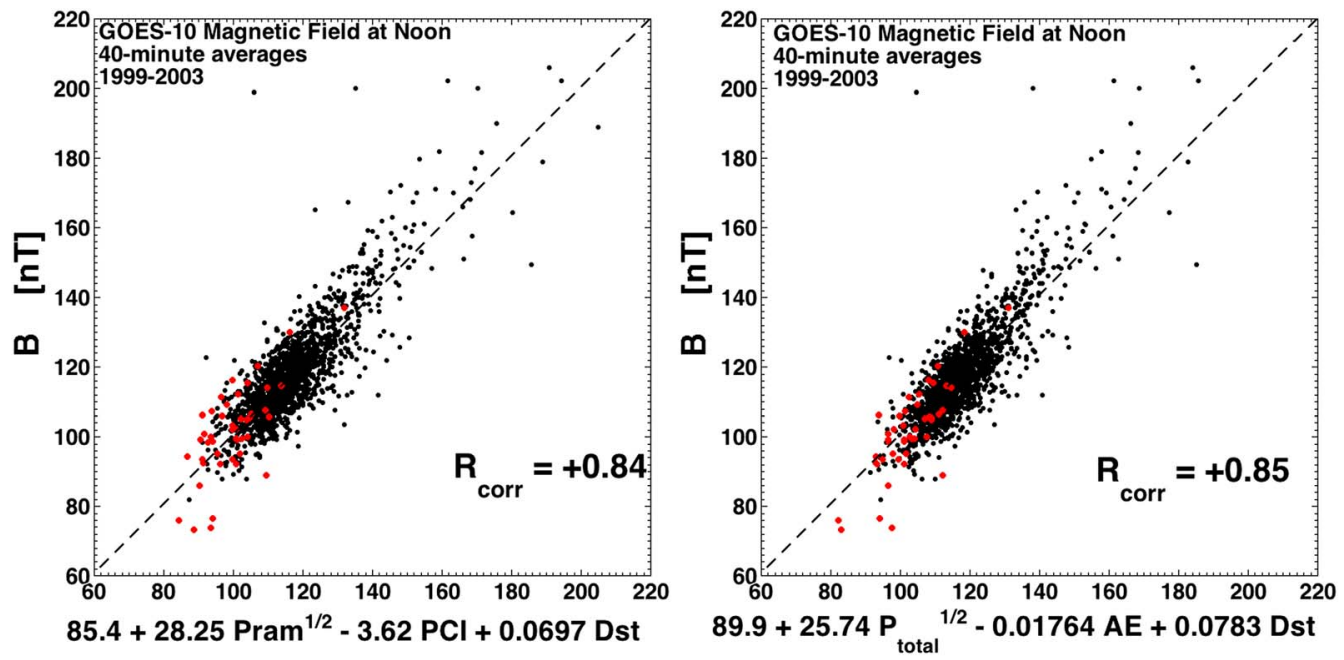

Figure 8. The measured magnetic field strength at geosynchronous-orbit local noon is plotted vertically as functions of formula fits to the data horizontally. The fit on the left uses PCI to gauge the Region-1 currents, whereas the fit on the right uses $A E$. The red-highlighted points pertain to solar wind Alfven Mach numbers of less than 3 . The Pearson correlation coefficients $\mathrm{R}_{\text {corr }}$ between the measured values and the fits are indicated on the plots. The dashed lines indicate $\mathrm{B}=$ fit formula. 


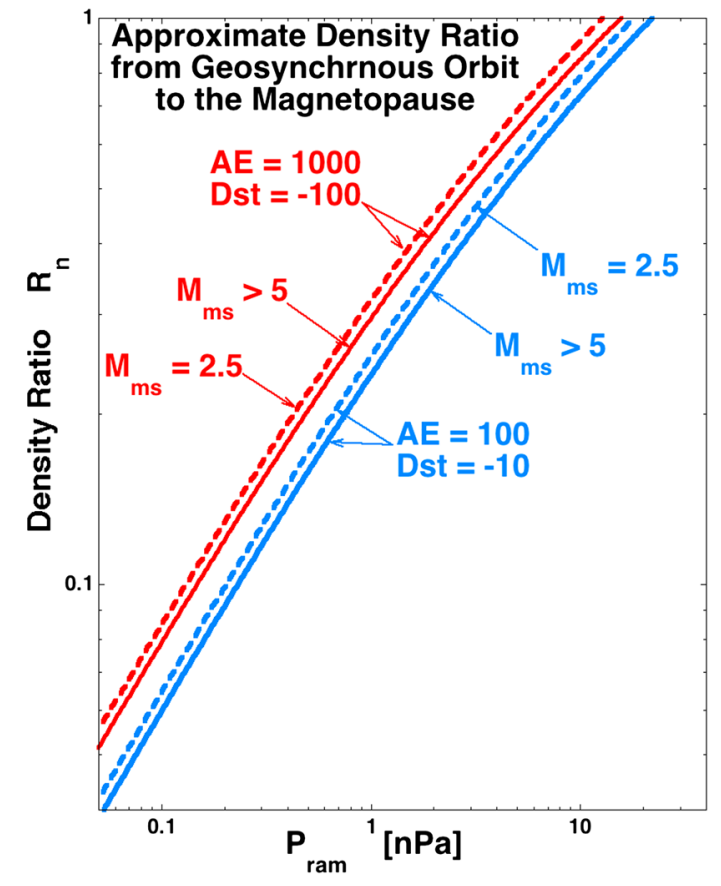

Figure 9. For two different solar wind Alfven Mach numbers and for two levels of geomagnetic activity, the density mapping factor $\mathrm{R}_{\mathrm{n}}$ (expressions (24) and (23b)) from geosynchronous orbit to the magnetopause is plotted as a function of the ram pressure of the solar wind.

with Earth, $\mathrm{P}_{\text {ram }}$ should be replaced by $\mathrm{P}_{\text {total }}$ at low Mach number, where

$$
\begin{aligned}
\mathrm{P}_{\text {total }} & =\rho_{\mathrm{sw}} \mathrm{v}_{\mathrm{sw}}{ }^{2}+\mathrm{n}_{\mathrm{sw}} \mathrm{k}_{\mathrm{B}}\left(\mathrm{T}_{\mathrm{i}-\mathrm{sw}}+\mathrm{T}_{\mathrm{e}-\mathrm{sw}}\right)+\mathrm{B}_{\mathrm{sw}}{ }^{2} / 8 \pi \\
& =\mathrm{P}_{\mathrm{ram}}\left(1+0.5 \mathrm{M}_{\mathrm{ms}}{ }^{-2}\right),
\end{aligned}
$$

[cf. Borovsky, 2008, section 3.1], where $\mathrm{M}_{\mathrm{ms}}=\mathrm{v}_{\mathrm{sw}} /\left(\mathrm{C}_{\mathrm{s}}{ }^{2}+\mathrm{v}_{\mathrm{A}}{ }^{2}\right)^{1 / 2}$ is the magnetosonic Mach number of the solar wind. Using expression (20), the expression $r_{\mathrm{mp}}=11.7 \mathrm{P}_{\mathrm{ram}}{ }^{-1 / 6}$ becomes

$$
\mathrm{r}_{\mathrm{mp}}=11.7 \mathrm{P}_{\mathrm{ram}}{ }^{-1 / 6}\left(1+0.5 \mathrm{M}_{\mathrm{ms}}{ }^{-2}\right)^{-1 / 6}
$$

where $\mathrm{r}_{\mathrm{mp}}$ is in $R_{E}$ and $\mathrm{P}_{\text {ram }}$ is in $\mathrm{nPa}$. It is almost always the case in the solar wind that when $\mathrm{M}_{\mathrm{ms}}$ becomes low (where the term $\left(1+0.5 \mathrm{M}_{\mathrm{ms}}{ }^{-2}\right)^{-1 / 6}$ in expression (21) deviates substantially from unity), $\mathrm{M}_{\mathrm{A}}>>\mathrm{M}_{\mathrm{s}}$ so that $\mathrm{M}_{\mathrm{ms}} \approx \mathrm{M}_{\mathrm{A}}$ and thus $\mathrm{M}_{\mathrm{A}}$ can be used to replace $M_{m s}$ in expression (21).

[17] From pressure balance with the solar wind, the magnetic field strength in the nose of the magnetosphere at the magnetopause $B_{m p}$ is given at high Mach number by $\mathrm{B}_{\mathrm{mp}}=47 \mathrm{P}_{\mathrm{ram}}^{1 / 2}$ [cf. Schield, 1969], where $\mathrm{B}_{\mathrm{mp}}$ is in units of $n T$ and $P_{\text {ram }}$ is in units of $n P a$. Using expression (20), the expression $\mathrm{B}_{\mathrm{mp}}=47 \mathrm{P}_{\mathrm{ram}}{ }^{1 / 2}$ becomes

$$
\mathrm{B}_{\mathrm{mp}}=47 \mathrm{P}_{\mathrm{ram}}{ }^{1 / 2}\left(1+0.5 \mathrm{M}_{\mathrm{ms}}{ }^{-2}\right)^{1 / 2},
$$

for all Mach numbers.

[18] For high-speed-stream-driven geomagnetic storms, the measured magnetic field strength at geosynchronous-orbit local noon has been fit as $B_{\text {geo }}=106+6.3 \mathrm{P}_{\text {ram }}$ [Borovsky and Denton, 2010a, equation (2)], where $\mathrm{B}_{\mathrm{geo}}$ is in units of $\mathrm{nT}$ and $\mathrm{P}_{\text {ram }}$ is in units of $\mathrm{nPa}$. The dipole field strength at geosynchronous orbit is $106 \mathrm{nT}$. The expression $\mathrm{B}_{\text {geo }}=106+6.3 \mathrm{P}_{\text {ram }}$ reflects the increase above dipole values of the magnetic field strength in the dayside magnetosphere owing to the pressure-driven Chapman-Ferraro currents. Owing to the magnetic perturbation of the Region1 currents flowing in the dawn-to-dusk fashion and to plasma diamagnetism, for low-Mach-number solar wind the magnetic field in the dayside magnetosphere can be depressed to strengths below that of the dipole [Borovsky et al., 2009]. In Figure 7 the magnetic field strength measured at local noon at geosynchronous orbit by GOES-10 [Singer et al., 1996; Dunham et al., 1996] during the years 1999-2003 is plotted as a function of the Alfven Mach number $\mathrm{M}_{\mathrm{A}}$ of the solar wind. The magnetic field values are 40 min averages as the spacecraft crosses local noon. The red dashed line is the dipole field strength for geosynchronous orbit: 106 nT [Borovsky and Denton, 2010a]. As can be seen at low Mach number, the magnetic field strength at geosynchronous orbit local noon tends to be below dipolar values. For $\mathrm{M}_{\mathrm{A}}<3,69 \%$ of the measured values at noon were below the dipole value. To approximately account for the depression of the magnetic field strength by the Region1 currents, the measured magnetic field strength at noon can be fit as a function of the polar cap index (PCI) or auroral-electrojet index $(A E)$, both of which are measures of the strength of the Region-1 currents in the Northern Hemisphere [e.g., Nisbet, 1982; Troshichev et al., 1988]. Likewise, to approximately account for the depression of the magnetic field strength by plasma diamagnetism [cf. Dessler and Karplus, 1961; Hilmer and Voigt, 1995], the measured magnetic field strength at noon can be fit as a function of the Dst index. In the two panels of Figure 8 the measured magnetic field strength at geosynchronous-orbit local noon is plotted (vertical) as functions of such fits (horizontal). The two fits to the magnetic field at geosynchronous orbit local noon are

$$
\begin{gathered}
\mathrm{B}_{\text {geo }}=89.9+25.74 \mathrm{P}_{\text {total }}^{1 / 2}-3.34 \mathrm{PCI}+0.0871 \text { Dst } \\
\mathrm{B}_{\text {geo }}=89.9+25.74 \mathrm{P}_{\text {total }}^{1 / 2}-0.01764 A E+0.0783 \text { Dst }
\end{gathered}
$$

where $\mathrm{B}, A E$, and Dst are in units of $\mathrm{nT}$ and $\mathrm{P}_{\text {total }}=\mathrm{P}_{\text {ram }}+\mathrm{B}^{2} /$ $8 \pi+\mathrm{nk}_{\mathrm{B}}\left(\mathrm{T}_{\mathrm{i}}+\mathrm{T}_{\mathrm{e}}\right)=\mathrm{P}_{\mathrm{ram}}\left(1+0.5 \mathrm{M}_{\mathrm{ms}}{ }^{-2}\right)$ of the solar wind is in units of $\mathrm{nPa}$. In the two panels of Figure 8 the Pearson linear correlation coefficient $\mathrm{R}_{\text {corr }}$ between the measured magnetic field strength and the fit is displayed: the fits are quite good with correlation coefficients of +0.84 and +0.85 for 1520 points. In expressions (23a) and (23b) the dayside magnetic field strength increases with increasing total pressure of the solar wind owing to the Chapman-Ferraro current, the dayside magnetic field strength decreases with increasing PCI or $A E$ owing to the northern and southern Region-1 currents, and the dayside magnetic field strength decreases with increasing Dst owing to plasma diamagnetism in the magnetosphere. Note that only the Region-1 current of the Northern Hemisphere is directly measured by PCI or $A E$; if the Southern Hemisphere Region-1 current could be independently measured, the fits of expressions (23a) and (23b) might be further improved. In expressions (23a) and (23b), if $\mathrm{P}_{\text {total }}$ of the solar wind cannot be calculated, $\mathrm{P}_{\text {ram }}$ can be used in its place without strongly affecting the quality of the fits. 

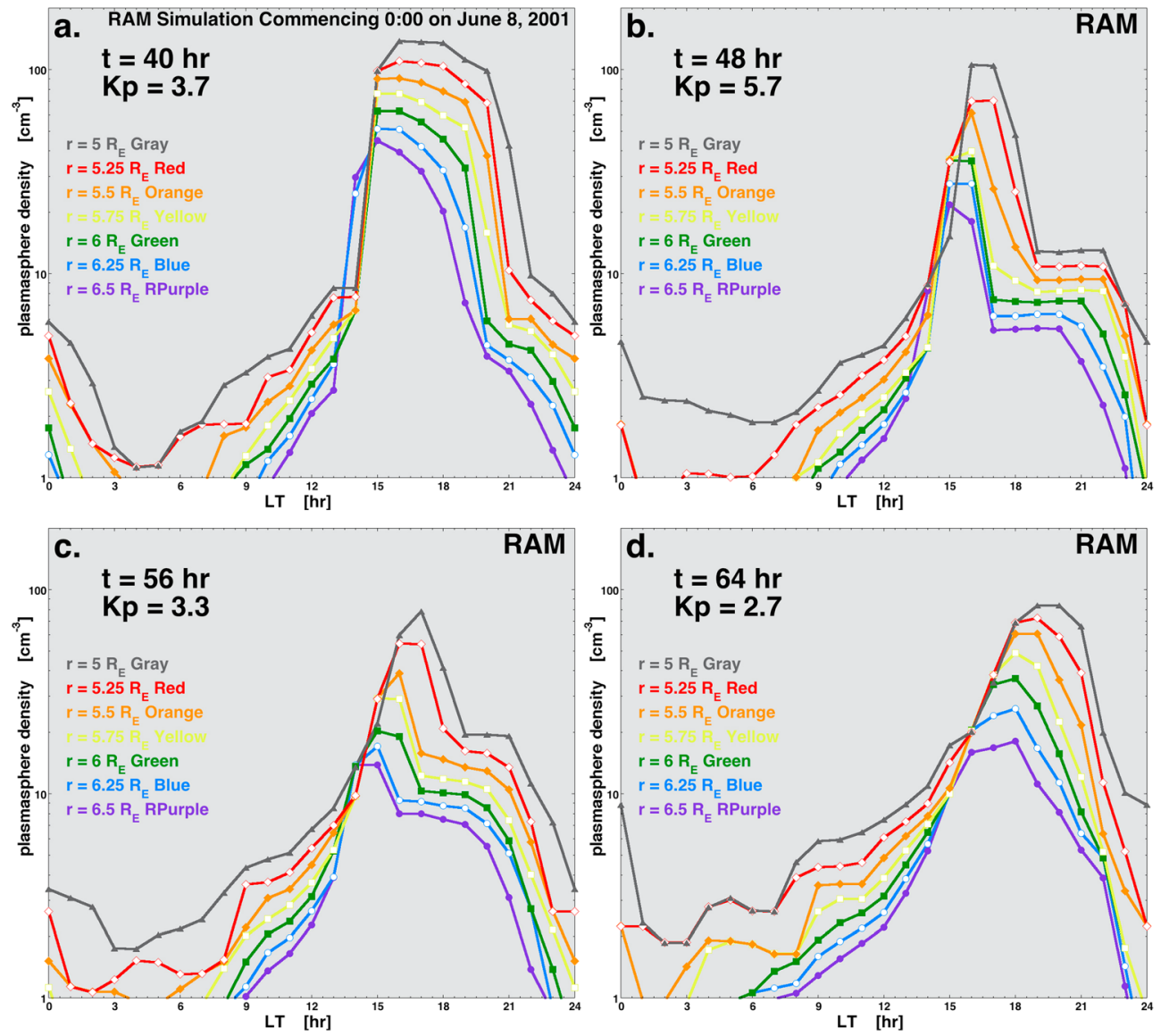

Figure 10. From four snapshots of a RAM computer simulation, the local-time profile of the plasmaspheric drainage plume is shown in cuts from $\mathrm{r}=5 R_{E}$ to $\mathrm{R}=6.5 R_{E}$.

[19] Using expressions (22) and (21), expression (19) for the ratio of the number density at the magnetopause $\mathrm{n}_{\mathrm{mp}}$ to the number density at geosynchronous orbit $\mathrm{n}_{\text {geo }}$ becomes

$$
\mathrm{R}_{\mathrm{n}}=\mathrm{n}_{\mathrm{mp}} / \mathrm{n}_{\text {geo }}=26.5 \mathrm{P}_{\mathrm{ram}}^{2 / 3}\left(1+0.5 \mathrm{M}_{\mathrm{ms}}{ }^{-2}\right)^{2 / 3} / \mathrm{B}_{\text {geo }},
$$

where $\mathrm{B}_{\mathrm{geo}}$ is given by expression (23a) or (23b). As noted earlier, without loss of accuracy $\mathrm{M}_{\mathrm{ms}}$ can be replaced by $\mathrm{M}_{\mathrm{A}}$ in expression (24).

[20] Using expressions (24) and (23b), the plasma density ratio between geosynchronous orbit at noon and the magnetopause is plotted in Figure 9 as a function of $\mathrm{P}_{\mathrm{ram}}$ of the solar wind for high solar wind Mach numbers (solid curves) and for a solar wind magnetosonic Mach number of 2.5 (dashed curves). The ratio is plotted for two values of $A E$ and $D s t$ : mild current systems (blue) where $A E=100$ and $D s t=-10$ and strong current systems (red) where $A E=1000$ and $D s t=-100$. The strong dependence on the ram pressure of the solar wind $\mathrm{P}_{\text {ram }}$ is seen, with the reduction in density being less for high values of $\mathrm{P}_{\mathrm{ram}}$. Note that the reduction of the plasma density convecting in the dayside magnetosphere from geosynchronous orbit to the magnetopause is slightly less for the low-Mach-number solar wind than it is during the morecommon high-Mach-number solar wind. Note also that the density reduction $R_{n}$ between geosynchronous orbit and the magnetopause is less when the magnetospheric currents are stronger (red).
[21] In determining the properties of the plasmaspheric drainage plume at the magnetopause from measurements at geosynchronous orbit, the variation of the width of the drainage plume between geosynchronous orbit and the magnetopause is also relevant. In the next three paragraphs we will present arguments that the plumes (1) become narrower, (2) stay about the same width, and (3) become wider as the material convects past geosynchronous orbit to the dayside magnetopause.

[22] For high-Mach-number solar wind, plasmaspheric drainage plumes might become more narrow as the plume material convects past geosynchronous orbit to the dayside magnetopause. Using LFM-code global-MHD simulations, examination of the flow pattern in the dayside magnetosphere as functions of the solar wind Alfven Mach number $\mathrm{M}_{\mathrm{A}}$ finds flow streamlines that converge toward the nose of the magnetopause for high $\mathrm{M}_{\mathrm{A}}$ values (cf. middle and bottom panels of Figure 6). With such a convergence of streamlines in the equatorial plane, a narrowing of flow structures is anticipated, at least for high-Mach-number solar wind.

[23] In Figure 10 the local-time profiles of the plasmaspheric-plasma density is shown at four snapshots of time from ring current-atmosphere coupling (RAM)code [Jordanova et al., 1997, 2008, 2010] computer simulations of convection in the magnetosphere during a very brief corotating interaction region (CIR)-driven storm associated with a high-speed stream preceded by a 


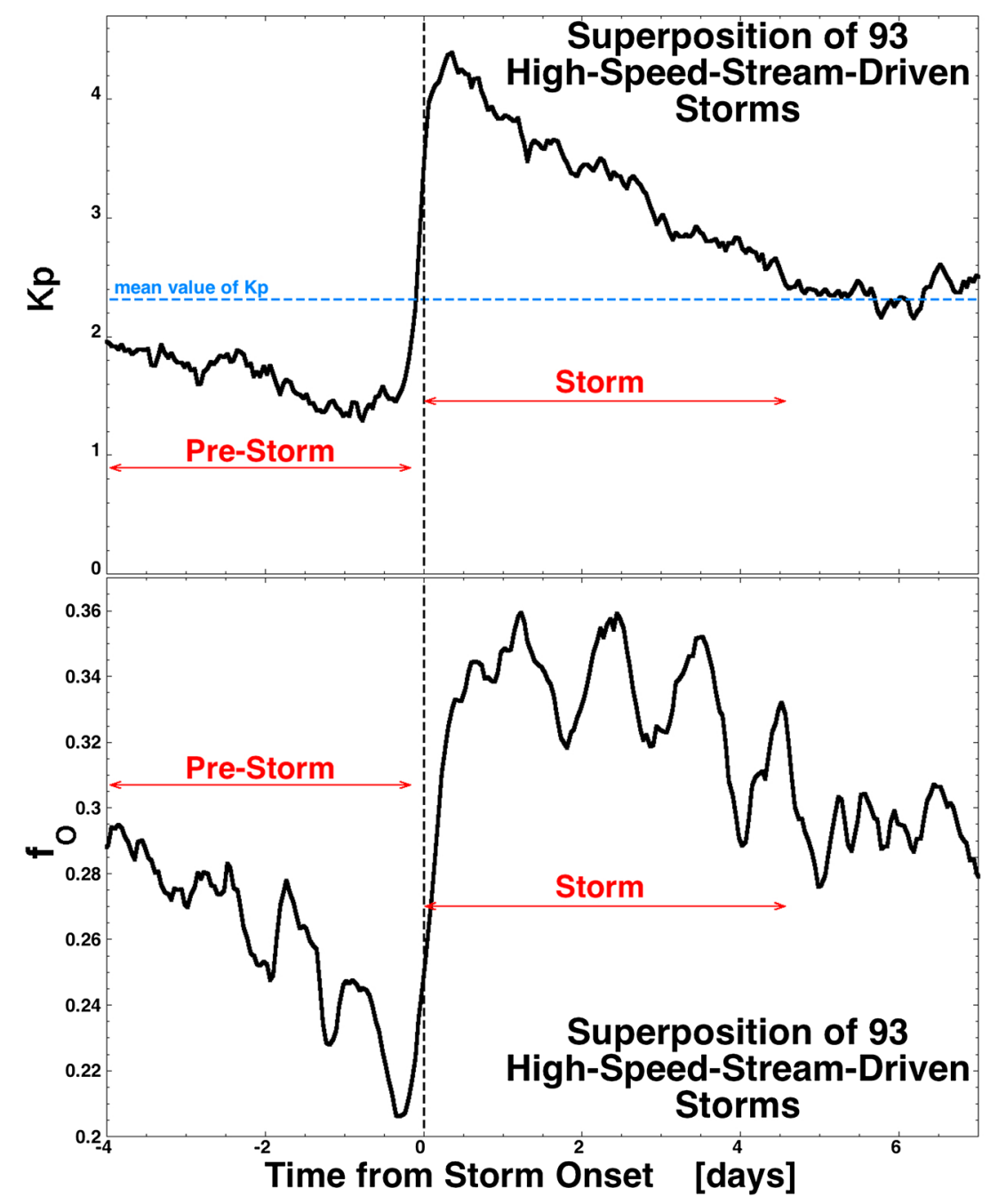

Figure 11. For 93 high-quality high-speed-stream-driven storms, (top) the superposed average of the $K p$ index and (bottom) the superposed average of the estimated oxygen fraction $f_{O}$ of the ion plasma sheet are plotted. The estimate of $f_{O}$ is obtained using MPA measurements near local midnight using the methodology of Denton et al. [2005]. The zero epoch is the onset of storm levels of magnetospheric convection.

pseudostreamer. In each of the four panels of Figure 10 the local-time profile of the density is plotted at different radii from the earth in different colors. Examining the plumes in the noon-dusk sector of local time, it is seen that the width in local time of the plumes narrows slightly in going from $5.5 R_{E}$ (orange) to $6.5 R_{E}$ (purple). If the plume kept a constant width (in kilometers) in passing 5.5 and $6.5 R_{E}$, the local-time width would decrease to $85 \%$ of its $5.5 R_{E}$ value at $6.5 R_{E}$. Hence, the plumes are about constant width in kilometers in passing from 5.5 to $6.5 R_{E}$ in the RAM simulation. At $6.5 R_{E}$ (approximately geosynchronous orbit), the plume widths from the RAM simulation in Figure 10 are $2-4 \mathrm{~h}$ of local time, which are well within the range of plume widths seen at geosynchronous orbit [cf. Borovsky and Denton, 2008, Figure 8].

[24] For the same event, a simulation of the plasmaspheric dynamics was also run using the SAMI3 code [Huba et al., 2008; Huba and Krall, 2013; Krall and Huba, 2013], which is based on SAMI2 [Huba et al., 2000] but modified to work with the Weimer [2005] solar wind-parameterized ionospheric potential patterns. In the SAMI3 simulation the local-time width of the plume increases with increasing distance from the Earth, going from $3.3 \mathrm{~h}$ of local time at $5.4 R_{E}$ to $4.1 \mathrm{~h}$ of local time at 7.8 $R_{E}$. At $6.8 R_{E}$ (approximately geosynchronous orbit) the plume width is $4.6 \mathrm{~h}$ of local time, which is well within the range of plumes seen at geosynchronous orbit [cf. Borovsky and Denton, 2008, Figure 8]. This is an increase of physical width of the plume with distance as 4.7 to 8.2 to $8.4 R_{E}$ at the distances of 5.4, 6.8, and 7.8 $R_{E}$.

\section{The Effect of the Ion Plasma Sheet Mass Density on Dayside Reconnection}

[25] In this section the effect of the mass density of the ion plasma sheet in the dayside magnetosphere will be explored. The focus will be on storm times. In Table 1 three cases will be examined: (1) during the superdense-plasma-sheet phase early in high-speed-stream-driven storms, (2) the later phases of high-speed-stream-driven storms, and (3) during the magnetic-cloud portions of CME-driven storms. 
[26] Satellites in geosynchronous orbit regularly measure the ion plasma sheet as they cross the dayside magnetosphere. Surveys using the multisatellite MPA (Magnetospheric Plasma Analyzer) instruments [Bame et al., 1993] at geosynchronous orbit report hot-ion number densities $n_{\text {hot }} \sim 0.6 \mathrm{~cm}^{-3}$ across the dayside at low $K p$ and $\mathrm{n}_{\text {hot }} \sim 0.7 \mathrm{~cm}^{-3}$ across the dayside at high Kp [Korth et al., 1999; Denton et al., 2005]. These dayside ion-plasma-sheet densities are lower than the nightside densities owing to charge-exchange losses in the transport of the ion plasma sheet through the hydrogen geocorona [cf. Kistler et al., 1989; Maurice et al., 1998]. During the superdense-plasma-sheet phase early in highspeed-stream-driven storms the MPA-measured ion plasma sheet density can average $0.8 \mathrm{~cm}^{-3}$ on the dayside at geosynchronous orbit [cf. Denton and Borovsky, 2008; Borovsky and Denton, 2010a], and during the superdense-plasma-sheet phase of CME-driven storms the ion plasma sheet number density can average $1.2 \mathrm{~cm}^{-3}$ on the dayside at geosynchronous orbit [cf. Denton et al., 2006; Zhang et al., 2006].

[27] What is of pertinence for the dayside reconnection rate is the mass density of the magnetospheric plasma. Normally, the composition of the ion plasma sheet is dominated by $\mathrm{H}^{+}$ [cf. Lennartsson and Shelley, 1986], but at high Kp and during solar maximum, $\mathrm{O}^{+}$can be an important constituent [Young et al., 1982; Denton et al., 2005]. The MPA instruments are electrostatic analyzers, and the ion number densities produced in the data set are calculated assuming that all of the ions reaching the detector are protons [Thomsen et al., 1999]. In Figure 11 the oxygen-ion number-density fraction $f_{O}$ is estimated for high-speed-stream-driven storms using MPA ion and electron measurements and the methodology of Denton et al. [2005]: this methodology compares the hot-electron and hot-ion measured number densities in the near-midnight region of local time and attributes the deficit of the ion number density relative to the electron number density to the oxygen fraction in the ion plasma sheet. This methodology yields measurements of $f_{O}$ on the nightside: the oxygen fraction $f_{O}$ may be higher on the dayside owing to (a) additional oxygen outflows into the ion plasma sheet as it convects from the nightside to the dayside and (b) the shorter charge-exchange lifetime of $\mathrm{H}^{+}$ions than $\mathrm{O}^{+}$ions at $\sim 10 \mathrm{keV}$ [cf. Smith and Bewtra, 1978; Fok et al., 1991] as the ion plasma sheet is transported through the neutral-hydrogen geocorona on its way to the dayside. In the bottom panel of Figure 11 the superposed average of $\mathrm{f}_{\mathrm{O}}$ is plotted for the 93 high-speed-stream-driven storms of Borovsky and Denton [2010a] from the years 1993-2005. The zero epoch for the superposition in Figure 11 is the onset of storm levels of magnetospheric convection. In the top panel of Figure 11 the superposed average of the $K p$ index is plotted for the 93 storms, with a horizontal dashed line indicating $K p=2.3$, which is the long-term average value of $K p$. As can be seen, prior to the onset of the storms, the superposed average of $K p$ is well below the long-term average: this is the systematic calm before the storm [Borovsky and Steinberg, 2006]. After the onset of the high-speed-stream-driven storms, the superposed average of $K p$ remains elevated for more than 4 days. The superposed average of the ion-plasma-sheet oxygen fraction $\mathrm{f}_{\mathrm{O}}$ reflects the pattern in $K p$ : $\mathrm{f}_{\mathrm{O}}$ is low during the calm before the storm, its value increases at the onset of the storms, and it remains elevated for about 4 days.

[28] If the fraction of ions in the plasma that are $\mathrm{H}^{+}, \mathrm{He}^{+}$, and $\mathrm{O}^{+}$are $\mathrm{f}_{\mathrm{H}}, \mathrm{f}_{\mathrm{He}}$, and $\mathrm{f}_{\mathrm{O}}$ where $\mathrm{f}_{\mathrm{H}}+\mathrm{f}_{\mathrm{He}}+\mathrm{f}_{\mathrm{O}}=1$ and if the temperature of all three species are the same, then the total number density of ions $\mathrm{n}_{\text {geo }}$ at geosynchronous orbit is underestimated by the MPA-measured value $n_{\text {meas }}$ by the factor

$$
\mathrm{n}_{\text {geo }}=\mathrm{n}_{\text {meas }} /\left(\mathrm{f}_{\mathrm{H}}+0.5 \mathrm{f}_{\mathrm{He}}+0.25 \mathrm{f}_{\mathrm{O}}\right) .
$$

[29] The mass density ( $\left.\mathrm{amu} / \mathrm{cm}^{3}\right)$ of the plasma is given by $\left(f_{\mathrm{H}}+4 \mathrm{f}_{\mathrm{He}}+16 \mathrm{f}_{\mathrm{O}}\right)$ times the total number density $\mathrm{n}_{\mathrm{geo}}$ of the plasma. Hence, the mass density of the plasmaspheric plasma measured at geosynchronous orbit is

$$
\rho_{\text {geo }}=n_{\text {meas }}\left(f_{\mathrm{H}}+4 f_{\mathrm{He}}+16 f_{\mathrm{O}}\right) /\left(\mathrm{f}_{\mathrm{H}}+0.5 \mathrm{f}_{\mathrm{He}}+0.25 \mathrm{f}_{\mathrm{O}}\right),
$$

where $\rho_{\text {geo }}$ is in units of amu $/ \mathrm{cm}^{3}$ and $n_{\text {geo }}$ is in units of $\mathrm{cm}^{-3}$.

[30] For the superdense-plasma-sheet phase of high-speedstream-driven storms, which in the dayside magnetosphere peaks at about $12 \mathrm{~h}$ after storm onset, $\mathrm{n}_{\mathrm{hot}}=0.8 \mathrm{~cm}^{-3}$ will be taken for the measured number density of hot ions at geosynchronous orbit on the dayside [cf. Denton and Borovsky, 2009, Figure 3]. This value is entered into the first row of the first column of Table 1. Figure 11 (12 h after storm onset) yields $\mathrm{f}_{\mathrm{O}} \approx 0.34$ (with $\mathrm{f}_{\mathrm{H}}=0.66$ and $\mathrm{f}_{\mathrm{He}}=0$ ): with this, expression (26) yields $\rho_{\mathrm{geo}}=6.6 \mathrm{amu} / \mathrm{cm}^{3}$ at geosynchronous orbit. Taking $\mathrm{P}_{\text {ram }}=3.6 \mathrm{nPa}, \mathrm{n}_{\mathrm{sw}}=8.2 \mathrm{~cm}^{-3}$, and $\mathrm{M}_{\mathrm{A}}=7.2$ (all from Borovsky and Denton [2010a, Figure 1]) for the pertinent solar wind parameters $12 \mathrm{~h}$ after storm onset, with $\mathrm{B}_{\mathrm{geo}}=127 \mathrm{nT}$ [from Borovsky and Denton, 2010a, Figure 8], expression (24) yields $R_{n}=0.49$ for the density ratio between geosynchronous orbit and the dayside magnetopause. From $\rho_{\text {geo }}=6.6 \mathrm{amu} / \mathrm{cm}^{3}$, this gives $\rho_{\mathrm{m}}=3.2 \mathrm{amu} / \mathrm{cm}^{3}$ for the ionplasma-sheet mass density at the magnetopause. The ratio of the mass density of the dayside magnetosphere at the magnetopause to the solar wind mass density (for $\rho_{\mathrm{o}}=8.2 \mathrm{amu} / \mathrm{cm}^{3}$ for $\mathrm{n}_{\mathrm{sw}}=8.2 \mathrm{~cm}^{-3}$ ) is $\rho_{\mathrm{m}} / \rho_{\mathrm{o}}=0.39$. With this density ratio and $\mathrm{M}_{\mathrm{A}}=7.2$, expression (9) gives $\mathrm{p}=0.074$ for the masscorrection factor. For this $\mathrm{p}$ value, expression (3) then gives $\mathrm{M}=0.96$ for the multiplicative mass factor for dayside reconnection owing to the mass density of the ion plasma sheet. The quantity $1-\mathrm{M}=3.5 \%$ is the fractional reduction of the dayside reconnection rate owing to the plasma sheet mass density. Since the ion plasma sheet flows into all regions of the dayside $\mathrm{X}$-line, the quantity $1-\mathrm{M}=3.5 \%$ is also the fractional reduction of the length $\mathrm{L}_{\mathrm{X} \text {-line }}$ of the dayside $\mathrm{X}$-line (cf. expression (18)). The factor $\mathrm{M}^{2}=0.93$ is the multiplicative factor for the total dayside reconnection rate owing to the mass density of the ion plasma sheet. The quantity $1-\mathrm{M}^{2}=6.9 \%$ is the estimate of the fractional reduction of solar wind/ magnetosphere coupling caused by the mass density of the dayside ion plasma sheet during the superdense-plasma-sheet phase of high-speed-stream-driven storms.

[31] For the later phase of a high-speed-stream-driven storm, $\mathrm{n}_{\text {hot }}=0.6 \mathrm{~cm}^{-3}$ will be taken for the measured number density of hot ions at geosynchronous orbit on the dayside [cf. Denton and Borovsky, 2009, Figure 3]. Figure 11, 2 days after storm onset, yields $\mathrm{f}_{\mathrm{O}} \approx 0.34$ (with $\mathrm{f}_{\mathrm{H}}=0.66$ and $\mathrm{f}_{\mathrm{He}}=0$ ): with this, expression (26) yields $\rho_{\mathrm{geo}}=4.9 \mathrm{amu} / \mathrm{cm}^{3}$ at geosynchronous orbit. During the later days of highspeed-stream-driven storms the fundamental solar wind parameters used are (from Figure 1 of Borovsky and Denton [2010b]) $\mathrm{n}_{\mathrm{sw}}=3 \mathrm{~cm}^{-3}, \quad \mathrm{v}_{\mathrm{sw}}=625 \mathrm{~km} / \mathrm{s}$, and $\mathrm{v}_{\mathrm{A}}=60 \mathrm{~km} / \mathrm{s}$, which yield $\mathrm{P}_{\text {ram }}=1.9 \mathrm{nPa}$ and $\mathrm{M}_{\mathrm{A}}=10.4$. For the magnetic 


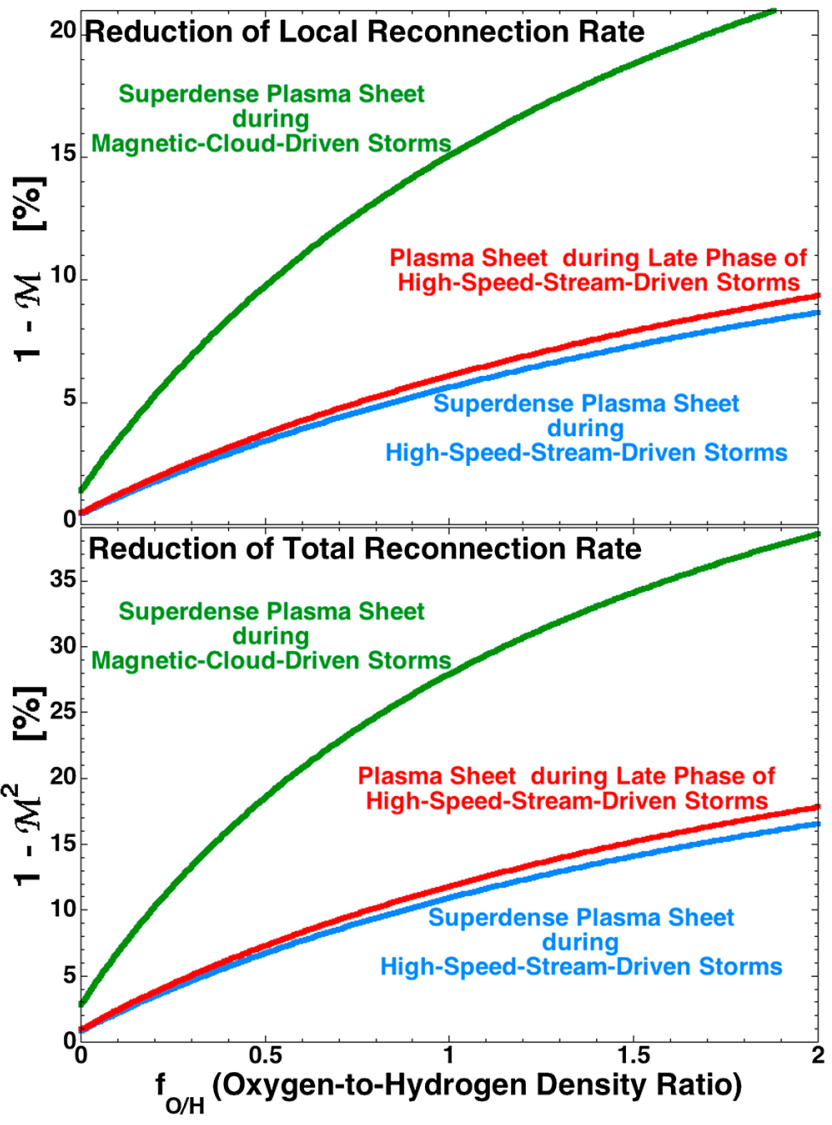

Figure 12. The estimated fractional reduction of (top) the local reconnection rate and (bottom) the total dayside reconnection rate is plotted as a function of the ratio of the oxygen-to-proton number density of the ion plasma sheet for three cases as labeled.

field strength in the dayside magnetosphere at geosynchronous orbit, $\mathrm{B}_{\mathrm{geo}}=115 \mathrm{nT}$ is taken [from Borovsky and Denton, 2010a, Figure 8]. These values in expression (24), with $\mathrm{M}_{\mathrm{ms}} \approx \mathrm{M}_{\mathrm{A}}$, yield $\mathrm{R}_{\mathrm{n}}=0.36$ for the mapping factor of geosynchronous density $\rho_{\text {geo }}$ to the magnetospheric density at the magnetopause $\rho_{\mathrm{m}}$. The values in the second column of Table 1 lead to $\rho_{\mathrm{m}}=1.7 \mathrm{amu} / \mathrm{cm}^{3}$ and $\rho_{\mathrm{m}} / \rho_{\mathrm{o}}=0.58$. With this density ratio and $\mathrm{M}_{\mathrm{A}}=10.4$, expression (9) gives $\mathrm{p}=0.081$ for the mass-correction factor. This $\mathrm{p}$ value then gives $\mathrm{M}=0.96$. The quantity $1-\mathrm{M}=3.8 \%$ is the fractional reduction of the dayside reconnection rate owing to the plasma sheet mass density in the later stages of high-speed-stream-driven storms. The quantity $1-\mathrm{M}=3.8 \%$ is also the fractional reduction of the length $\mathrm{L}_{\mathrm{X} \text {-line }}$ of the dayside $\mathrm{X}$-line (cf. expression (18)). The factor $\mathrm{M}^{2}=0.93$ is the multiplicative factor for the total dayside reconnection rate owing to the mass density of the ion plasma sheet. The quantity $1-\mathrm{M}^{2}=7.5 \%$ is an estimate of the fractional reduction of solar wind/magnetosphere coupling caused by the mass density of the dayside ion plasma sheet during the later phase of high-speed-streamdriven storms.

[32] For the ion plasma sheet at geosynchronous orbit during magnetic-cloud-driven storms, statistical measurements for CME-driven storms will be used: in Denton et al. [2006, Figure 3] the measured ion-plasma-sheet number density can go to $1.2 \mathrm{~cm}^{-3}$ on the dayside during CME- driven storms. Unfortunately, the solar wind drivers for this figure are not separated according to CME-sheath driving of geomagnetic activity versus magnetic-cloud driving of geomagnetic activity. This value of $n_{\text {hot }}=1.2 \mathrm{~cm}^{-3}$ will be taken for the estimate of the effect of the ion-plasma-sheet mass density on dayside reconnection during magneticcloud-driven storms. Denton et al. [2006, Figure 7] indicates that the oxygen fraction $\mathrm{f}_{\mathrm{O}}$ is higher for CME-driven storms than it is for high-speed-stream-driven storms. Cloud-driven storms tend to occur at solar maximum, and they are typically high $K p$, so $\mathrm{f}_{\mathrm{O}} \sim 0.5$ is probably a good approximation. For the solar wind parameters during cloud-driven storms, the OMNI2 data set [King and Papitashvili, 2005] is used to obtain median values for solar wind parameters during the $K p>4$ portions of the Lepping et al. [2005] collection of magnetic clouds. A survey of these $K p>4$ times yield $\mathrm{n}_{\mathrm{sw}}=5.5 \mathrm{~cm}^{-3}, \mathrm{P}_{\mathrm{ram}}=2.2 \mathrm{nPa}$, and $\mathrm{M}_{\mathrm{A}}=3.6$ for the median values. To obtain $B_{\text {geo }}$ via expression (23a), the median value of $\mathrm{PCI}=3.3$ and the median value of $D s t=-89.5 \mathrm{nT}$ during these $K p>4$ Lepping-cloud intervals. With these values, expression (23a) yields $B_{\text {geo }}=110 \mathrm{nT}$. For $\mathrm{f}_{\mathrm{H}}=0.5$ and $\mathrm{f}_{\mathrm{o}}=$ 0.5 , expression (26) yields $\rho_{\text {geo }}=16 \mathrm{amu} / \mathrm{cm}^{3}$ at geosynchronous orbit. The values in the third column of Table 1 in expression (24), with $\mathrm{M}_{\mathrm{ms}} \approx \mathrm{M}_{\mathrm{A}}$, yield $\mathrm{R}_{\mathrm{n}}=0.41$ for the mapping factor, which gives $\rho_{\mathrm{m}}=6.7 \mathrm{amu} / \mathrm{cm}^{3}$ for the ion-plasma-sheet mass density at the magnetopause, which gives (for $\rho_{\mathrm{o}}=5.5$ $\mathrm{amu} / \mathrm{cm}^{3}$ for $\left.\mathrm{n}_{\mathrm{sw}}=5.5 \mathrm{~cm}^{-3}\right) \rho_{\mathrm{m}} / \rho_{\mathrm{o}}=1.2$. With these density ratios and $\mathrm{M}_{\mathrm{A}}=3.6$, expression (9) gives $\mathrm{p}=0.39$. For this $\mathrm{p}$ value, $\mathrm{M}=0.85$ for the multiplicative mass factor for dayside reconnection owing to the mass density of the ion plasma sheet. The quantity $1-\mathrm{M}=15 \%$ for the fractional reduction of the dayside reconnection rate owing to the plasma sheet mass density in magnetic-cloud-driven storms. The quantity $1-M=15 \%$ is also the fractional reduction of the length $\mathrm{L}_{\mathrm{X}-\text {-line }}$ of the dayside $\mathrm{X}$-line (cf. expression (18)). The factor $\mathrm{M}^{2}=0.72$ : this is the multiplicative factor for the total dayside reconnection rate owing to the mass density of the ion plasma sheet. The quantity $1-\mathrm{M}^{2}=28 \%$ is the fractional reduction of solar wind/magnetosphere coupling during magnetic-cloud-driven storms caused by the mass density of the dayside ion plasma sheet.

[33] The effect of the fractional content of oxygen in the ion plasma sheet is explored in Figure 12. From expression (9) it is seen that $\mathrm{p}$ is linearly proportional to $\rho_{\mathrm{m}}$, which by expression (24) is $\rho_{m}=\rho_{\text {geo }} R_{n}$. Using expression (26), the quantity $\rho_{m}$ for the plasma sheet can be written as $\rho_{\mathrm{m}}=\mathrm{n}_{\text {meas }} \mathrm{R}_{\mathrm{n}}\left(\mathrm{f}_{\mathrm{H}}+16 \mathrm{f}_{\mathrm{O}}\right) /$ $\left(f_{\mathrm{H}}+0.25 f_{\mathrm{O}}\right)$, where $\mathrm{f}_{\mathrm{He}}=0$ has been taken for the plasma sheet. With this, expression (9) can be written as

$$
\begin{aligned}
\mathrm{p} & =\left(\mathrm{n}_{\text {meas }} \mathrm{R}_{\mathrm{n}} / \rho_{\mathrm{o}}\right) \mathrm{C}^{-1}\left[1+\left(\mathrm{M}_{\mathrm{A}} / 6\right)^{1.92}\right]^{-1 / 2}\left(\mathrm{f}_{\mathrm{H}}+16 \mathrm{f}_{\mathrm{O}}\right) /\left(\mathrm{f}_{\mathrm{H}}+0.25 \mathrm{f}_{\mathrm{O}}\right) \\
& =\mathrm{p}_{\mathrm{o}}\left(1+16 \mathrm{f}_{\mathrm{O} / \mathrm{H}}\right) /\left(1+0.25 \mathrm{f}_{\mathrm{O} / \mathrm{H}}\right)
\end{aligned}
$$

where $f_{O / H}=f_{O} / f_{H}=f_{O} /\left(1-f_{O}\right)$ and where $p_{o}=\left(n_{\text {meas }} R_{n} / \rho_{o}\right)$ $\mathrm{C}^{-1}\left[1+\left(\mathrm{M}_{\mathrm{A}} / 6\right)^{1.92}\right]^{-1 / 2}$ is the value of $\mathrm{p}$ for $\mathrm{f}_{\mathrm{O} / \mathrm{H}}=0$. For the three cases in Table 1, the values of $p_{o}$ are $p_{o}=9.0 \times 10^{-3}$ for the superdense-plasma-sheet phase of high-speed-streamdriven storms, $\mathrm{p}_{\mathrm{o}}=9.9 \times 10^{-3}$ for the later phase of highspeed-stream-driven storms, and $\mathrm{p}_{\mathrm{o}}=2.9 \times 10^{-2}$ for the superdense-plasma-sheet phase of magnetic-cloud-driven storms. Using expression (27) for the mass-correction factor $\mathrm{p}$, the fractional reduction of the local reconnection rate 


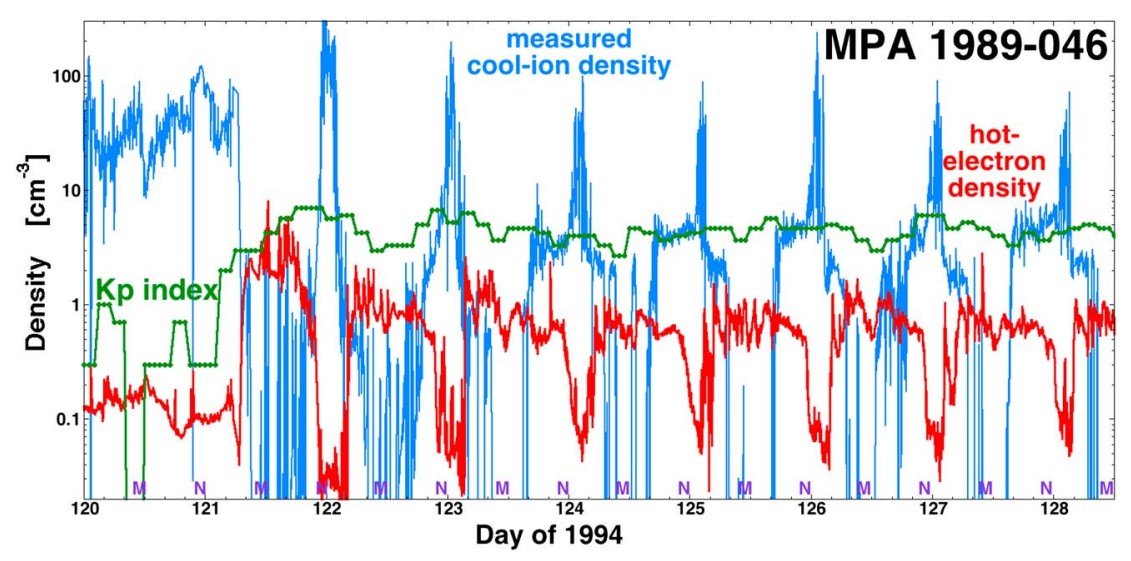

Figure 13. For a long-lived high-speed-stream-driven storm, the measured cold plasma density at geosynchronous orbit is plotted logarithmically as the spacecraft crosses the plume once per day for 7 days. When the $K p$ index (green curve) is low before the storm, the outer plasmasphere is seen at all local times. The measured number density of the electron plasma sheet is plotted in red.

$1-M=1-(1-p)^{-1 / 2}$ and the fractional reduction of the total reconnection rate $1-\mathrm{M}^{2}=1-(1-\mathrm{p})^{-1}$ are plotted for these three cases in the two panels of Figure 12 as functions of the oxygen-to-proton number-density ratio $\mathrm{f}_{\mathrm{O} / \mathrm{H}}=\mathrm{f}_{\mathrm{O}} / \mathrm{f}_{\mathrm{H}}$. For $\mathrm{f}_{\mathrm{O} / \mathrm{H}}$ $=0$ (no oxygen) the reductions of the local reconnection rate are $1.5 \%$ or less and the reductions of the total reconnection rate are $3 \%$ or less. As the ratio $\mathrm{f}_{\mathrm{O} / \mathrm{H}}$ increases toward unity (50\% oxygen by number), which is applicable to high $K p$ and solar maximum, the reductions of the local reconnection rate are $5 \%$ to $15 \%$ and the reductions of the total reconnection rate are $10 \%$ to $30 \%$ (see also Table 1 ).

[34] The magnitudes of the reductions for the dayside reconnection rate by the dayside ion plasma sheet will be assessed in section 8 .

\section{The Plasmaspheric Drainage Plume}

[35] The effect of plasmaspheric drainage plumes on dayside reconnection will be explored in Table 2 for four cases: (1) early in high-speed-stream-driven storms, (2) later in high-speed-stream-driven storms, (3) during the CME-sheath portions of CME-driven storms, and (4) during the magneticcloud portions of CME-driven storms. For each of these four cases, statistics of plume measurements at geosynchronous orbit will be utilized.

\subsection{The Properties of Plasmaspheric Drainage Plumes at Geosynchronous Orbit}

[36] To estimate the magnitude of the effect that plasmasphericdrainage-plume plasma has on the rate of dayside reconnection between the solar wind and the magnetosphere, measurements of plasmaspheric plasma flowing across geosynchronous orbit from the multisatellite MPA instruments [Bame et al., 1993] will be used. Testing the MPA cold-ion-density measurements against plasma-wave measurements of density during satellite near conjunctions, Lawrence et al. [1999] and Denton et al. [2011] both developed greater-than-unity multiplicative factors to bring the MPA number densities statistically in line with plasma-wave number densities: no such factors will be used here. Hence, the MPA cool-ion number densities used here may be underestimates.
[37] An example of a plasmaspheric drainage plume during a long-duration high-speed-stream-driven storm appears in Figure 13; here the storm commences (green curve of $\mathrm{Kp}$ ) early on day 121 of 1994 and $K p$ remains elevated for many days (7 days of which are plotted in Figure 13). Once per day during the storm the MPA instrument on the spacecraft 1989-046 crosses through the drainage plume in the postnoon sector of local time and measures high densities of ions (blue curve in Figure 13).

[38] Values for the properties of plasmaspheric drainage plumes will be obtained from (1) the MPA measurements obtained in the Borovsky and Denton [2008] survey of plasmaspheric drainage plumes during high-speed-streamdriven storms and (2) MPA measurements obtained in a new survey of plasmaspheric drainage plumes during magneticcloud-driven storms. The Borovsky and Denton [2008] survey involved 210 satellite crossings of plumes during high-speedstream-driven storms; the new survey involves 40 satellite crossings of plumes during the CME-sheath portions of CME-driven storms and 48 satellite crossings of plumes during the magnetic-cloud portions of CME-driven storms.

[39] High-speed-stream-driven storms can be divided into two stages: (1) the first day of the storm wherein the storm is driven by the CIR, which is compressed streamer belt and compressed coronal-hole plasma, and (2) the later days of the storm when the storm is driven by uncompressed high-speed coronal-hole-origin wind. The plasma density of the CIR is high, resulting in a superdense-plasma-sheet phase of the storm during the first day with extra-strong stretching of the nightside magnetosphere.

[40] For high-speed-stream-driven storms the number density and width of plasmaspheric drainage plumes have been fit and the expressions for those fits appear in Borovsky and Denton [2008, Table 1]. The measured ion number density averaged across each plasmaspheric drainage plume at geosynchronous orbit has been fit as

$$
\mathrm{n}_{\text {meas }}=33 \mathrm{~cm}^{-3} \exp (-\mathrm{t} / 78)
$$

where $\mathrm{t}$ is the age of the storm in hours: as the storm progresses the drainage plumes become on average less dense. For high-speed-stream-driven storms the local-time width 


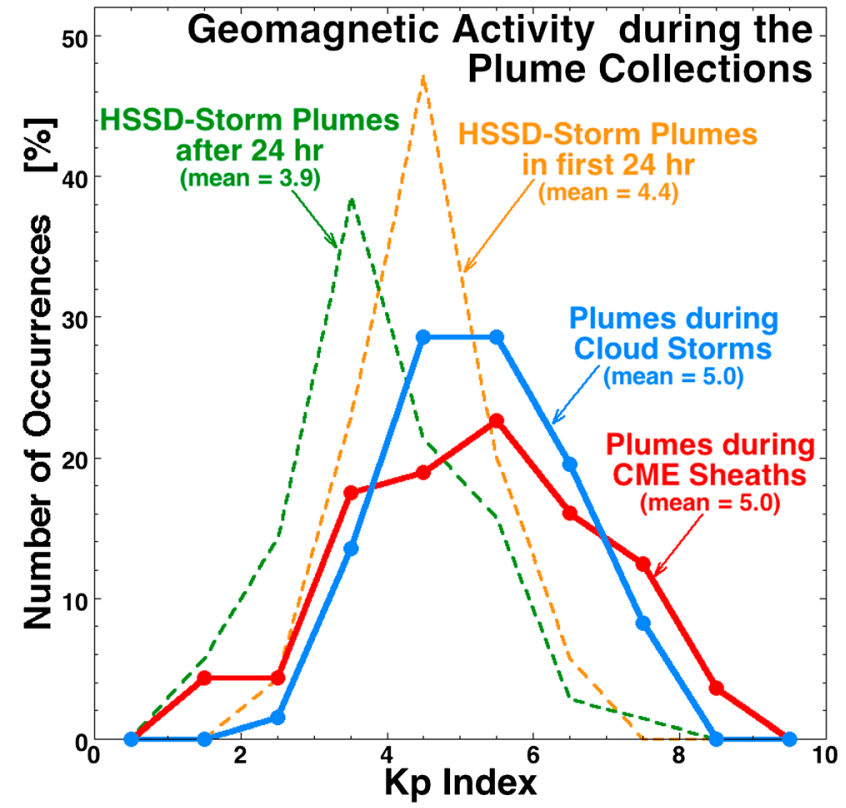

Figure 14. For the four collections of plasmaspheric drainage plumes during the two types of storms, the $K p$ index during the plume observations is binned. The mean value of $K p$ for each collection of plume is indicated on the plot.

of the plasmaspheric drainage plume at geosynchronous orbit has been fit as

$$
\mathrm{w}_{\text {geo }}=4.0-0.024 \mathrm{t},
$$

where $\mathrm{w}_{\text {geo }}$ is in units of hours of local time and $\mathrm{t}$ is the age of the storm in hours: as the storms progress the plumes become on average narrower. With $1 \mathrm{~h}$ of local time at geosynchronous orbit being $1.73 R_{E}$, expression (29) is converted to

$$
\mathrm{W}_{\text {geo }}=6.9-0.041 \mathrm{t},
$$

where $\mathrm{W}_{\text {geo }}$ is in units of $R_{E}$ and $\mathrm{t}$ is the age of the storm in hours.

[41] The chronology of CME-driven storms can be separated into two temporal stages: (a) geomagnetic storm activity driven by the compressed sheath plasma ahead of a magnetic cloud propagating through the ambient solar wind and (b) geomagnetic activity driven by the passage of the magnetic cloud itself. The driving of the magnetosphere during these two stages is expected to be quite different [cf. Borovsky and Denton, 2006a; Lavraud and Borovsky, 2008]: the CME-sheath plasma has high density, a Parkerspiral-oriented magnetic field, and passes the Earth as a high-Mach-number flow; the magnetic-cloud plasma often has a low density, has a non-Parker-spiral-oriented magnetic field, and sometimes flows past the Earth at low Mach numbers. Here, surveys are performed of plasmaspheric drainage plumes during the passage of the magnetic clouds and of plasmaspheric drainage plumes during the passage of the sheath plasma preceding magnetic clouds. For the surveys, the collection of Lepping et al. [2005] magnetic clouds was used. For the cloud-plume survey, plasmaspheric drainage plumes encountered by the seven MPA spacecraft during high geomagnetic activity $(K p \geq 3.7)$ portions of the Lepping clouds were collected. The search for plasmaspheric drainage plumes during the magnetic-cloud-driven portions of CME storms resulted in 48 plume crossings (one plume crossed by one satellite) from 28 different clouds; the plumes are from the years 1995-2003. CME-sheath plasma was taken to be the plasma between the leading edges of the Lepping magnetic clouds and the interplanetary shocks preceding the magnetic clouds. Only clouds with interplanetary shocks that appeared in the WIND [cf. Pulupa et al, 2010] or Advanced Composition Explorer (ACE) [Vorotnikov et al., 2011] online interplanetary shock catalogs were used to collect plumes for the study. The search for plasmaspheric drainage plumes during the CME sheaths resulted in 40 plume crossings (one plume crossed by one satellite) from 19 different clouds; the plumes are from the years 1995-2003.

[42] The MPA instruments measure three-dimensional ion and electron distribution functions every $86 \mathrm{~s}$ over the energy range $1 \mathrm{eV}$ to $40 \mathrm{keV}$. Each distribution function is acquired in $10 \mathrm{~s}$. The MPA spacecraft charge negatively with respect to the ambient plasma enabling efficient analysis of the cool-ion populations of the magnetosphere. Moments of the distribution functions of plasmaspheric ions are used, specifically the number density $n_{\text {meas }}$. Entry of a spacecraft into a plume is defined by a rapid rise in the measured cool-ion density from a low-density background, and exit of a spacecraft from a plume is defined by a rapid fall in the measured coolion density to background levels. As noted in Borovsky and Denton [2008], the density of the drainage plumes is very structured and the two edges of a plume are defined to be the outer envelope of the density structure.

[43] In Figure 14 the $K p$ index is binned for the times during which the MPA spacecraft measure the plasmaspheric drainage plumes in the four collections of plumes. Plotted in red is the occurrence distribution of $K p$ during the CMEsheath plumes, and plotted in blue is the occurrence distribu-

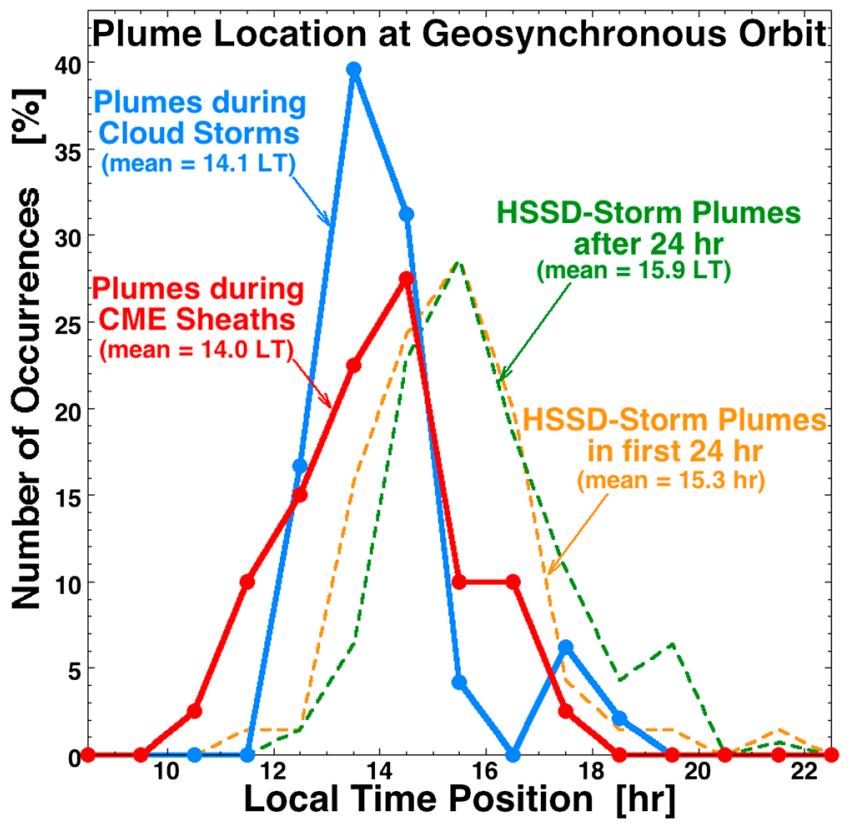

Figure 15. For the four collections of plasmaspheric drainage plumes during the two types of storms, the local-time position of the center of the plume is binned. The mean value of the local-time position for each collection of plumes is indicated on the plot. 


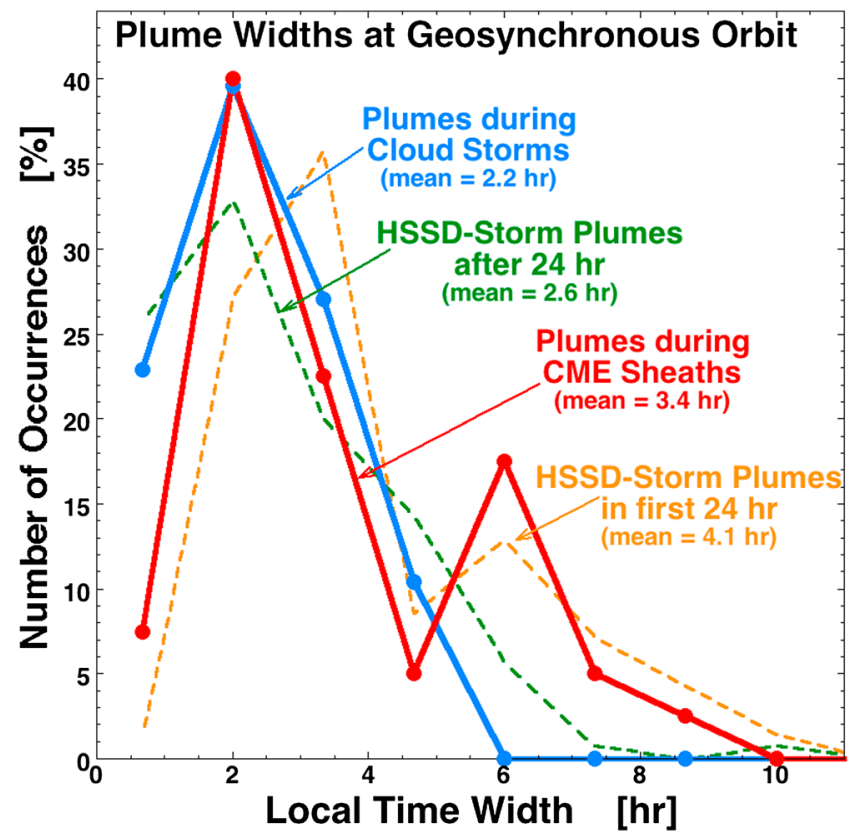

Figure 16. For the four collections of plasmaspheric drainage plumes during the two types of storms, the local-time widths $\mathrm{w}_{\text {geo }}$ are binned. The mean value of $\mathrm{w}_{\mathrm{geo}}$ for each collection of plumes is indicated on the plot.

tion of $K p$ during the magnetic-cloud plumes. The occurrence distribution of $K p$ during the Borovsky and Denton [2008] high-speed-stream-driven-storm plumes are plotted, split into those plumes occurring during the first day of the storms ( 70 of the 210 plumes, orange) and those plumes occurring during the later portions of the storms ( 140 of the 210 plumes, green). In Figure 14 the mean values of $K p$ for the different plume collections are indicated in the plot. The $K p$ activity of the magnetosphere is on average higher during the sheath plumes and cloud plumes than it is during the high-speed-stream-driven storms (see also Borovsky and Denton [2006a]; Turner et al. [2006, 2009]).

[44] In Figure 15 the local-time positions of the centers of the drainage plumes are binned: the distribution of positions of the 40 CME-sheath plumes is plotted in red, the distribution of positions of the 48 cloud-storm drainage plumes is plotted in blue, the distribution of the 70 early time highspeed-stream-driven-storm plumes is plotted in orange, and the distribution of the 140 later-time high-speed-streamdriven-storm plumes is plotted in green. The mean local-time position of the plumes in each collection is indicated on the plot. The cloud-storm drainage plumes and the CME-sheath drainage plumes are located much closer to local noon than are the high-speed-stream-driven-storm plumes. This may reflect, in part, (a) a greater value of $K p$ on average during the magnetic-cloud-driven storms and during the sheaths than during the extended high-speed-stream-driven storms and (b) the $K p$ dependence of the local-time position of plumes [cf. Borovsky and Denton, 2008, Figure 9].

[45] The local-time widths of the drainage plumes in the various collections are binned in Figure 16; the distribution of widths is plotted in red for the CME-sheath plumes, in blue for the magnetic-cloud storms, in orange for the early time high-speed-stream-driven storms, and in green for the later- time high-speed-stream-driven storms. The width of a plume is defined as the distance in local time between spacecraft's first entry into the plume material and the last exit from plume material; when measuring the width as the point of first entry to the point of last exit, we are really measuring the width of a channel that contains the plume material. The distributions of plume widths for CME sheaths and for early time high-speed-stream-driven storms have large-width tails: it is likely that the large-width plumes are sunward surges of the outer plasmasphere during the early portions of geomagnetic activity. The widths of magnetic-cloud plumes and of later-time high-speed-stream plumes are on average narrower, probably because geomagnetic activity has been ongoing for a while and the outer plasmasphere has been stripped away [cf. Chen and Wolf, 1972; Goldstein, 2006]. The mean width of the sheath plumes is $3.4 \mathrm{~h}$ of local time at geosynchronous orbit, and the mean width of the cloud plumes is $2.2 \mathrm{~h}$ of local time; for highspeed-stream-driven storms the mean width of the day 1 plumes is $4.1 \mathrm{~h}$ and the mean width of the later-day plumes is $2.6 \mathrm{~h}$. As can be seen in Figure 16, (a) the widths of the CME-sheath drainage plumes statistically look similar to the widths of the early time (orange) high-speed-streamdriven-storm drainage plumes and (b) the widths of the cloud-storm drainage plumes statistically look similar to the widths of the later-time (green) high-speed-stream-drivenstorm drainage plumes.

[46] The average number density of cold ions $n_{\text {meas }}$ measured by the MPA instruments for each collection of plumes is binned in Figure 17. Note that the drainage plumes are "lumpy" [Moldwin et al., 1995; Goldstein et al., 2004; Borovsky and Denton, 2008; Matsui et al., 2012] and the

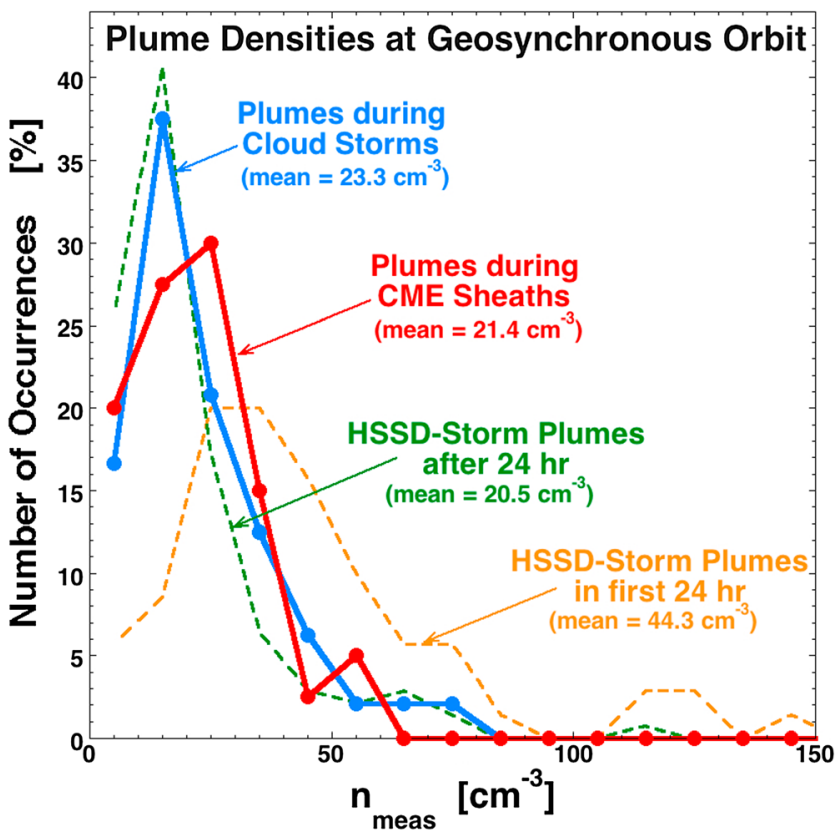

Figure 17. For the four collections of plasmaspheric drainage plumes during the two types of storms, the average measured number density $\mathrm{n}_{\text {meas }}$ of each plume is binned. The mean value of $\mathrm{n}_{\text {meas }}$ for each collection of plumes is indicated on the plot 


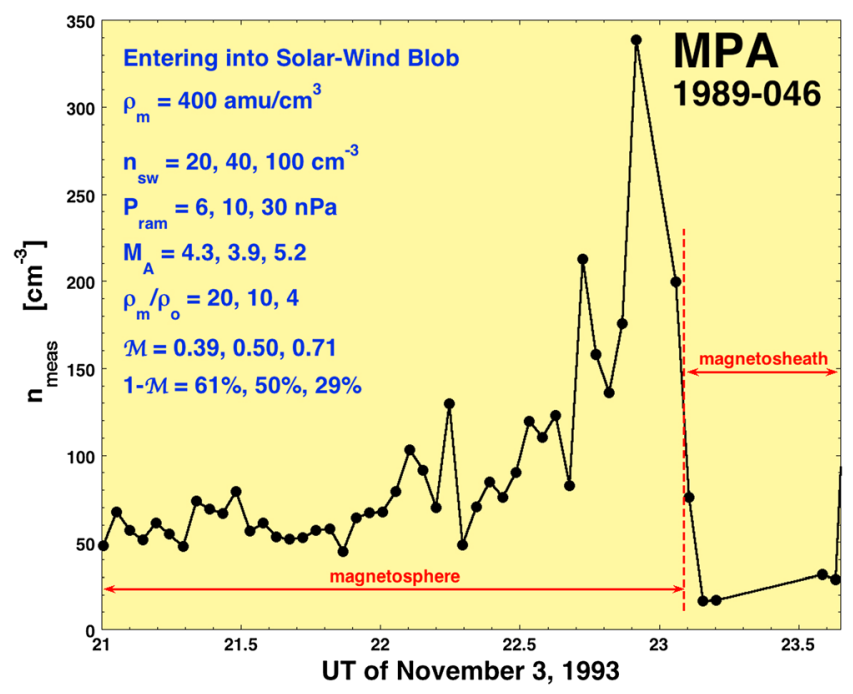

Figure 18. The measured number density of cool ions is plotted as a function of time as the spacecraft carrying the MPA instrument passes from the magnetosphere into the magnetosheath as the magnetopause crosses geosynchronous orbit.

density within a plume varies from values much greater than the average to much less than the average. (The mean value of $\delta n / n=|n 2-n 1| /(0.5(n 1+n 2))$, where $n 1$ and $n 2$ are the densities measured $86 \mathrm{~s}$ apart, was $\mathrm{dn}=0.57$ for the plume plasma in the Borovsky and Denton [2008] survey.) In Figure 17 the distributions of plume average densities are plotted with the same color schemes as used in Figures 15 and 16. The mean measured number density for CME-sheath plumes $\mathrm{n}_{\text {meas }}=21.4 \mathrm{~cm}^{-3}$ (which are early time in CME storms) is considerably less than the mean measured number density for day 1 high-speed-stream-driven-storm plumes $\mathrm{n}_{\text {meas }}=44.3 \mathrm{~cm}^{-3}$. High-speed-stream-driven storms are usually preceded by a "calm before the storm" [Borovsky and Steinberg, 2006], and the outer plasmasphere tends to fill during the calms before the storms [cf. Borovsky et al., 1998, Figure 2; Denton and Borovsky, 2008, Figure 7]; at early times in high-speed-stream-driven storms, the surge of this filled outer plasmasphere toward the dayside magnetopause produces a dense early time drainage plume. Most CMEdriven storms are not preceded by a calm before the storm, and so the outer plasmasphere is not expected to be filled before the commencement of a CME-driven storm; hence, CME-driven storms should have an early time drainage plume that is less dense. At later times in the storms, the mean number densities of the drainage plumes during the clouddriven storms is statistically similar to the mean number densities of the drainage plumes during the later days of high-speed-stream-driven storms.

[47] The number density of the plasmaspheric plasma at geosynchronous orbit was measured by the MPA (Magnetospheric Plasma Analyzer) instrument. For the plasmasphere, estimates of $\mathrm{f}_{\mathrm{He}}$ range from 0.02 [Farrugia et al., 1998] to 0.2 [Horwitz et al. 1981]. Estimates of $\mathrm{f}_{\mathrm{O}}$ range from less than $1 \%$ to a few percent [Young et al., 1977, Horwitz et al., 1984]. For a plasmasphere composition mix that is high on heavy ions $\left(f_{\mathrm{H}}=0.77, \mathrm{f}_{\mathrm{He}}=0.20\right.$, $f_{O}=0.03$ ) expression (26) yields $\rho_{\text {geo }}=2.3 \quad n_{\text {geo }}$; for $a$ plasmasphere composition mix that is low on heavy ions $\left(\mathrm{f}_{\mathrm{H}}=0.95, \mathrm{f}_{\mathrm{He}}=0.04, \mathrm{f}_{\mathrm{O}}=0.01\right)$ expression (26) yields $\rho_{\text {geo }}=1.31 \mathrm{n}_{\text {geo }}$. As a working value, $\rho_{\text {geo }} \approx 2 \mathrm{n}_{\text {geo }}$ will be taken [cf. Takahashi et al., 2006, Figure 8]. With this, expression (28) yields

$$
\rho_{\mathrm{geo}} \approx 66 \mathrm{amu} / \mathrm{cm}^{3} \exp (-\mathrm{t} / 78)
$$

for the plasmaspheric drainage plumes during high-speedstream-driven storms.

\subsection{Estimates of the Reduction of the Local Reconnection Rate by Plume Plasma}

[48] The evaluation of the effect of plasmaspheric drainage plumes on the local reconnection rate at the dayside magnetopause begins with the measurements of the number density of drainage plumes at geosynchronous orbit: for the two phases of the two types of storms the range of plume average densities $n_{\text {meas }}$ in the four collections of plumes are entered into the top line of Table 2. To evaluate the effect of magnetospheric mass density on the dayside local reconnection rate, the solar wind number density $\mathrm{n}_{\mathrm{sw}}$, ram pressure $\mathrm{P}_{\text {ram }}$, and Alfven Mach number $\mathrm{M}_{\mathrm{A}}$ are needed (cf. expressions (9) and (24)). The geomagnetic indices PCI and Dst are also needed to produce an estimate of the magnetic field strength at geosynchronous orbit (cf. expression (23a)) where the plume densities are measured. For the four collections of plumes, the median values of those solar wind parameters and geomagnetic indices during the times of plume observation by MPA are obtained from the OMNI2 data set [King and Papitashvili, 2005], and the values are entered into rows 2-6 of Table 2 . With these values for $\mathrm{P}_{\text {ram }}, \mathrm{PCI}$, and Dst, expression (23a) is used to estimate the magnetic field strength $\mathrm{B}_{\text {geo }}$ at geosynchronous orbit in the dayside magnetosphere, which is entered into the seventh row of Table 2. Note that in Table 2 for the high-speed-stream-driven storms and for the CME sheaths $\mathrm{B}_{\text {geo }}$ is estimated to be larger than the dipole value of $106 \mathrm{nT}$ : for the magnetic-cloud portion of CME storms it is estimated to be approximately the dipole value. Using the values of $\mathrm{B}_{\text {geo }}, \mathrm{P}_{\text {ram }}$, and $\mathrm{M}_{\mathrm{A}}$ in Table 2, expression (24) (with $M_{m s}$ replaced by $M_{A}$ ) is evaluated to yield values for the ratio $R_{n}$ of the cold-ion number density at the magnetopause to the cold-ion number density at geosynchronous orbit: those $R_{n}$ values are entered into the eighth row of Table 2. For all four cases, the density ratio is in the range $0.39-0.52$. From the values of $R_{n}$ and $n_{\text {geo }}$ in Table 2 , the definition $\mathrm{n}_{\mathrm{m}}=\mathrm{R}_{\mathrm{n}} \mathrm{n}_{\text {geo }}$ of expression (24) is used to obtain the number density $\mathrm{n}_{\mathrm{m}}$ of cold ions at the magnetopause: these $n_{m}$ values are entered into the ninth row of Table 2 . There is a wide range of values reflecting the wide range of measured plume densities. The estimated mass density $\rho_{\mathrm{m}}$ of cold ions at the magnetopause is obtained from expression (26) by taking $\rho_{\mathrm{m}}=2 \mathrm{n}_{\mathrm{m}}$. Those $\rho_{\mathrm{m}}$ values are entered into the tenth row of Table 2 . The mass ratio $\rho_{m} / \rho_{o}$ is obtained from these $\rho_{\mathrm{m}}$ values and the solar wind number densities $\mathrm{n}_{\mathrm{sw}}$ in Table 2 by assuming $\rho_{\mathrm{o}}=1 \mathrm{n}_{\mathrm{sw}}$ : the values for the $\rho_{\mathrm{m}} / \rho_{\mathrm{o}}$ ratios are entered into the eleventh row of Table 2. From the Alfven Mach numbers $M_{A}$ in Table 2 the density compression ratio $\mathrm{C}$ of the bow shock is calculated from expression (8b) (assuming $\theta_{\mathrm{Bn}} \sim 90^{\circ}$ ); using these values for $C$ and the values of $\rho_{m} / \rho_{o}$ and $M_{A}$ in 


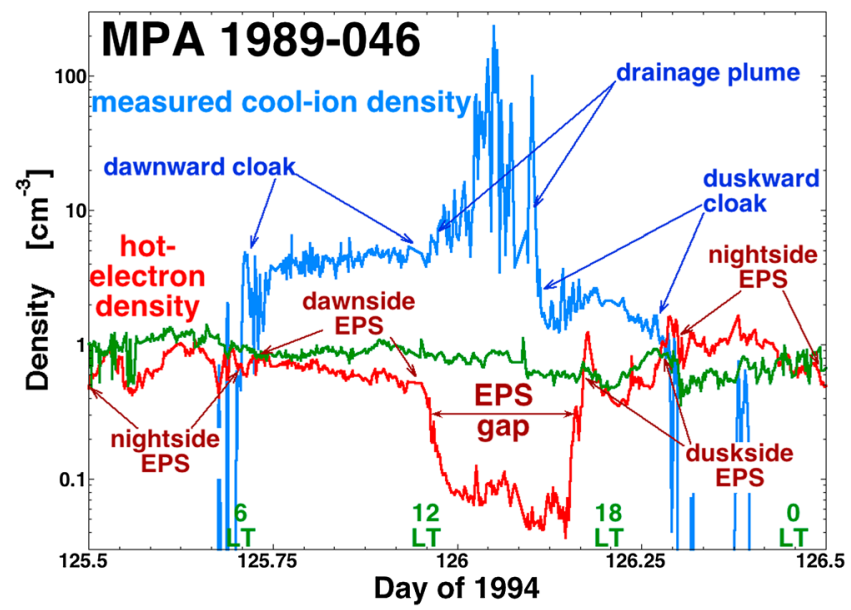

Figure 19. The drainage plume observed in Figure 13 on day 126 is replotted in blue in more detail. The number density of the electron plasma sheet is plotted in red, and the number density of the ion plasma sheet is plotted in green. The drainage plume and dawnward and duskward cloak plasmas are labeled. Note that the electron plasma sheet is absent where the plume is but present where the cloak is.

Table 2, the density-correction ratio $\mathrm{p}$ is calculated from expression (9), and those $p$ values are entered into the twelfth row of Table 2 . Finally, from those values of $p$ the multiplicative factor $\mathrm{M}$ for the local reconnection rate quantifying the rate reduction from mass loading by ions in the magnetospheric plasma is obtained from expression (3). Those $\mathrm{M}$ values are entered into the thirteenth row of Table 2 .

[49] As can be seen in Table 2, for each of the four types of storm phases the values of $\mathrm{M}$ vary from about 0.95 to about 0.45 . The $\sim 0.95$ values represent a slight reduction of the reconnection rate: these values correspond to low values of the measured plume number densities $n_{\text {meas }}$ at geosynchronous orbit. The $\sim 0.45$ values represent reductions of the reconnection rate to about $45 \%$ of its original value corresponding to significant mass loading of dayside reconnection when the measured values $n_{\text {meas }}$ of the plume number density at geosynchronous orbit are large. Note that this reduction in the reconnection rate is only in the portion of the dayside X-line where the plume plasma flows into it.

[50] The MPA instruments on occasion measure the number density of plasmaspheric-drainage-plume plasma at the magnetopause when the magnetopause crosses over geosynchronous orbit [cf. Su et al., 2000, 2001a] (see also Walsh et al. [2013]). In Figure 18 a case is shown wherein the measured number density $\mathrm{n}_{\text {meas }}$ of the plume plasma is $\sim 200 \mathrm{~cm}^{-3}$ at the magnetopause (see also Borovsky et al. [1997, Figure 4]). In this event the magnetopause moves past geosynchronous orbit as a high-density blob of solar wind plasma with strong southward IMF compresses the magnetosphere as a high-speed-stream-driven storm is commencing. Utilizing Knipp et al. [1998, Figure 4], the solar wind parameters (a) just before the blob, (b) during the strong density gradient on the front side of the blob, and (c) within the blob are, respectively, $\mathrm{n}_{\mathrm{sw}} \approx 20,40$, and $100 \mathrm{~cm}^{-3} ; \mathrm{P}_{\text {ram }} \approx 6,10$, and $30 \mathrm{nPa}$; and $\mathrm{M}_{\mathrm{A}} \approx 4.3,3.9$, and 5.2. Taking from Figure 18 the drainage-plume number density at the magnetopause to be $n_{\text {meas }}=200 \mathrm{~cm}^{-3}$ and the mass density to be $\rho_{\mathrm{m}}=400 \mathrm{~cm}^{-3}$, the three values of $\rho_{\mathrm{m}} / \rho_{\mathrm{o}}$ are 20,10 , and 4 before, during the gradient, and during the blob. These, with the solar wind values, lead to $M$ values from expressions (3) and (9) of $\mathrm{M} \approx 0.39,0.50$, and 0.71 . These estimated reductions in the local rate of reconnection are $1-\mathrm{M} \approx 61 \%$, $50 \%$, and $29 \%$. The middle value corresponding to the time of the gradient in solar wind density is probably most appropriate to the time of magnetopause crossing: a reduction of $50 \%$ in the local rate of reconnection owing to the drainage plume.

[51] Note also that drainage plumes are very lumpy (cf. Figure 19) [Moldwin et al., 1995; Borovsky and Denton, 2008], with local values of the mass density that are very high and local values that are quite low. Owing to this density structure, the reconnection reduction will be sporadic in detail along the X-line within the plume channel.

\subsection{Reduction of the Total Amount of Dayside Reconnection by Drainage Plumes}

[52] As plasmaspheric-drainage-plume plasma flows into the dayside reconnection $\mathrm{X}$-line, the reconnection rate will be reduced by the multiplicative factor $M$ on a portion of the $\mathrm{X}$-line with a length equal to the width $\mathrm{W}_{\mathrm{mp}}$ of the plume at the magnetopause. On the portions of the dayside X-line outside of the plume region, the reconnection rate will be unaltered by the plume. In the absence of the drainage plume, the total reconnection rate $R_{0}$ can be denoted as the local reconnection rate $\mathrm{R}$ times the effective length of the dayside $\mathrm{X}$-line $\mathrm{L}_{\mathrm{X} \text {-line, }}$, i.e., $\mathrm{R}_{\mathrm{o}}=\mathrm{RL}_{\mathrm{X} \text {-line }}$. With the plume reducing the reconnection rate on a length $\mathrm{W}_{\mathrm{mp}}$ of the $\mathrm{X}$-line, the total reconnection rate is $\mathrm{R}=\mathrm{R}\left(\mathrm{L}_{\mathrm{X} \text {-line }}-\mathrm{W}_{\mathrm{mp}}\right)+\mathrm{MRW}_{\mathrm{mp}}$. The reduction in the total reconnection rate $\Delta R=R_{o}-R$ is

$$
\Delta \mathrm{R}=(1-\mathrm{M}) \mathrm{R} \mathrm{W}_{\mathrm{mp}},
$$

and the fractional reduction of the total reconnection rate by the plume is

$$
\Delta \mathrm{R} / \mathrm{R}_{\mathrm{o}}=(1-\mathrm{M}) \mathrm{W}_{\mathrm{mp}} / \mathrm{L}_{\mathrm{X} \text {-line }},
$$

where $\mathrm{M}$ is the multiplicative reduction of the local reconnection rate by the plume mass density and $W_{m p}$ is the width of the plume at the magnetopause.

[53] In Table 3 the reduction factor for the total reconnection rate by plasmaspheric drainage plumes is explored for the four collections of plumes during the early and later portions of high-speed-stream-driven and CMEdriven storms. In the top row of Table 3 the ranges of values of the multiplicative reduction factors $M$ are entered for the four collections of drainage plumes. These $M$ values are from the bottom of Table 2. In the second row of Table 3 the reduction factors $(1-\mathrm{M})$ are entered. The mean plume widths at geosynchronous orbit $\mathrm{W}_{\text {geo }}$ for the four collections of plumes (obtained from Figure 16) are entered into the third line of Table 3. The median values of the solar wind ram pressure $\mathrm{P}_{\text {ram }}$ and Alfven Mach number $\mathrm{M}_{\mathrm{A}}$ during each of the four collections of plumes are entered into Table 3: these values enable the calculation of the distance to the dayside magnetopause $r_{m p}$ to be calculated via expression (21) and entered into Table 3. Expression (17a) along with the values of $M_{A}$ and $\mathrm{P}_{\text {ram }}$ is used to calculate the length of the dayside $\mathrm{X}$-line

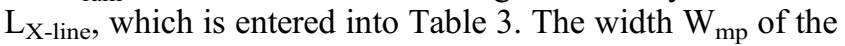
drainage plume at the magnetopause is estimated two ways: 

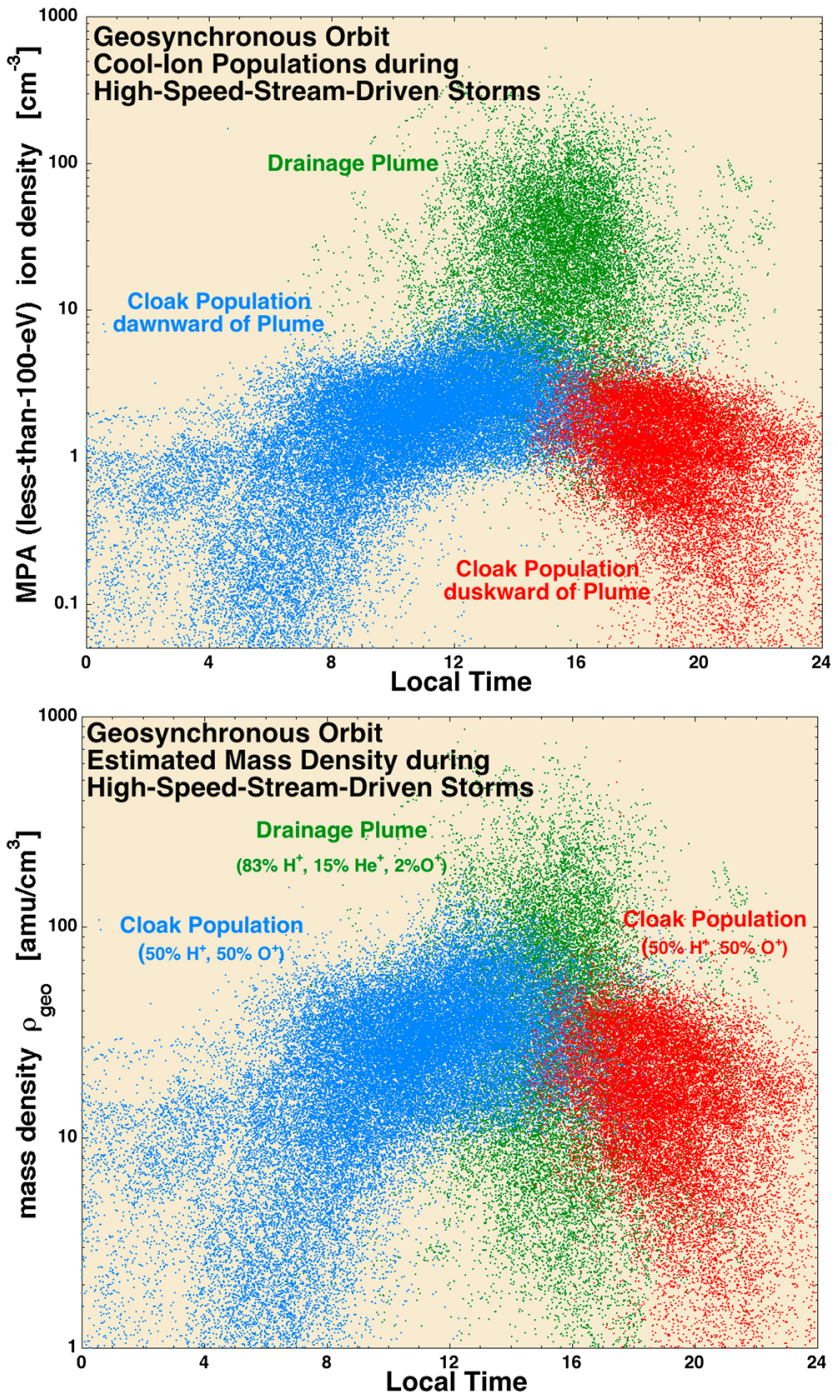

Figure 20. During a collection of high-speed-streamdriven storms, a survey of the plasmaspheric drainage plume (green) and the cloak plasma seen dawnward of the plume (blue) and duskward of the plume (red). (top) Plot of the measured ion number density $\mathrm{n}_{\text {meas }}$ assuming all ions are protons. (bottom) Plot of the mass density for guesses (indicated on the plot) about the fractional ion composition.

(1) it is assumed that the drainage plume measured at geosynchronous orbit keeps its width in kilometers as it propagates to the magnetopause from geosynchronous orbit, and (2) it is assumed that the drainage plume measured at geosynchronous orbit keeps its width in local time as it propagates to the magnetopause from geosynchronous orbit. In case (1) $\mathrm{W}_{\mathrm{mp}}=\mathrm{W}_{\text {geo }}$ and in case (2) $\mathrm{W}_{\mathrm{mp}}=\mathrm{W}_{\text {geo }}\left(\mathrm{r}_{\mathrm{mp}} / \mathrm{r}_{\text {geo }}\right)$, where $\mathrm{r}_{\text {geo }}=6.6 R_{E}$. The values of $\mathrm{W}_{\mathrm{mp}}$ for both of these cases are entered into Table 3 for the four collections of plumes. With those $\mathrm{W}_{\mathrm{mp}}$ values, the ratios $\mathrm{W}_{\mathrm{mp}} / \mathrm{L}_{\mathrm{X} \text {-line }}$ are entered into Table 3. For the early time portions of high-speedstream-driven storms (driving by the CIRs) the fractional width of $\mathrm{L}_{\mathrm{X} \text {-line }}$ occupied by the drainage plumes is greatest: the fraction is the least for the magnetic-cloud portions of CME-driven storms (because at lower Mach numbers $\mathrm{L}_{\mathrm{X} \text {-line }}$ is longer). Finally, in the bottom two rows of Table 3 expression (33) is used to calculate the fractional reduction of the total dayside reconnection rate owed to the drainage plumes for the two methods of estimating the plume width at the magnetopause.

[54] Values on the order of $10 \%$ to $25 \%$ reduction of solar wind/magnetosphere coupling are obtained in the bottom rows of Table 3 for the denser drainage plumes in all of the four collections of plumes. In particular the reduction is on average greater during the CIR-driven portions of highspeed-stream-driven storms (first day of the storms) than for the portion of the storm driven by the uncompressed high-speed (coronal-hole-origin) wind (after the first day of the storms). This difference might be owed to the fact that high-speed-stream-driven storms are usually preconditioned by a calm before the storm [Borovsky and Steinberg, 2006], which results in a filled outer plasmasphere before the storm commences, which may lead to an extra-dense drainage plume in the early portion of the storm as the outer plasmasphere surges to the dayside magnetopause. This may be evidenced in the third row of Figure 7 of Denton and Borovsky [2008], where storms with calms beforehand are compared with storms without calms beforehand, and it may be evidenced in J. E. Borovsky and M. H. Denton (The differences between storms driven by helmet-streamer CIRs and storms driven by pseudostreamer CIRs, submitted to Journal of Geophysical Research, 2012, Figure 5), where the plasmaspheric plasma is compared for helmet-streamerCIR-driven storms (which tend to have a calm) and lesscommon pseudostreamer-CIR-driven storms (which tend not to have a calm).

[55] The difference in the reduction of the total reconnection rate between the sheath-driven portions of CME storms and the magnetic-cloud portions of CME

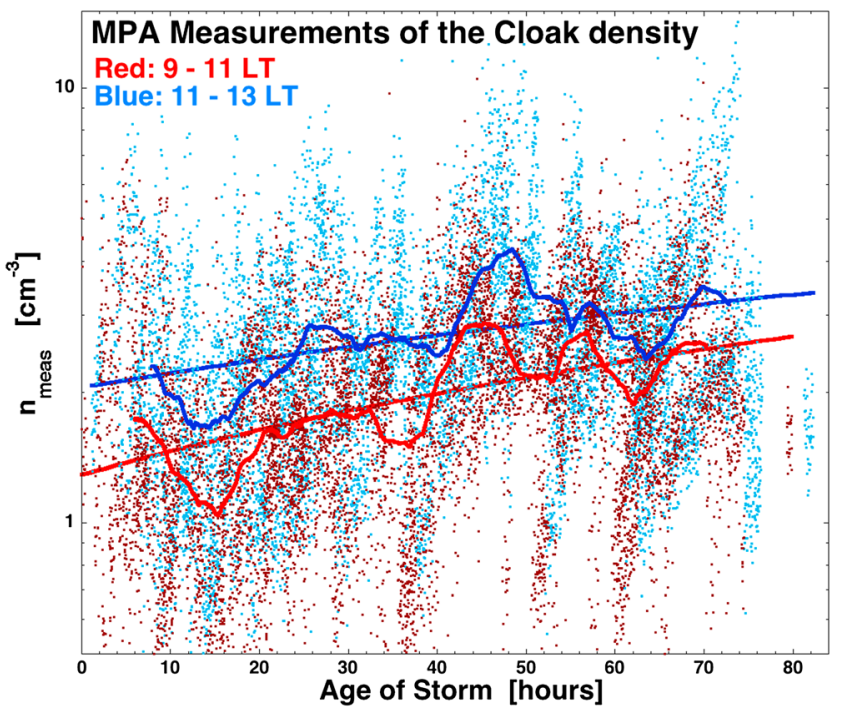

Figure 21. In two local-time sectors (9-11 LT in red and 11-13 LT in blue), the measured ion number density (assuming protons) of the cloak plasma during highspeed-stream-driven storms is plotted logarithmically as a function of the time since storm commencement. The bumpy curves are 800-point running averages of the data points, and the smooth curves are linear-regression fits (in linear-linear coordinates) to the data points. 


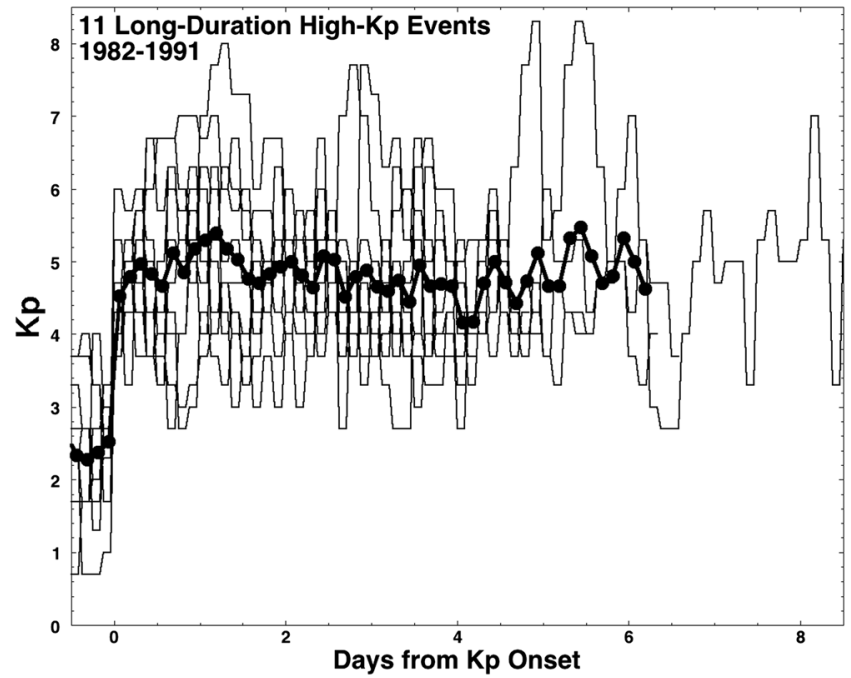

Figure 22. For 11 storms in 1982-1991 with extended intervals of sustained high $K p$, the temporal $K p$ curves are plotted (thin curves) as a function of time from the commencement of the storms, and the mean value of $K p$ of all of the 11 storms is plotted as the thick curve with points.

storms is less strong. Following the argument of the previous paragraph, this weaker difference may be owed to the fact that the magnetosphere is typically not preconditioned by a calm before a CME-driven storm.

[56] The magnitudes of the reductions for the dayside reconnection rate will be assessed in section 8 .

\section{Ionospheric Outflows Convecting Through the Dayside Magnetosphere: The Plasma Cloak}

[57] During high-speed-stream-driven geomagnetic storms, cool (tens of eV) ions are regularly seen throughout the dayside portions of geosynchronous orbit outside of the plasmaspheric drainage plume [cf. Borovsky and Denton, 2008]. This material was referred to as the "warm plasma cloak" by Chappell et al. [2008]; it has also been referred to as the oxygen torus [Chappell, 1982; Horwitz et al., 1984; Fraser et al., 2005]. This material can be seen as the $\mathrm{n}_{\text {meas }} \sim 5 \mathrm{~cm}^{-3}$ regions outside of the drainage plumes in the blue curve of Figure 13. For the plume of day 126 in Figure 13, the data are replotted in Figure 19 where the various plasma regions are labeled. In particular, on both sides of the plasmaspheric drainage plume there is cloak plasma, more prevalent on the dawnward side of the plume. In red in Figure 19 the density of hot electrons as measured by MPA are plotted. These hot electrons are the electron plasma sheet, which is robust on the nightside of geosynchronous orbit and weaker on the dayside (presumably because of precipitation into the loss cone as they convect from the nightside to the dayside making the diffuse aurora [Thomsen et al., 1998]). The hot electrons are an indication of open drift trajectories outside of the plasmasphere [Su et al., 2001b]; note the gap in the electron plasma sheet where the plasmaspheric drainage plume resides. The electron plasma sheet corresponds to the auroral zone with diffuse and discrete aurora
[Meng et al., 1979; Galperin and Feldstein, 1991; Mauk and Meng, 1991], as sketched in Figure 1. Hence, the origin of these cool ions throughout the dayside magnetosphere during storms is likely auroral outflows on the nightside into the nightside magnetosphere with $E \times B$ convection (blue arrows in Figure 1) bringing those ions across geosynchronous orbit on the dayside on their way to the reconnection X-line on the dayside magnetopause. Such cool-ion outflows are seen by low-altitude spacecraft traversing the nightside auroral oval [Yau et al., 1984, 1996; Yau and Andre, 1997]. Timescales for $\mathrm{O}^{+}$ions to travel from the ionosphere to the equator at $\mathrm{L}=6.6$ range from $1.9 \mathrm{~h}$ for $10 \mathrm{eV} \mathrm{O}^{+}$to $35 \mathrm{~min}$ for $100 \mathrm{eV} \mathrm{O}^{+}$; plasma $E \times B$ convection timescales from the nightside to the dayside during high-speed-stream-driven storms are on the order of 7$10 \mathrm{~h}$ [Denton and Borovsky, 2009].

[58] For the high-speed-stream-driven storms from which the plasmaspheric drainage plumes for the study of Borovsky and Denton [2008] were collected, the cool-ion number densities $\mathrm{n}_{\text {meas }}$ measured by MPA at geosynchronous orbit are plotted in Figure 20. Green points are measurements inside the plasmaspheric drainage plumes, blue points are measurements made dawnward of the drainage plume, and red points are measurements made duskward of the drainage plume: each point represents an $86 \mathrm{~s}$ measurement. The cloak plasma is usually weaker on the first day of a storm than it is on subsequent days. This can be discerned by examining the cold ion number density plotted in blue in Figure 13. In Figure 21 the measured number density $n_{\text {meas }}$ of the cloak plasma is plotted at local noon (blue) and prenoon (red) as a function of the age of the storm. Linear-regression fits are plotted as the dark blue and dark red lines in Figure 21, and 800-point running averages are plotted as the dark blue and dark red curves. The low-density trend on day 1 of the storms can be seen.

[59] MPA cannot discern the ion species and the data analysis is made assuming all ions are protons (e.g., Figure 20, top). Ion-composition measurements of the "torus

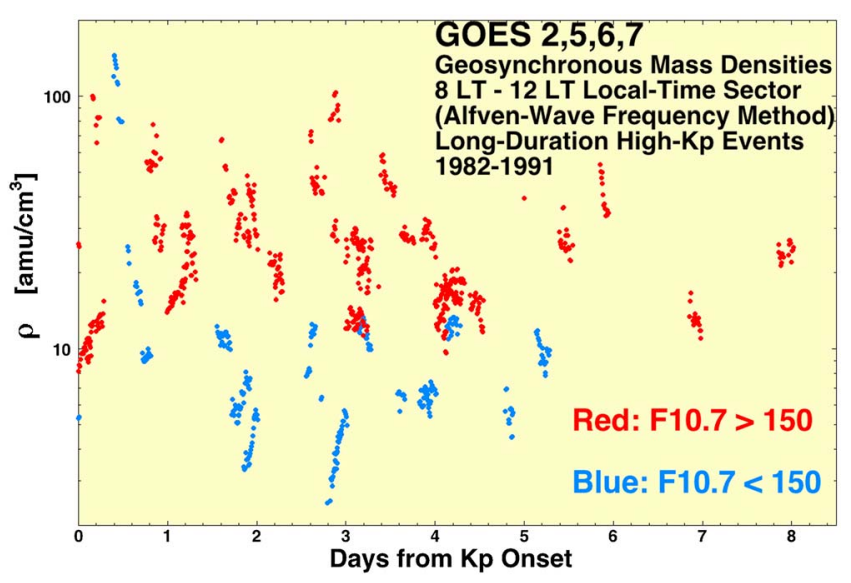

Figure 23. For the 11 intervals of sustained high $K p$ plotted in Figure 22, the mass density at geosynchronous orbit in the 8-12 LT sector of local time determined from analysis of observed standing Alfven waves is plotted logarithmically as a function of time since each storm started. The red points pertain to $F_{10.7}>150$ at the time of Alfven-wave observation, and the blue points pertain to $F_{10.7}<150$ at the time of Alfven-wave observation. 


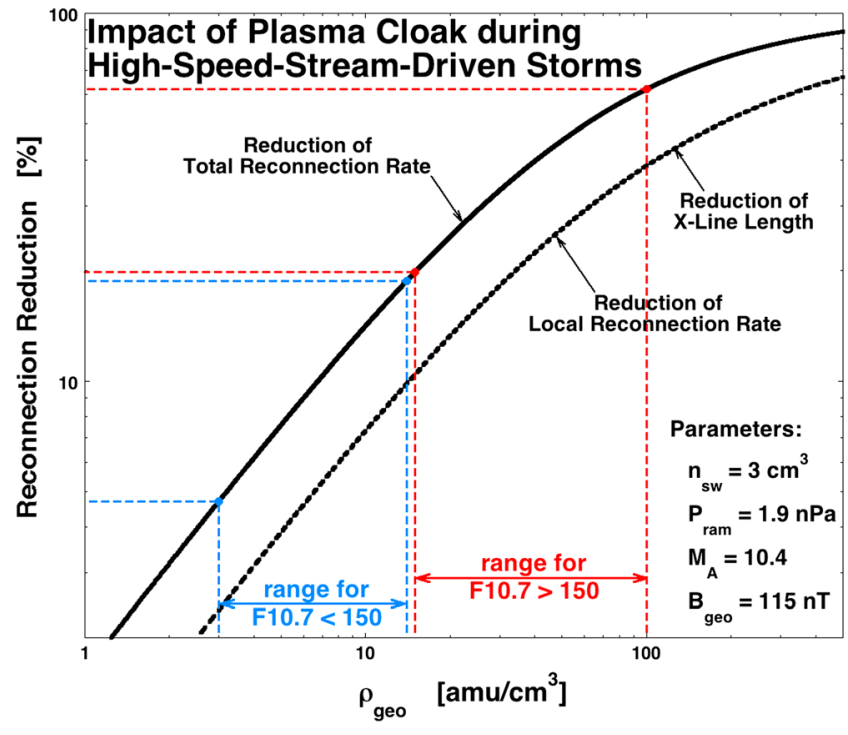

Figure 24. For typical parameters of the solar wind and magnetosphere during the later stages of a high-speed-streamdriven storm, the expected fractional reduction in reconnection is plotted as a function of the mass density $\rho_{\text {geo }}$ at geosynchronous orbit. The ranges of values of $\rho_{\text {geo }}$ from Figure 23 are indicated by the dashed blue and dashed red lines.

of oxygen" [Chappell, 1982] just outside the plasmasphere have found fractional oxygen number densities $\mathrm{f}_{\mathrm{O}} \sim 0.5$ [Horwitz et al., 1984; Grew et al., 2007; Nose et al., 2011] (see also Fraser et al. [2005] and Dent et al. [2006]). Making a guess at the composition, expression (26) can be used to guess the ion mass density $\rho_{\text {geo }}$ from the measured ion-count density $\mathrm{n}_{\text {meas }}$. For the cloak, estimating that $\mathrm{f}_{\mathrm{H}}=0.5$ and $\mathrm{f}_{\mathrm{O}}=0.5$, the estimated mass density at geosynchronous orbit for the cloak is plotted in the bottom panel of Figure 20 in blue and red, with the estimated plasmaspheric-drainage-plume mass density plotted in green assuming $\mathrm{f}_{\mathrm{H}}=0.83, \mathrm{f}_{\mathrm{He}}=0.15$, and $\mathrm{f}_{\mathrm{O}}=0.02$ for the plume plasma. As can be seen in the bottom panel, for these estimates of the ion composition, the cloak plasma (red and blue) has a mass density comparable to that of the drainage plume (green). However, the local-time extent of the cloak plasma is much greater than the width of the plume (cf. Figure 1).

[60] To obtain measurements of the mass density $\rho_{\text {geo }}$ of the storm time cloak-plasma population at geosynchronous orbit, the Denton et al. [2011] (see also Takahashi et al. [2010]) GOES Alfven-wave data set of 1980-1991 is used. The analyzed intervals during those years are sparse, and solar wind data are also sparse. The sparseness of the solar wind data makes it difficult to unambiguously identify high-speed-stream-driven storms, and the sparseness of the Alfven-wave analyzed events makes it difficult to thoroughly examine any one storm and to discern cloak measurements from plume measurements. To overcome these difficulties, 11 long-duration high- $K p$ events were identified during the years of the GOES measurements. The individual $K p$ time series for the 11 events are plotted as the thin curves in Figure 22 as a function of the time after onset of $K p$, and the mean value of $K p$ is plotted as the thick curve with points. For a storm with sustained high $K p$, after the first day of the storm the drainage plume is well behaved and restricted to the postnoon sector of local time at geosynchronous orbit (during the first day a wide plume may occur as the outer plasmasphere surges sunward across geosynchronous orbit). Hence, after the first day of the high- $K p$ events, any GOES measurements taken in the prenoon sector will be measurements of cloak plasma and not of drainage-plume plasma. In Figure 23, for the 11 events of Figure 22, all of the GOES mass-density measurements $\rho_{\text {geo }}$ from the 8-12 LT sector are plotted: they are plotted in blue if the solar $10.7 \mathrm{~cm}$ radio flux $F_{10.7}$ was less than 150 at the time of measurement, and they are plotted in red if $F_{10.7}$ was greater than 150 at the time of measurement. As can be seen in Figure 23, the storm time mass density of the cloak at geosynchronous orbit strongly depends on $F_{10.7}$ (i.e., it depends on the phase of the solar cycle). If $F_{10.7}$ is low, mass densities $\rho_{\text {geo }} \sim 3-15 \mathrm{amu} / \mathrm{cm}^{3}$ are found; if $F_{10.7}$ is high, mass densities $\rho_{\text {geo }} \sim 15-100 \mathrm{amu} / \mathrm{cm}^{3}$ are found.

[61] For the cloak plasma, the expected fractional reduction of dayside reconnection is plotted in Figure 24 as a function of $\rho_{\text {geo }}$ for typical parameters of the solar wind during the later days of high-speed-stream-driven storms. The fundamental solar wind parameters used are [from Borovsky and Denton, $2010 \mathrm{~b}$, Figure 1] $\mathrm{n}_{\mathrm{sw}}=3 \mathrm{~cm}^{-3}, \quad \mathrm{v}_{\mathrm{sw}}=625 \mathrm{~km} / \mathrm{s}$, and $\mathrm{v}_{\mathrm{A}}=60 \mathrm{~km} / \mathrm{s}$, which yield $\mathrm{P}_{\text {ram }}=1.9 \mathrm{nPa}$ and $\mathrm{M}_{\mathrm{A}}=10.4$. For the magnetic field strength in the dayside magnetosphere at geosynchronous orbit, $\mathrm{B}_{\mathrm{geo}}=115 \mathrm{nT}$ is taken [from Borovsky and Denton, 2010a, Figure 8]. These parameters in expression (24), with $\mathrm{M}_{\mathrm{ms}} \approx \mathrm{M}_{\mathrm{A}}$, yields $\mathrm{R}_{\mathrm{n}}=0.36$ for the mapping factor of geosynchronous density $\rho_{\text {geo }}$ to the magnetospheric density at the magnetopause $\rho_{\mathrm{m}}$. These factors along with the variable $\rho_{\text {geo }}$ go into expressions (9) and (3) to calculate $\mathrm{M}\left(\rho_{\text {geo }}\right)$. In Figure 24 the quantities $1-\mathrm{M}$ and $1-\mathrm{M}^{2}$ are plotted. The quantity $1-\mathrm{M}$ (dashed black curve) is the fractional reduction of the local rate of reconnection caused by the cloak plasma with mass density $\rho_{\text {geo }}$ at geosynchronous orbit. Since the cloak plasma is global in extent, the quantity $1-\mathrm{M}$ is also the fractional reduction of the length of the dayside reconnection $\mathrm{X}$-line $\mathrm{L}_{\mathrm{X} \text {-line }}$ (cf. expression (18)) owing to the cloak plasma with mass density $\rho_{\text {geo. }}$. If the reconnection rate $\mathrm{R}$ is reduced by the multiplicative factor $\mathrm{M}$ (cf. the definition of expression (2)) and if the length of the reconnection X-line is reduced by a multiplicative factor of $\mathrm{M}$ (cf. expression (18)), then the total reconnection rate $\mathrm{R}=\mathrm{R} \mathrm{L}_{\mathrm{X} \text {-line }}$ is reduced by the multiplicative factor $\mathrm{M}^{2}$. Hence, the fractional reduction of the total reconnection rate $\mathrm{R}$ is given by $1-\mathrm{M}^{2}$, which is plotted as the solid black curve in Figure 24.

[62] With the blue dashed lines and the red dashed lines in Figure 24, the ranges of geosynchronous-orbit mass densities $\rho_{\text {geo }}$ of the cloak plasma for low $F_{10.7}$ and for high $F_{10.7}$ are noted in the plot. The range of low $F_{10.7}$ values $\left(\rho_{\text {geo }}=3-15 \mathrm{amu} / \mathrm{cm}^{3}\right)$ corresponds to an estimated reduction of the total dayside reconnection rate by about $5 \%-20 \%$. The range of high $F_{10.7}$ values $\left(\rho_{\text {geo }}=15-100 \mathrm{amu} / \mathrm{cm}^{3}\right)$ corresponds to an estimated reduction of the total dayside reconnection rate by about $20 \%-60 \%$. (For the fractional reduction of the local reconnection rate and for the length of the dayside reconnection X-line, values of $2 \%-10 \%$ for low $F_{10.7}$ are obtained and values of $10 \%-40 \%$ for high $F_{10.7}$ are obtained.)

[63] The magnitudes of these reductions of dayside reconnection by the cloak plasma will be assessed in section 8 . 


\section{Summary: Assessment of the Reduction of Solar Wind/Magnetosphere Coupling}

[64] The estimates of fractional reductions of the dayside reconnection rates owed to the mass density of the magnetospheric plasma are collected in Table 4 . The estimates pertain to storm times.

[65] For the effect of the mass density of the ion plasma sheet in the dayside magnetosphere, fractional reductions of $3.5 \%-15 \%$ for the local dayside reconnection rates and for the lengths of the dayside reconnection X-lines were obtain during high-speed-stream-driven-driven storms and during magnetic-cloud-driven storms. Fractional reductions of the total dayside reconnection rates of $6.9 \%-28 \%$ were found for high-speed-stream-driven storms and magneticcloud-driven storms. These reductions are sensitive to the fraction of oxygen ions in the ion plasma sheet, and hence the reductions are highest at high $K p$ values and at solar maximum.

[66] For the effect of plasmaspheric drainage plumes during high-speed-stream-driven storms, fractional reductions of $3 \%-45 \%$ for the local reconnection rate at the plume are obtained. Accounting for the width of the plumes, fractional reductions of the total dayside reconnection rates of $1 \%-22 \%$ are obtained.

[67] For the effect of the warm plasma cloak (ionosphericion outflows into the electron plasma sheet), the estimated storm time fractional reductions of reconnection are sensitive to the solar $F_{10.7}$ radio flux (a proxy for solar ultraviolet intensity). Values of $2 \%-40 \%$ for the fractional reduction in the local reconnection rate and for the fractional reduction in the length of the dayside reconnection X-line are obtained. Values of $5 \%-60 \%$ for the fractional reduction of the total dayside reconnection rate by cloak plasma are obtained.

[68] The role of the plasmaspheric drainage plume in solar wind/magnetosphere coupling has been discussed before [e.g., Borovsky and Steinberg, 2006; Borovsky and Denton, 2006b, 2008; Borovsky and Hesse, 2007; Borovsky et al., 2008; McFadden et al., 2008; Walsh et al., 2013], the role of the dayside ion plasma sheet has been suggested [Borovsky, 2008], and the role of the cloak has been suggested [Borovsky, 2008]. The estimates of Table 4 indicate that all three of these plasmas - the ion plasma sheet with oxygen, the plume, and the cloak - can be important factors for solar wind/magnetosphere coupling. Through these ionospheric-origin plasmas the magnetosphere can exert some control over solar wind/magnetosphere coupling.

[69] The estimated fractional reductions of solar wind/ magnetosphere coupling vary from slight to significant (cf. Table 4): basically they are on the order of tens of percent. This amount is not ignorable and should encourage work to incorporate ionospheric ions into solar wind/ magnetosphere coupling studies.

\section{Needed Improvements}

[70] The improvements needed to better understand the role of ionospheric-origin plasma in solar wind/magnetosphere coupling fall into three areas: better values of plasma densities and plume widths, improved theory, and a statistical investigation of solar wind/magnetosphere coupling.
[71] Ion-composition measurements of cold, warm, and hot plasma in the dayside magnetosphere are needed to develop an understanding of the mass density of the dayside magnetosphere, the source of that density, and the solar wind and geomagnetic parameters that it depends on. Better values of this mass density are critical to any quantification of the effects of magnetospheric mass on dayside reconnection and solar wind/magnetosphere coupling.

[72] An understanding of the widths of plasmaspheric drainage plumes where they flow into the dayside magnetopause is lacking. High-quality global-MHD simulations of plume formation and evolution all the way to the dayside magnetopause, with correct reconnection rates, are needed to provide trustworthy estimates of the plume width beyond geosynchronous orbit.

[73] To obtain better formulas for the length $L_{X-\text { line }}$ of the dayside reconnection X-line, a systematic simulation study of the effects of flow shear on asymmetric non-antiparallel reconnection is needed, with varying directions of flow shear and varying magnetic field clock angles. The purpose of the simulations would be to parameterize the reconnection rate as a function of the properties of the two plasmas, the clock angle of the magnetic fields, and the magnitude and direction of the flow shear.

[74] To better understand reconnection rates where lumpy drainage-plume plasma flows into the dayside reconnection $\mathrm{X}$-line, a simulation study of lumpy-plasma 3-D reconnection is needed. At the location along a reconnection X-line where a high-density lump of plasma is reconnecting, the reconnection rate should be locally reduced. For a magnetic field clock angle of $180^{\circ}$ (purely southward IMF) the local reconnection rate should be independent of neighboring reconnection rates, but at clock angles significantly different from $180^{\circ}$ the slower-outflow newly reconnected flux tubes resulting from reconnection at high-density locations may become entangled with faster-outflow newly reconnected flux tubes from lowerdensity location, and the resulting reconnection rates may become coupled.

[75] For statistical investigations of solar wind/magnetosphere coupling and the driving of the magnetosphereionosphere system by the solar wind (such as Newell et al. [2007] or Borovsky [2013b]), a parameterization of the mass density $\rho_{\mathrm{m}}$ of the dayside magnetosphere is needed. Such a parameterization will probably be functions of $F_{10.7}$ and the time history of $K p$ (which can be expressed as the time history of a solar wind driver function). For the warm plasma cloak in particular, a better understanding of the origin and evolution of that population is needed before a parameterization can be attempted.

[76] Once a parameterization of $\rho_{\mathrm{m}}$ is obtained, that parameterization can be used to create magnetospheric driver functions that depend on solar wind parameters and on the magnetospheric mass density. The Cassak-Shay equation (expression (1)) applied at the magnetopause is a natural starting point to derive such driver functions.

[77] With such driver functions, statistical studies of solar wind/magnetosphere coupling can be performed to statistically quantify the role of magnetospheric mass density (and ionospheric plasmas in particular) in solar wind/magnetosphere coupling and to gain a fuller physical understanding of the driving of the magnetosphere-ionosphere system by the solar wind and of the behavior of the magnetosphereionosphere system. 
[78] Acknowledgments. The authors wish to thank Joachim Birn, Paul Cassak, Benoit Lavraud, John Lyon, Antonius Otto, Lutz Rastatter, and Michelle Thomsen for their help and to thank Kazue Takahashi for the codevelopment of the GOES density data set. Global-MHD simulations were performed at the CCMC. This work was supported at Space Science Institute by the NSF GEM Program and the NASA CCMSM-24 Program and supported at the University of Michigan by the NASA Geospace SR\&T Program. Work at Dartmouth College, Los Alamos National Laboratory, and Naval Research Laboratory was supported by the NASA LWS TR\&T program. Work at Dartmouth College was also supported by the NASA Heliophysics Theory Program NNX11AO59G.

[79] Masaki Fujimoto thanks Yi-Jiun Su for assistance in evaluating this paper.

\section{References}

Bame, S. J., D. J. McComas, M. F. Thomsen, B. L. Barraclough, R. C. Elphic, J. P. Glore, J. T. Gosling, J. C. Chavez, E. P. Evans, and F. J. Wymer (1993) Magnetospheric plasma analyzer for spacecraft with constrained resources, Rev. Sci. Instrum., 64, 1026-1033.

Bellaire, P. J. (2006), Community Coordinated Modeling Center 2005 Workshop report, Space Weather, 4, S02004, doi:10.1029/2005SW000206.

Birn, J., et al. (2001), Geospace Environment Modeling (GEM) magnetic reconnection challenge, J. Geophys. Res., 106, 3715-3719.

Birn, J., J. E. Borovsky, and M. Hesse (2008), Properties of asymmetric magnetic reconnection, Phys. Plasmas, 15, 032101.

Birn, J., J. E. Borovsky, M. Hesse, and K. Schindler (2010), Scaling of asymmetric reconnection in compressible plasmas, Phys. Plasmas, 17, 052108

Birn, J., J. E. Borovsky, and M. Hesse (2012), The role of compressibility in energy release by magnetic reconnection, Phys. Plasmas, 19, 082109.

Borovsky, J. E. (2008), The rudiments of a theory of solar-wind/magnetosphere coupling derived from first principles, J. Geophys. Res., 113, A08228, doi:10.1029/2007JA012646.

Borovsky, J. E. (2013a), Physical improvements to the solar-wind reconnection control function for the Earth's magnetosphere, J. Geophys. Res. Space Physics, 118, 2113-2121, doi:10.1002/jgra.50110.

Borovsky, J. E. (2013b), Physics based solar-wind driver functions for the magnetosphere: Combining the reconnection-coupled MHD generator with the viscous interaction, J. Geophys. Res., Space Physics, doi:10.1002/ jgra.50557, in press.

Borovsky, J. E., and M. H. Denton (2006a), The differences between CMEdriven storms and CIR-driven storms, J. Geophys. Res., 111, A07S08, doi:10.1029/2005JA011447.

Borovsky, J. E., and M. H. Denton (2006b), The effect of plasmaspheric drainage plumes on solar-wind/magnetosphere coupling, Geophys. Res. Lett., 33, L20101, doi:10.1029/2006GL026519.

Borovsky, J. E., and M. H. Denton (2008), A statistical look at plasmaspheric drainage plumes, J. Geophys. Res., 113, A09221, doi:10.1029/2007JA012994.

Borovsky, J. E., and M. H. Denton (2010a), The magnetic field at geosynchronous orbit during high-speed-stream-driven storms: Connections to the solar wind, the plasma sheet, and the outer electron radiation belt, J. Geophys. Res., 115, A08217, doi:10.1029/2009JA015116.

Borovsky, J. E., and M. H. Denton (2010b), Solar-wind turbulence and shear: A superposed-epoch analysis of corotating interaction regions at 1 AU, J. Geophys. Res., 115, A10101, doi:10.1029/2009JA014966.

Borovsky, J. E., and M. Hesse (2007), The reconnection of magnetic fields between plasmas with different densities: Scaling relations, Phys. Plasmas, 14 102309.

Borovsky, J. E., and J. T. Steinberg (2006), The "calm before the storm" in $\mathrm{CIR} /$ magnetosphere interactions: Occurrence statistics, solar-wind statistics, and magnetospheric preconditioning, J. Geophys. Res., 111, A07S10, doi:10.1029/2005JA011397.

Borovsky, J. E., M. F. Thomsen, and D. J. McComas (1997), The superdense plasma sheet: Plasmaspheric origin, solar-wind origin, or ionospheric origin?, J. Geophys. Res., 102, 22,089-22,097.

Borovsky, J. E., M. F. Thomsen, D. J. McComas, T. E. Cayton, and D. J. Knipp (1998), Magnetospheric dynamics and mass flow during the November-1993 storm, J. Geophys. Res., 103, 26,373-26,394.

Borovsky, J. E., M. Hesse, J. Birn, and M. M. Kuznetsova (2008), What determines the reconnection rate at the dayside magnetosphere?, J. Geophys. Res., 113, A07210, doi:10.1029/2007JA012645.

Borovsky, J. E., B. Lavraud, and M. M. Kuznetsova (2009), Polar cap potential saturation, dayside reconnection, and changes to the magnetosphere, J. Geophys. Res., 114, A03224, doi:10.1029/2009JA014058.

Cassak, P. A., and A. Otto (2011), Scaling of the magnetic reconnection rate with symmetric shear flow, Phys. Fluids, 18, 074501.

Cassak, P. A., and M. A. Shay (2007), Scaling of asymmetric magnetic reconnection: General theory and collisional simulations, Phys. Plasmas, 14, 102114.
Chappell, C. R. (1982), Initial observations of thermal plasma composition and energetics from Dynamics Explorer-1, Geophys. Res. Lett., 9, 929-932.

Chappell, C. R., M. M. Huddleston, T. E. Moore, B. L. Giles, and D. C. Delcourt (2008), Observations of the warm plasma cloak and an explanation of its formation in the magnetosphere, J. Geophys. Res., 113, A09206, doi:10.1029/2007JA012945

Chen, A. J., and R. A. Wolf (1972), Effects on the plasmasphere of a timevarying convection electric field, Planet. Space Sci., 20, 483.

Chen, Q., A. Otto, and L. C. Lee (1997), Tearing instability, KelvinHelmholtz instability, and magnetic reconnection, J. Geophys. Res., 102, 151-161.

Dent, Z. C., I. R. Mann, J. Goldstein, F. W. Menk, and L. G. Ozeke (2006), Plasmaspheric depletion, refilling, and plasmapause dynamics: A coordinated ground-based and IMAGE satellite study, J. Geophys. Res., 111, A03205, doi:10.1029/2005JA011046.

Denton, M. H., and J. E. Borovsky (2008), Superposed epoch analysis of highspeed-stream effects at geosynchronous orbit: Hot plasma, cold plasma, and the solar wind, J. Geophys. Res., 113, A07216, doi:10.1029/2007JA012998.

Denton, M. H., and J. E. Borovsky (2009), The superdense plasma sheet in the magnetosphere during high-speed-steam-driven storms: Plasma transport timescales, J. Atmos. Sol. Terr. Phys., 71, 1045.

Denton, M. H., M. F. Thomsen, H. Korth, S. Lynch, J. C. Zhang, and M. W. Liemohn (2005), Bulk plasma properties at geosynchronous orbit, J. Geophys. Res., 110, A07223, doi:10.1029/2004JA010861.

Denton, M. H., J. E. Borovsky, R. M. Skoug, M. F. Thomsen, B. Lavraud, M. G. Henderson, R. L. McPherron, J. C. Zhang, and M. W. Liemohn (2006), Geomagnetic storms driven by ICME- and CIR-dominated solar wind, J. Geophys. Res., 111, A07S07, doi:10.1029/2005JA011436.

Denton, R. E., M. F. Thomsen, K. Takahashi, R. R. Anderson, and H. J. Singer (2011), Solar cycle dependence of bulk ion composition at geosynchronous orbit, J. Geophys. Res., 116, A03212, doi:10.1029/2010JA016027.

Dessler, A. J., and R. Karplus (1961), Some effects of diamagnetic ring currents on Van Allen radiation, J. Geophys. Res., 66, 2289-2295.

Dunham, W. D., S. A. MacIntyre, and C. R. Upton (1996), Design and performance of the GOES-8 high resolution magnetometer, SPIE Proc., 2812, 365.

Farrugia, C. J., J. Geiss, D. T. Young, and H. Balsiger (1998), GEOS 1 observations of low-energy ions in the Earth's plasmasphere: A study on composition, and temperature and density structure under quiet geomagnetic conditions, Adv. Space Res., 8(8), 25.

Fok, M.-C., J. U. Kozyra, A. F. Nagy, and T. E. Cravens (1991), Lifetime of ring current particles due to Coulomb collisions in the plasmasphere, J. Geophys. Res., 96, 7861-7867.

Fraser, B. J., J. L. Horwitz, J. A. Slavin, Z. C. Dent, and I. R. Mann (2005), Heavy ion mass loading of the geomagnetic field near the plasmapause and ULF wave implications, Geophys. Res. Lett., 32, L04102, doi:10.1029/ 2004GL021315.

Galperin, Y. I., and Y. I. Feldstein (1991), Auroral luminosity and its relationship to magnetospheric plasma domains, in Auroral Physics, edited by C.-I. Meng, M. J. Rycroft, and L. A. Frank, pp. 207-222, Cambridge Univ. Press, New York.

Goldstein, J. (2006), Plasmasphere response: Tutorial and review of recent imaging results, Space Sci. Rev., 124, 203.

Goldstein, J., B. R. Sandel, M. F. Thomsen, M. Spasojevic, and P. H. Reiff (2004), Simultaneous remote sensing and in situ observations of plasmaspheric drainage plumes, J. Geophys. Res., 109, A03202, doi:10.1029/2003JA010281.

Grew, R. S., F. W. Menk, M. A. Clilverd, and B. R. Sandel (2007), Mass and electron densities in the inner magnetosphere during a prolonged disturbed interval, Geophys. Res. Lett., 34, L02108, doi:10.1029/2006GL028254.

Hilmer, R. V., and G.-H. Voigt (1995), A magnetospheric magnetic field model with flexible current systems driven by independent physical parameters, J. Geophys. Res., 100, 5613-5626.

Horwitz, J. L., C. R. Baugher, C. R. Chappell, E. G. Shelley, D. T. Young, and R. R. Anderson (1981), ISEE 1 observations of thermal plasma in the vicinity of the plasmasphere during periods of quieting magnetic activity, J. Geophys. Res., 86, 9989-10,001.

Horwitz, J. L., R. H. Comfort, and C. R. Chappell (1984), Thermal ion composition measurements of the formation of the new outer plasmasphere and double plasmapause during storm recovery phase, Geophys. Res. Lett., 8, 701-704.

Huba, J., and J. Krall (2013), Modeling the plasmasphere with SAMI3, Geophys. Res. Lett., 40, 6-10, doi:10.1029/2012GL054300.

Huba, J. D., G. Joyce, and J. A. Fedder (2000), Sami2 is Another Model of the Ionosphere (SAMI2): A new low-latitude ionosphere model, J. Geophys. Res., 105, 23,035-23,053.

Huba, J., G. Joyce, and J. Krall (2008), Three-dimensional equatorial spread F modeling, Geophys. Res. Lett., 35, L10102, doi:10.1029/2008GL033509.

Jordanova, V. K., J. U. Kozyra, A. F. Nagy, and G. V. Khazanov (1997), Kinetic model of the ring current-atmosphere interactions, J. Geophys. Res., 102, 14,279-14,291. 
Jordanova, V. K., J. Albert, and Y. Miyoshi (2008), Relativistic electron precipitation by EMIC waves from self-consistent global simulations, J. Geophys. Res., 113, A00A10, doi:10.1029/2008JA013239.

Jordanova, V. K., S. Zaharia, and D. T. Welling (2010), Comparative study of ring current development using empirical, dipolar, and self-consistent magnetic field simulations, J. Geophys. Res., 115, A00J11, doi:10.1029/ 2010JA015671.

King, J. H., and N. E. Papitashvili (2005), Solar wind spatial scales in and comparisons of hourly Wind and ACE plasma and magnetic field data, J. Geophys. Res., 110, A02104, doi:10.1029/2004JA010649.

Kistler, L. M., F. M. Ipavich, D. C. Hamilton, G. Gloeckler, B. Wilken, G. Dremser, and W. Studemann (1989), Energy spectra of the major ion species in the ring current during geomagnetic storms, J. Geophys. Res., 94, 3579-3599.

Knipp, D. J., et al. (1998), An overview of the early November 1993 geomagnetic storm, J. Geophys. Res., 103, 26,197-26,220.

Korth, H., M. F. Thomsen, J. E. Borovsky, and D. J. McComas (1999), Plasma sheet access to geosynchronous orbit, J. Geophys. Res., 104, $25,047-25,061$.

Krall, J., and J. D. Huba (2013), SAMI3 simulation of plasmasphere refilling, Geophys. Res. Lett., 40, 2484-2488, doi:10.1002/grl.50458.

Kuznetsova, M. M., M. Hesse, L. Rastatter, A. Taktakishvili, G. Toth, D. L. DeZeeuw, A. Ridley, and T. I. Gombosi (2007), Multiscale modeling of magnetospheric reconnection, J. Geophys. Res., 112, A10210, doi:10.1029/2007JA012316.

La Belle-Hamer, A. L., A. Otto, and L. C. Lee (1994), Magnetic reconnection in the presence of sheared plasma flow: Intermediate shock formation, Phys. Plasmas, 1, 706.

Lavraud, B., and J. E. Borovsky (2008), Altered solar wind-magnetosphere interaction at low Mach numbers: Coronal mass ejections, J. Geophys. Res., 113, A00B08, doi:10.1029/2008JA013192.

Lawrence, D. J., M. F. Thomsen, J. E. Borovsky, and D. J. McComas (1999), Measurements of early and late time plasmasphere refilling as observed from geosynchronous orbit, J. Geophys. Res., 104, $14,691-14,704$

Lennartsson, W., and E. G. Shelley (1986), Survey of 0.1- to 16-keV/e plasma sheet ion composition, J. Geophys. Res., 91, 3061-3076.

Lepping, R. P., C.-C. Wu, and D. B. Berdichevsky (2005), Automated identification of magnetic clouds and cloud-like regions at $1 \mathrm{AU}$ : Occurrence rate and other properties, Ann. Geophys., 23, 2687.

Lyon, J. G., J. A. Fedder, and C. M. Mobarry (2004), The Lyon-FedderMobarry (LFM) global MHD magnetospheric simulation code, J. Atmos. Sol. Terr. Phys., 66, 1333.

Matsui, H., F. Darrouzet, J. Goldstein, P. A. Puhl-Quinn, Y. V. Khotyaintsev, P.-A. Lindqvist, E. Georgescu, C. G. Mouikis, and R. B. Torbert (2012), Multi-spacecraft observations of small-scale fluctuations in density and fields in plasmaspheric plumes, Ann. Geophys., 30, 623.

Mauk, B. H., and C.-I. Meng (1991), The aurora and middle magnetospheric processes, in Auroral Physics, edited by C.-I. Meng, M. J. Rycroft, and L. A. Frank, pp. 223, Cambridge Univ. Press, Cambridge.

Maurice, S., M. F. Thomsen, D. J. McComas, and R. C. Elphic (1998), Quiet time densities of hot ions at geosynchronous orbit, J. Geophys. Res., 103, $17,571-17,585$.

McFadden, J. P., C. W. Carlson, D. Larson, J. Bonnell, F. S. Mozer, V. Angelopoulos, K.-H. Glassmeier, and U. Auster (2008), Structure of plasmaspheric plumes and their participation in magnetopause reconnection: First results from THEMIS, Geophys. Res. Lett., 35, L17S10, doi:10.1029/2008GL033677.

Meng, C.-I., B. Mauk, and C. E. McIlwain (1979), Electron precipitation of evening diffuse aurora and its conjugate electron fluxes near the magnetospheric equator, J. Geophys. Res., 84, 2545-2558.

Mitchell, H. G., and J. R. Kan (1978), Merging of magnetic fields with fieldaligned plasma flow components, J. Plasma Phys., 20, 31.

Moldwin, M. B., M. F. Thomsen, S. J. Bame, and D. McComas (1995), The finescale structure of the outer plasmasphere, J. Geophys. Res., 100, 8021-8029.

Newell, P. T., T. Sotirelis, K. Liou, C.-I. Meng, and F. J. Rich (2007), A nearly universal solar wind-magnetosphere coupling function inferred from 10 magnetospheric state variables, J. Geophys. Res., 112, A01206, doi:10.1029/2006JA012015.

Nisbet, J. S. (1982), Relations between the Birkeland currents, the auroral electrojet indices and high latitude Joule heating, J. Atmos. Sol. Terr. Phys., 44, 797.

Nose, M., K. Takahashi, R. R. Anderson, and H. J. Singer (2011), Oxygen torus in the deep inner magnetosphere and its contribution to recurrent process of $\mathrm{O}^{+}$-rich ring current formation, J. Geophys. Res., 116, A10224, doi:10.1029/2011JA016651.

Parker, E. N. (1973), The reconnection rate of magnetic fields, Astrophys. J., 180, 247.

Pulupa, M. P., S. D. Bale, and J. C. Kasper (2010), Langmuir waves upstream of interplanetary shocks: Dependence on shock and plasma parameters, J. Geophys. Res., 115, A04104, doi:10.1029/2009JA014680.
Rastatter, L., M. M. Kuznetsova, D. G. Sibeck, and D. H. Berrios (2012), Scientific visualization to study flux transfer events at the Community Coordinated Modeling Center, Adv. Space Res., 49, 1623.

Schield, M. A. (1969), Pressure balance between solar wind and magnetosphere, J. Geophys. Res., 74, 1275-1286.

Shay, M. A., J. F. Drake, B. N. Rogers, and R. E. Denton (1999), The scaling of collisionless, magnetic reconnection for large systems, Geophys. Res. Lett., 26, 2163-2166.

Singer, H. J., L. Matheson, R. Grubb, A. Newman, and S. D. Bouwer (1996), Monitoring space weather with the GOES magnetometers, SPIE Proc., $2812,299$.

Smith, P. H., and N. K. Bewtra (1978), Charge exchange lifetimes for ring current ions, Space Sci. Rev., 22, 301.

Su, Y.-J., J. E. Borovsky, M. F. Thomsen, R. C. Elphic, and D. J. McComas (2000), Plasmaspheric material at the reconnecting magnetopause, J. Geophys. Res., 105, 7591-7600.

Su, Y.-J., J. E. Borovsky, M. F. Thomsen, N. Dubouloz, M. O. Chandler, T. E. Moore, and M. Bouhram (2001a), Plasmaspheric material on highlatitude open field lines, J. Geophys. Res., 106, 6085-6095.

Su, Y.-J., M. F. Thomsen, J. E. Borovsky, R. C. Elphic, D. J. Lawrence, and D. J. McComas (2001b), Plasmaspheric observations at geosynchronous orbit, J. Atmos. Sol. Terr. Phys., 63, 1185.

Takahashi, K., R. E. Denton, R. R. Anderson, and W. J. Hughes (2006), Mass density inferred from toroidal wave frequencies and its comparison to electron density, J. Geophys. Res., 111, A01201, doi:10.1029/2005JA011286.

Takahashi, K., R. E. Denton, and H. J. Singer (2010), Solar cycle variation of geosynchronous plasma mass density derived from the frequency of standing Alfven waves, J. Geophys. Res., 115, A07207, doi:10.1029/2009JA015243. Thomsen, M. F., D. J. McComas, J. E. Borovsky, and R. C. Elphic (1998), The magnetospheric trough, in Geospace Mass Transport and Energy Flow, edited by J. L. Horwitz, D. L. Gallagher, and W. K. Peterson, pp. 355, AGU, Washington, D. C.

Thomsen, M. F., E. Noveroske, J. E. Borovsky, and D. J. McComas (1999), Calculating the Moments from Measurements by the Los Alamos Magnetospheric Plasma Analyzer, LA-13566-MS, Los Alamos National Laboratory.

Troshichev, O. A., V. G. Andrezen, S. Verrerstrom, and E. Friis-Christensen (1988), Magnetic activity in the polar cap-A new index, Planet. Space Sci., 36, 1095 .

Turner, N. E., E. J. Mitchell, D. J. Knipp, and B. A. Emery (2006), Energetics of magnetic storms driven by corotating interaction regions: A study of geoeffectiveness, in Recurrent Magnetic Storms, edited by B. T. Tsurutani et al., pp. 113, AGU, Washington, D.C.

Turner, N. E., W. D. Cramer, S. K. Earles, and B. A. Emery (2009), Geoefficiency and energy partitioning in CIR-driven and CME-driven storms, J. Atmos. Sol. Terr. Phys., 71, 1023.

Vorotnikov, V. S., C. W. Smith, C. J. Farrugia, C. J. Meredith, Q. Hu, A. Szabo, R. M. Skoug, C. M. S. Cohen, A. J. Davis, and K. Yumoto (2011), Use of single-component wind speed in Rankine-Hugoniot analysis of interplanetary shocks, Space Weather, 9, S04001, doi:10.1029/2010SW000631.

Walker, R. J., and C. T. Russell (1995), Solar-wind interactions with magnetized planets, in Introduction to Space Physics, edited by M. G. Kivelson and C. T. Russell, pp. 164, Cambridge Univ. Press, New York.

Walsh, B. M., D. G. Sibeck, Y. Nishimura, and V. Angelopoulos (2013), Statistical analysis of the plasmaspheric plume at the magnetopause, J. Geophys. Res. Space Physics, doi:10.1002/jgra.50458.

Weimer, D. R. (2005), Improved ionospheric electrodynamic models and applications to calculating Joule heating rates, J. Geophys. Res., 110, A05306, doi:10.1029/2004JA010884.

Wiltberger, M., R. E. Lopez, and J. G. Lyon (2005), Results from magnetospheric Gedanken experiments using the LFM, Adv. Space Res., 36, 1797.

Yau, A. W., and M. Andre (1997), Sources of ion outflow in the high latitude ionosphere, Space Sci. Rev., 80, 1.

Yau, A. W., B. A. Whelan, W. K. Peterson, and E. G. Shelley (1984), Distribution of upflowing ionospheric ions in the high-altitude polar cap and auroral ionosphere, J. Geophys. Res., 89, 5507-5522.

Yau, A. W., T. Abe, and B. A. Whelan (1996), Cold plasma source of upflowing ionospheric ions in the nightside auroral ionosphere, J. Geomag, Geoelectr., 48, 947.

Young, D. T., J. Geiss, H. Balsiger, P. Eberhardt, A. Ghielmetti, and $\mathrm{H}$. Rosenbauer (1977), Discovery of $\mathrm{He}^{2+}$ and $\mathrm{O}^{2+}$ ions of terrestrial origin in the outer magnetosphere, Geophys. Res. Lett., 4, 561-564.

Young, D. T., H. Balsiger, and J. Geiss (1982), Correlations of magnetospheric ion composition with geomagnetic and solar activity, J. Geophys. Res., 87, 9077-9096.

Zhang, J., M. W. Liemohn, M. F. Thomsen, J. U. Kozyra, M. H. Denton, and J. E. Borovsky (2006), A statistical comparison of hot-ion properties at geosynchronous orbit during intense and moderate geomagnetic storms at solar maximum and minimum, J. Geophys. Res., 111, A07206, doi:10.1029/2005JA011559. 